\title{
Diversity patterns of herbaceous angiosperms along gradients of elevation and forest use intensity in Central Veracruz, Mexico
}

\author{
Dissertation \\ zur Erlangung des mathematisch-naturwissenschaftlichen Doktorgrades \\ "Doctor rerum naturalium“ \\ der Georg-August-Universität Göttingen \\ im Promotionsprogramm Geographie \\ der Georg-August University School of Science (GAUSS)
}

vorgelegt von

Jorge Antonio Gómez Díaz

aus Xalapa, Mexiko

Göttingen, 2016 


\section{Betreuungsausschuss}

Prof. Dr. Gerhard Gerold, Abteilung Landschaftsökologie, Universität Göttingen (Anleiter)

Prof. Dr. Holger Kreft, Abteilung Biodiversität, Makroökologie und Biogeographie, Universität Göttingen

Dr. Felix Heitkamp, Abteilung Physische Geographie, Universität Göttingen

\section{Mitglieder der Prüfungskommission}

Referent: Prof. Dr. Gerhard Gerold, Abteilung Landschaftsökologie, Universität Göttingen

Korreferent: Prof. Dr. Holger Kreft, Abteilung Biodiversität, Makroökologie und Biogeographie, Universität Göttingen

\section{Weitere Mitglieder der Prüfungskommission}

Dr. Thorsten Krömer, Centro de Investigaciones Tropicales, Universidad Veracruzana

Dr. Stefan Erasmi, Abteilung Kartographie, GIS und Fernerkundung, Universität Göttingen

Dr. Steffen Möller, Abteilung Physische Geographie, Universität Göttingen

Tag der mündlichen Prüfung: 27.01.2017 


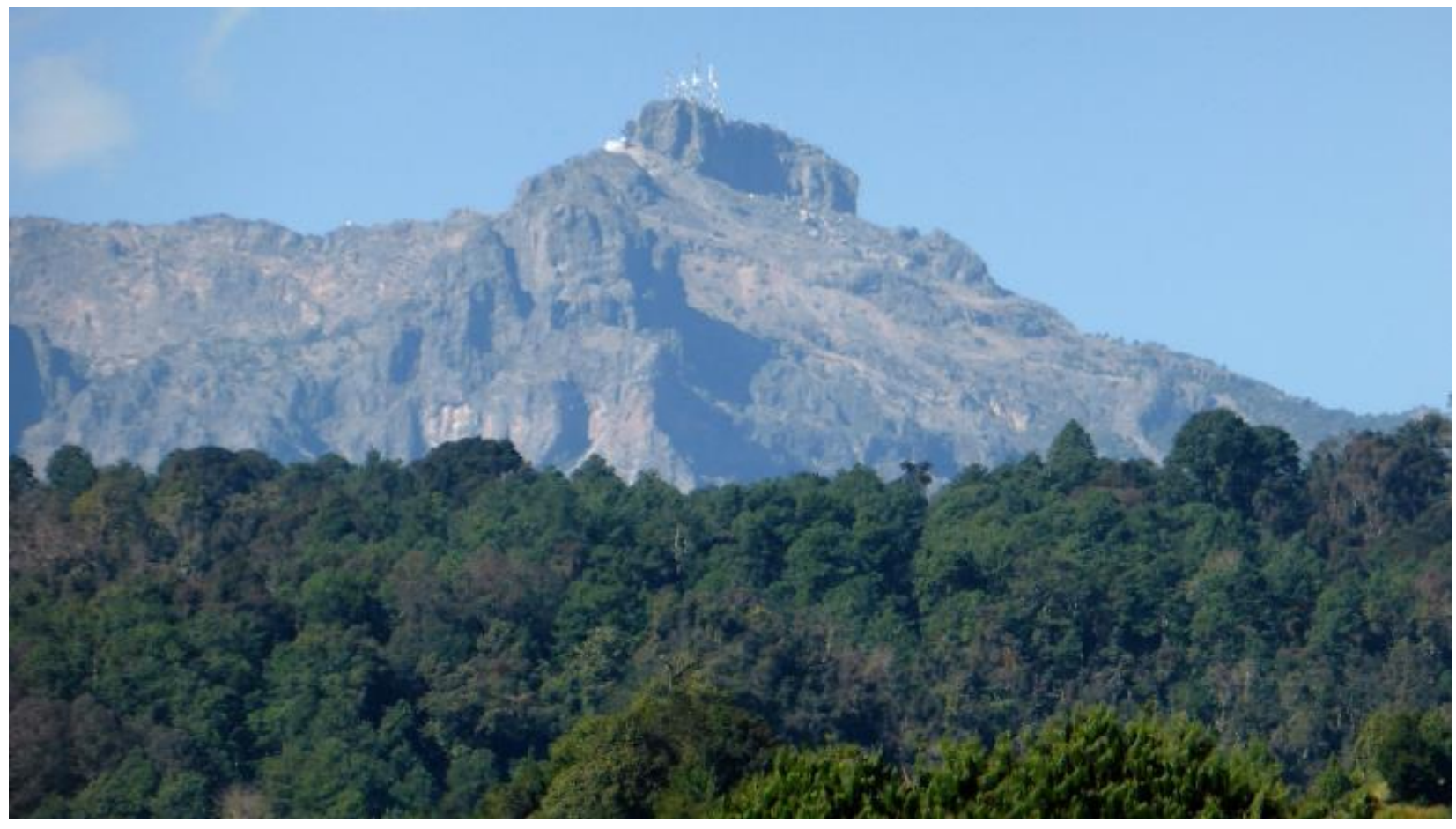

Cofre de Perote National Park, Veracruz, Mexiko 
A mi hijo Surem, quien es mi fuerza en la vida.

A Lupita, mi esposa, quien ha sido mi soporte durante este viaje, gracias. A mis padres, Claudia y Toño, por sus consejos y apoyo durante toda mi vida. 


\section{Table of contents}

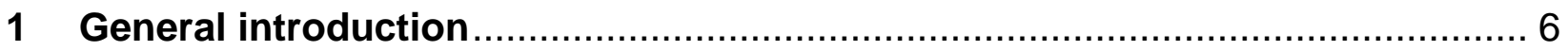

1.1 Plant diversity and distribution along elevational gradients in the tropics ........... 6

1.2 Deforestation as driver of species richness loss due to forest use alteration ... 10

1.3 Herbaceous angiosperms as a study model............................................. 15

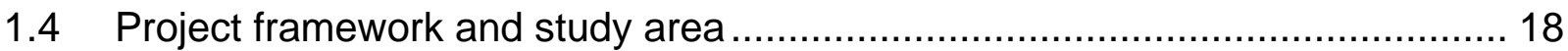

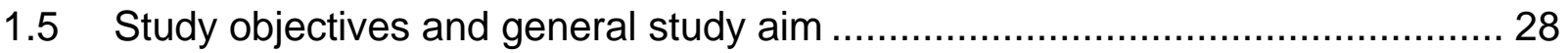

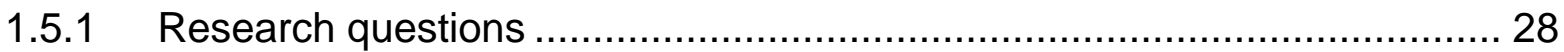

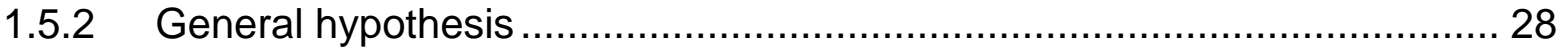

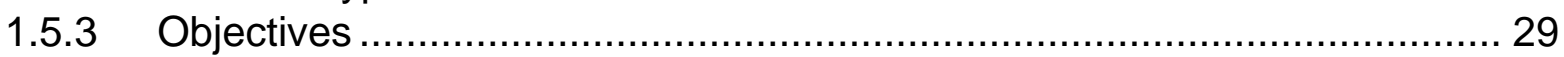

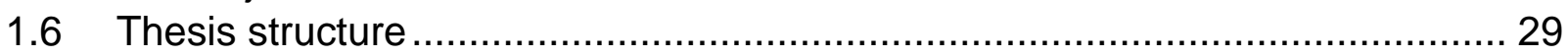

2 Richness and distribution of herbaceous angiosperms along gradients of elevation and forest disturbance in central Veracruz, Mexico ................................. 32

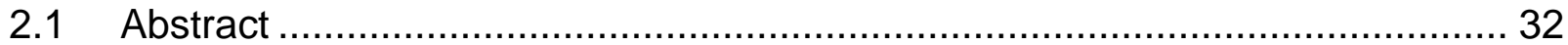

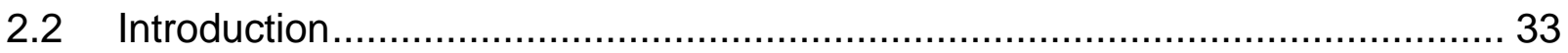

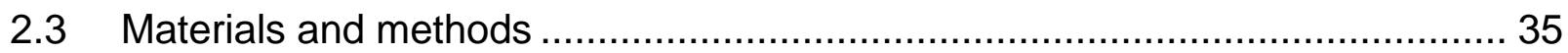

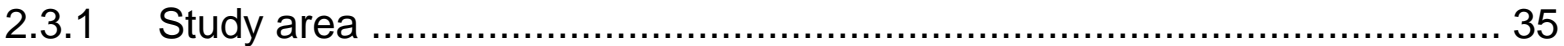

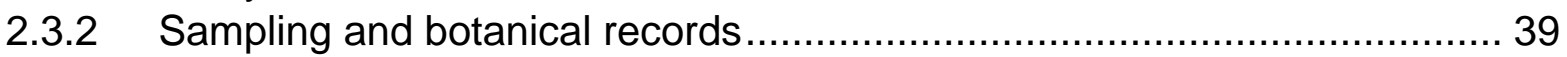

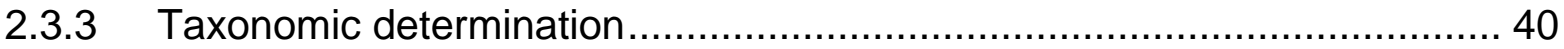

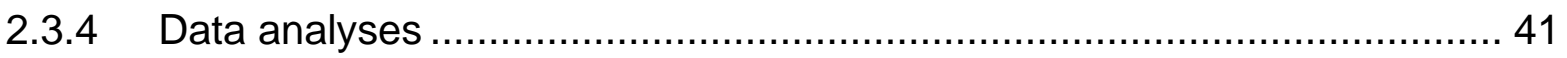

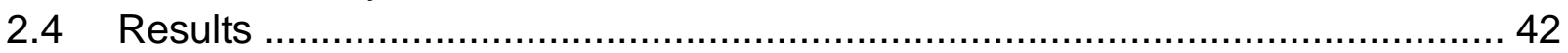



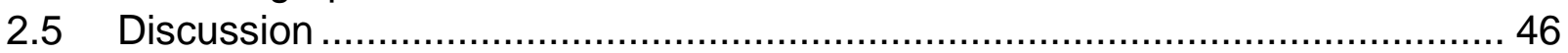

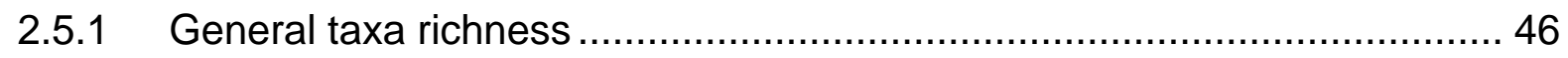

2.5.2 Patterns of richness along the elevational gradient................................. 48

2.5.3 Forest use intensity effect ................................................................. 49



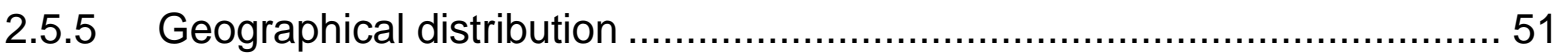

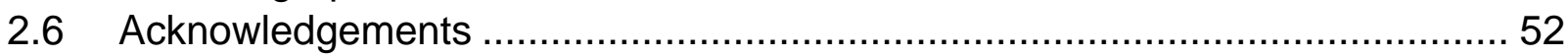

2.7 Appendix. Species of herbaceous angiosperms recorded along the elevational gradient at the Cofre de Perote, central Veracruz, Mexico...................................... 53

3 Diversity and Composition of Herbaceous Angiosperms along Gradients of

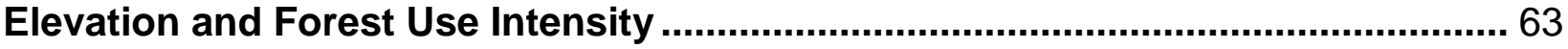

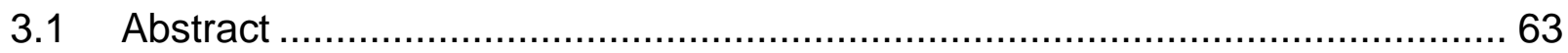

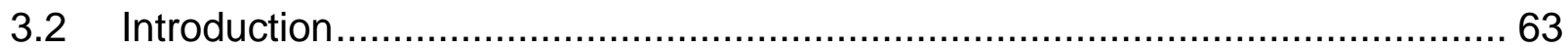

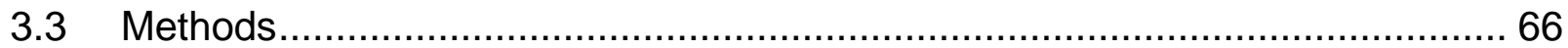

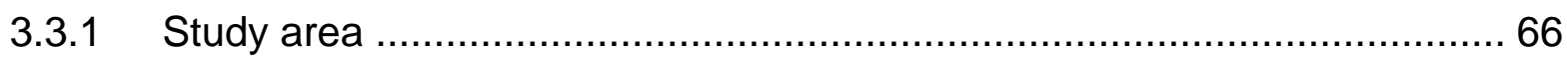






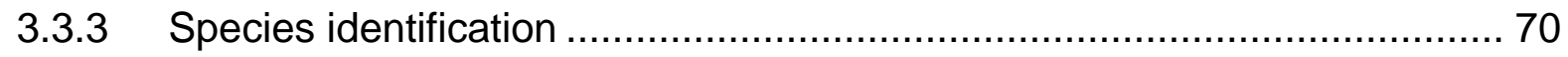

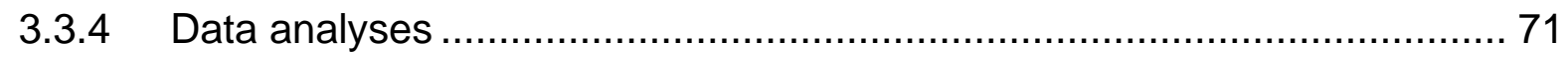

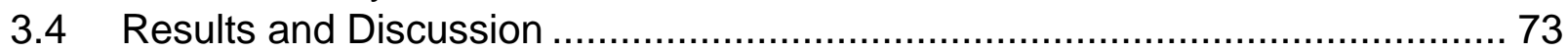



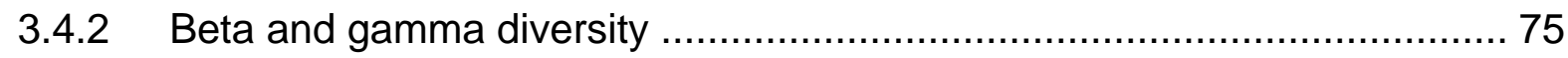

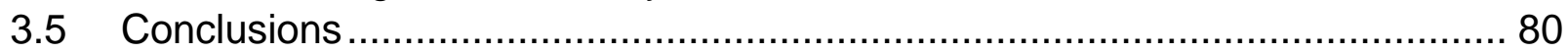

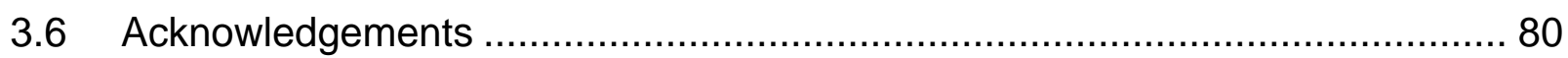

4 Long-term changes in the forest cover in central Veracruz, Mexico since the

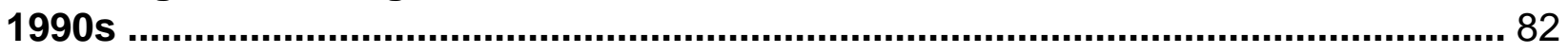

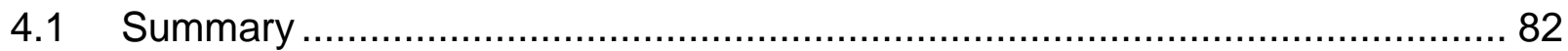

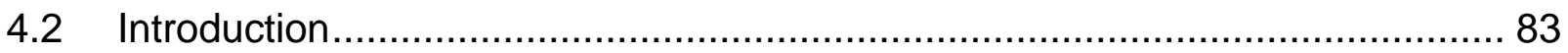

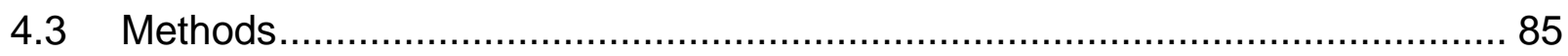



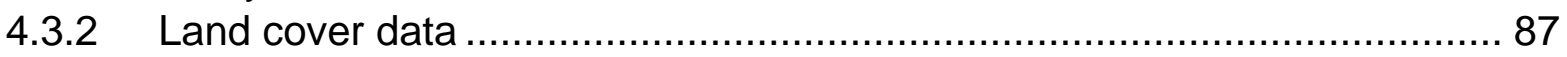

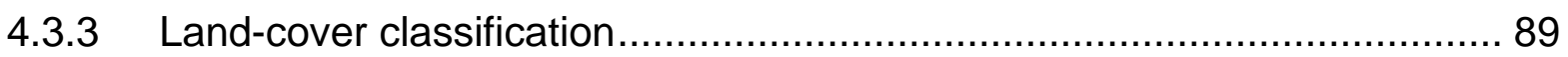

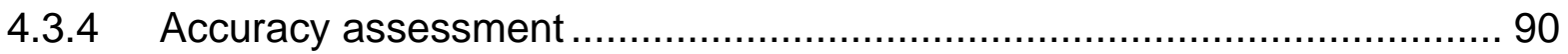

4.3.5 Deforestation for the diverse forest types and at area level .................... 91

4.3.6 Fragmentation analysis ..................................................................... 91

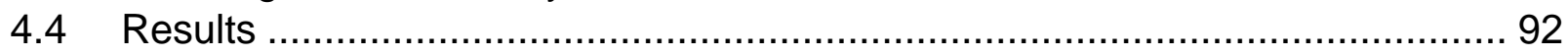

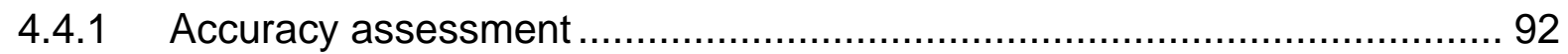

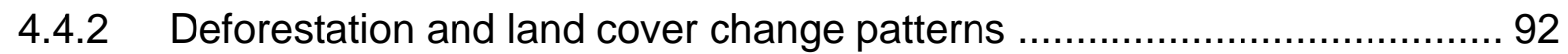

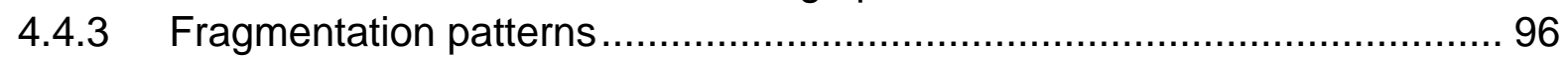

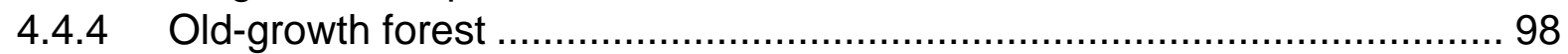

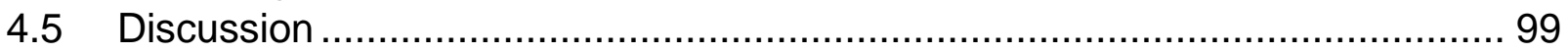

4.5.1 Deforestation patterns and fragmentation configurations........................ 99



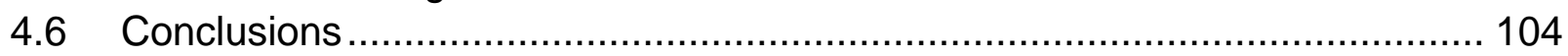

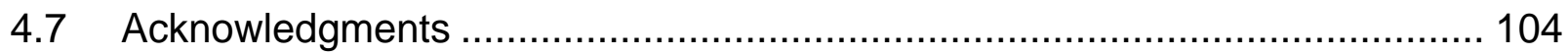

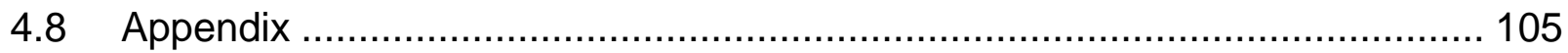



5.1 Objective 1: Evaluation of distributional and diversity patterns of herbaceous angiosperms along an elevational gradient ....................................................... 108 5.2 Objective 2: Evaluation of forest use intensity effect on the patterns of richness and composition of herb species................................................................... 110 5.3 Objective 3: Analysis of the current conservation status of forest fragments in the

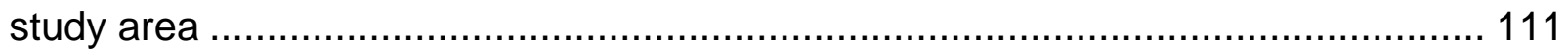

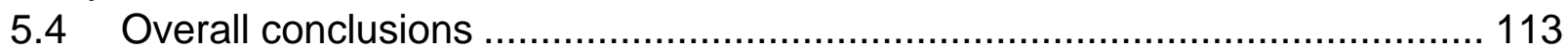

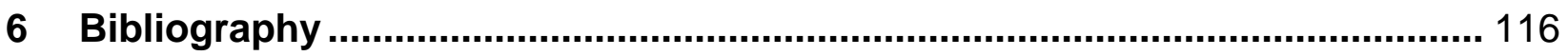




\section{Tables}

Table 1.1 Changes in land use coverage in Veracruz for the period 1971-2020.......... 14

Table 1.2 Indicator herbaceous angiosperms families found in tropical transects worldwide adapted from Cicuzza et al. (2013).

Table 2.1 Overview of the study sites along the elevational gradient at Cofre de Perote, central Veracruz, Mexico.

Table 2.2 Classification of habitats with different forest use intensities.

Table 2.3 Most representative families and genera of herbaceous angiosperms along the elevational gradient at the Cofre de Perote, central Veracruz, Mexico.

Table 2.4 Species richness of herbaceous angiosperms recorded in elevational gradient studies realized in Mexico and two different regions of the Neotropics.

Table 2.5 Geographic distribution and life strategy of species found along the elevational gradient at Cofre de Perote, central Veracruz, Mexico.

Table 3.1 List of the study locations along the elevational gradient at the Cofre de Perote, central Veracruz, Mexico..

Table 3.2 Classification of habitats with different forest use intensities. 69

Table 3.3 Average effects of the habitat change. 76

Table 4.1 Overview of the Landsat satellite scenes used for forest change analysis and the most important information about the scenes. 88

Table 4.2 Description of the cover classes used for the land use classification. 89

Table 4.3 Area covered by different natural forest types (FO), plantations, arable and grassland (AG) and other covers in 1993, 2000 and 2014 at different vegetation belts in Central Veracruz, Mexico..

Table 4.4 Variations in the spatial conformation of old-growth forests in Central Veracruz, Mexico throughout the period from 1993 to 2014. 


\section{Figures}

Figure 1.1 Elevational patterns of herbaceous angiosperm diversity in the Neotropics. . 7 Figure 1.2 Deforestation in Mexico between 2000 and 2014 (Hansen et al. 2016)....... 11 Figure 1.3 Forest cover loss in Veracruz, Mexico

Figure 1.4 Location of the eight study sites along the elevational gradient on the Eastern slopes of the Cofre de Perote, the central part of the state of Veracruz, Mexico.

Figure 1.5 Mean annual precipitation and temperature measured in different climatological stations operating along the elevational gradient.

Figure 1.6 Different vegetation types according to Miranda \& Hernández-Xolocotzi (1963) and climate zones (Lauer 1973) along the elevational gradient of the study area.

Figure 1.7 Tropical semi-deciduous forest: a) azonal riparian forest, b) herbaceous layer,

c) vegetation structure and d) soil profile.

Figure 1.8 Tropical oak forest: a) landscape view of the study site, b) forest structure, c) herbaceous layer and d) soil profile.

Figure 1.9 Humid montane forest: a) landscape view of the study site, b) forest structure, c) soil profile and d) herbaceous layer.

Figure 1.10 Pine-oak forest: a) herbaceous layer, b) azonal forest, c) soil profile and d) forest structure. 25

Figure 1.11 Pine forest: a) landscape view of the study site, b) forest structure, c) herbaceous layer and d) soil profile.

Figure 1.12 Fir forest: a) landscape view of the study site, b) forest structure, c) herbaceous layer and d) soil profile.

Figure 2.1 Location of the eight study sites along the elevational gradient at the Cofre de Perote, central Veracruz, Mexico. 36

Figure 2.2 Observed and estimated (Bootstrap species richness estimator) species richness of all species together per elevational belt..

Figure 3.1 Map of the Eastern slopes of the Cofre de Perote in Veracruz State, Mexico. Study locations are shown by black dots.

Figure 3.2 Schematic representation of the sampling design. $\alpha$-diversity is measured in plots of $20 \mathrm{~m} \times 20 \mathrm{~m}$ and is given as a mean of five plots.. 
Figure 3.3 $\alpha$-diversity of herbaceous angiosperms along gradients of elevation and forest use intensity at the Cofre de Perote, central Veracruz, Mexico. 74

Figure 3.4 Compositional heterogeneity (as a measure for $\beta$-diversity) between different changes in forest habitats along the elevational gradient at the Cofre de Perote. 77

Figure 3.5 Additive gamma partitioning. 78

Figure 4.1 Study area in Central Veracruz, Mexico. Overview on the potential natural vegetation belts in the states of Veracruz and Puebla. 87

Figure 4.2 Land cover maps for the studied years (1993, 2000 and 2014) 94

Figure 4.3 Annual net-forest change and gross forest loss rates (\%) in four natural vegetation types in Central Veracruz, Mexico.......................................................... 95

Figure 4.4 Variation of forest fragment size for 1993, 2000 and 2014 at the different vegetation belts.

96

Figure 4.5 Sites with high conservation value. Fragments of forests without change since 1993. 98

Figure 4.6 Change use analysis. Fragments of forests without change since 1993, forest grow since 1993 and forest loss since 1993. 99 


\section{Acknowledgments}

During the last few years, there has been a number of turning points in my life. When I started this journey I had no idea of the challenges that I would have to face; however, I learned many valuable lessons along the way. I have reached the end of this journey, and I want to thank everyone who at some point helped to make this dream come true.

First, I would like to thank Prof. Dr. Gerhard Gerold and Dr. Felix Heitkamp not only for their academic support but also for their support on a personal level, especially during the difficult times. I will always remember them for their valuable advice.

Special thanks to Dr. Thorsten Krömer for his scientific and technical support and for encouraging me to achieve one of my dreams, studying abroad.

I also wish to thank Prof. Dr. Holger Kreft and Dr. Stefan Erasmi for accepting to be members of my dissertation committee and their valuable comments that helped to improve the dissertation.

I am grateful for the financial support from the Consejo Nacional de Ciencia y Tecnología (CONACyT) of Mexico with the doctoral grant 311672 and the Deutscher Akademischer Austauschdienst (DAAD 91549681).

I also want to thank Maria Guadalupe Ruiz Gómez for trusting and believing in me, for always have a good mood when mine was not, and also for giving me the freedom to do what I like.

My gratitude to all my colleagues in the Department of Landscape Ecology who encouraged me and shared with me their scientific knowledge and daily experiences. Thanks to Kristof, Ulf, Wiebke, Rodolfo, Edgardo, Stephen, Nora, Harold, and Stephan. To the technicians and administrative staff of the department. Thanks to Petra, Anja, Maria, Kathy, Frau Hesse and Dr. Grotheer for their valuable advice, patient and support during this stage of my life.

Thanks to my friends in Xalapa César Carvajal Hernández, Valeria Guzmán Jacob, Francisco Calixto Benitez, Christian Alavez Tadeo, Meztli and Manuel Cuellar Martinez 
for their valuable support during the fieldwork and the help during my stays in Mexico, without your support this task would be harder.

Many thanks also to my friends with whom I have shared many beautiful moments in Göttingen: Gustavo Urquizo y Rosy Farfán, Guillermo Garnica, Adán, Arturo Vera, Dayssy Cárate, Ariana Valdez, Alex Parra, Antonio Garmendia, the members of the Verein Mexikaner in Göttingen, Amanda Taylor and especially Roberto Pérez for becoming as part of my family more than my friend.

Finally, I want to thank my family, the most important people in my life. Thank you, mom, you have been my best example of perseverance and effort. My father for his valuable support during all my life without your help I will not reach this goal. My brothers Jonatan and Tanya because they have always been by my side helping me. And my grandparents that teach me the value of hardworking to achieve my goals.

Thanks Lupita for being my partner, for sharing and living this dream with me, and thanks to my little son Surem who came into my life when I was at this stage of my life and even though this has required a great sacrifice by both of us, having you always beside me has given me the strength to continue. 


\section{Summary}

Terrestrial herbs are an important element in tropical forests; however, there is a lack of research on their diversity patterns and how they respond to different forest use intensities. Studying the richness and distributional patterns of this group along elevational gradients is important in order to understand the general processes that influence this distribution. Previous investigations have been done on elevational gradients and the effect of land use intensity on plant diversity, however, relevant research on herbaceous angiosperms is still scarce compared to other groups of vascular plants, such as trees. In order to bridge this gap, I studied herbaceous angiosperm distributions along gradients of elevation and disturbance. Therefore, the study of an elevational gradient proposed in this work provides an opportunity to analyze distributional patterns of herbs in a tropical area with contrasting environmental conditions. It is important to notice that this is the first study of its class on Mexico.

First, we analyzed species richness and floristic composition of herbaceous angiosperms at eight elevational sites (Chapter two). We compared those patterns with respect to land use intensities at Cofre de Perote, central Veracruz, Mexico. We established an elevational transect $(40$ to $3,520 \mathrm{~m}$ ) where we recorded the occurrence of terrestrial angiosperm herbs within a total of 135 plots of $20 \times 20 \mathrm{~m}$. We compared species richness and floristic composition between the different elevational belts and degrees of forest disturbance. We recorded a total of 264 herb species, 31 endemic to Mexico and three classified as threatened. The total number of species represents $5.7 \%$ of species of the Veracruz' herbaceous angiosperm flora. The elevational belts with highest species richness were 2,500 $\mathrm{m} \mathrm{(76)}$ and 1,500 m (52). In most cases, secondary forests showed the highest species richness along the elevational gradient, whereas old-growth forests had fewer species. The observed species richness, including endemic elements, highlights the importance of plant conservation in areas threatened by land use changes. Additionally, we suggest that environmental heterogeneity formed by mature, disturbed and secondary forests is acceptable (and unavoidable) and can even increase species richness. 
Second, we described the influence of elevation and forest use intensity on alpha, beta, and gamma diversity along gradients of elevation ( $50 \mathrm{~m}$ to $3500 \mathrm{~m}$ ) and human forest use intensity (Chapter three). We analyzed species richness and floristic composition in six vegetation belts at different elevations and in different habitats. We found some general elevational trends, such as the increase in $\alpha$ - diversity and $\beta b$-diversity and a decline in $\beta w$-diversity. Also, $y$-diversity follows a hump-shaped pattern with a peak between 2500 $\mathrm{m}$ and $3000 \mathrm{~m}$ and a decrease at the extremes of the elevational gradient. There was no effect of forest use intensity on $\alpha$-diversity, only $\beta$-diversity increased depending on the change of habitat with the highest values when old-growth forest are transformed into secondary forests. Therefore, a loss of a specific forest area is compensated by the occurrence of a similar assemblage at other areas of the same location. The observed high $\beta$-diversity, including endemic elements, suggests that a mix of different habitats is needed for reaching high $\mathrm{y}$-richness of terrestrial herbs.

Third, we described the deforestation and fragmentation patterns of the study area during three different time periods (1993, 2000 and 2014; Chapter four). We quantified the net change in forest area and the loss of original forest area. Our results showed a reduction in the area of the original vegetation by about $57 \%$. The annual net forest change rate for the first period (1993-2000) was $-0.44 \%$; and increased significantly to $0.11 \%$ for the second period (2000-2014). The old-growth forests of Central Veracruz have suffered high rates of land use change throughout the last twenty years with a reduction of this process during the last decade. In the first period, forest patches increased in irregularity, isolation and size with a reduction in the dimension of the fragments that represented the destruction of natural vegetation, whereas the second period experienced a slightly recovering of forest cover $(0.11 \%)$. This chapter provides a thorough analysis of the forest transformations in Central Veracruz that will increase the consciousness of stakeholders for proper planning and management to maintain biological integrity of the area.

Finally, I synthesize the principal findings of this thesis and highlight the implications for conservation. Also, I suggest potential topics be studied in the future with the data obtained, related with remaining forest and alpha and beta diversity patterns of endemic herbs (Chapter five). 


\section{CHAPTER 1: General introduction}



Humid montane old-growth forest in El Zapotal, Veracruz, Mexico at $2000 \mathrm{~m}$. 


\section{General introduction}

\subsection{Plant diversity and distribution along elevational gradients in the tropics}

The knowledge about the distribution of herbaceous angiosperms along elevational gradients worldwide is still scarce as only a limited number of extensive studies have been conducted. For example, in a transcontinental comparison, Cicuzza et al. (2013) studied the distributional patterns of tropical herbaceous angiosperms. They found that the local difference of herbaceous angiosperms species richness is influenced by factors such as temperature, elevation, and actual evapotranspiration. Additionally, they found that elevation promotes the herbaceous angiosperm richness but there was no relation with precipitation. They did not found a clear explanation for that pattern but suggested that apparently the effect of higher moisture in highlands, as well as evolutionary legacies, could explain it. In general, the treeline marks the limit of herbaceous angiosperm richness with a decrease close to and beyond this area (Wesche et al. 2008).

Desalegn \& Beierkuhnlein (2010) investigated at the landscape scale the mechanism that drives the structure of herbaceous diversity in the Southwest Ethiopian mountains. They found that herbs presented a cumulative increase tendency from 1100 to $1500 \mathrm{~m}$, a decrease at mid-elevations (1500-2000 m) and then a constant increase to upper elevations. They attributed that the herbs did not show a hump-shaped pattern due to the effect of an incomplete gradient. Therefore, from whole explicated variance, elevation had explained a low proportion of the variance (16\%) and the change in bedrock, as an indicator of the nutrient gradient, explained $27 \%$ of the variance for herbaceous diversity.

In a global meta-analysis, Nogués-Bravo et al. (2008) analyzed 37 elevational species richness gradients in a range from 0 to $6000 \mathrm{~m}$ of terrestrial plants finding that the most common pattern of diversity is the hump-shaped $(76 \%)$, followed by decreasing diversity with elevation (16\%). In the case of the hump-shaped pattern, the peak of diversity was in average at $1364 \mathrm{~m}(\mathrm{SD} \pm 531 \mathrm{~m})$.

Along an elevational gradient at the Mt. Kilimanjaro, Hemp (2005) recorded 858 herb species $(70 \%$ of the total vascular plant richness). The peak of species richness was found 
at $1700 \mathrm{~m}$ and most of the variance was explained by elevation ( $r=0.91)$, mean annual temperature $(r=0.87)$, mean annual minimum temperature $(r=0.86)$ and $\mathrm{pH}(r=0.81)$.

There are few studies realized in the Neotropics (Fig. 1.1), for example in Ecuador, along with a gradient from 1850 to 3000 m, where Homeier et al. (2013) studied the factors that are involved in the diversity patterns. They found 552 species at the lowest part of the gradient (ca. $1850 \mathrm{~m}$ ), which was the site with highest species concentration. The authors explain that soil nutrient concentration and geographical gradients of some abiotic factors such edaphic, precipitation and landform conditions appear to be the major factors determining differences in elevational locations.

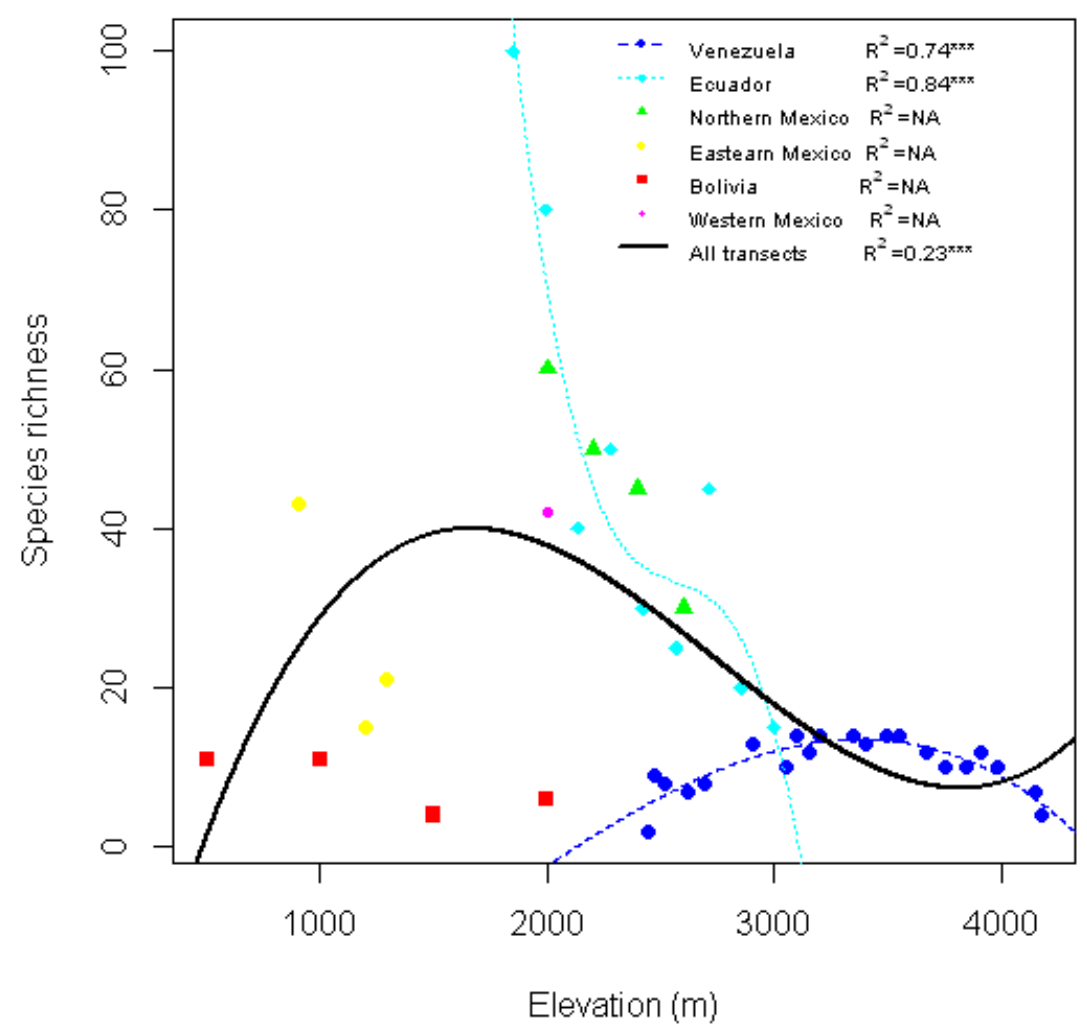

Figure 1.1 Elevational patterns of herbaceous angiosperm diversity in the Neotropics based on the following studies: Bolivia (Kessler et al. 2000), Ecuador (Homeier et al. 2013), Northern Mexico (Encina-Domínguez et al. 2007), Eastern Mexico (Krömer et al. 2013), Western Mexico (Vázquez \& Givnish 1998), and Venezuela (Márquez et al. 2004). The black line marks the general pattern of the six combined transects. 
In Venezuela, Márquez et al. (2004) studied the distribution of grasses along an elevation gradient between 2500 and $4200 \mathrm{~m}$. They found 47 grass species along the gradient, with a richness peak at ca. $3500 \mathrm{~m}$ (Fig. 1.1). They attributed the elevational pattern to the phytogeographical origin and abiotic processes, such as low temperatures, high incoming radiation, water stress and slope aspect.

In Bolivia, Kessler et al. (2000) studied selected plant groups along an elevational gradient from 500 to $2450 \mathrm{~m}$. They found 32 species of herbaceous angiosperms and a linear decrease of species richness with elevation (Fig. 1.1). They attributed the decrease of species richness to the high frequency of night frosts.

In western Mexico, Vázquez \& Givnish (1998) studied several plant groups along an elevational gradient from 1500 to $2500 \mathrm{~m}$. They found 181 terrestrial herbs with a peak of 42 species at $2000 \mathrm{~m}$ (Fig. 1.1). Understorey herbs were negatively correlated with elevation, the authors hypothesized this pattern due that at drier and lower elevations the habitats have more totally deciduous canopies and are more exposed to disturb. Likewise, elevation affects soil fertility and anti-herbivore defenses which can drop the diversity with elevation.

Encina-Domínguez et al. (2007) along with a gradient in Northern Mexico from 1590 to $3140 \mathrm{~m}$ recorded 171 herbs. The authors found a high diversity in mid-elevations (2100 $\mathrm{m}$ ) due to the border effect of the transition areas between plant communities (Fig. 1.1). Also, they attribute the high herb richness to the migrant effect, which is explained by the immigration of species between two different forest types. Finally, they also found a high beta-diversity attributed to a high environmental (climatic and edaphic) heterogeneity associated with the relief.

In the state of Veracruz, Eastern Mexico, Krömer et al. (2013) studied the effect of elevational locations area and climate on herb richness. They studied five taxonomical assemblages along three elevational gradients finding 50 herbaceous angiosperms. The elevational pattern depended on the taxonomical group, with specific groups that presented important variations related with elevation: Araceae presented a decrease with elevation, whereas there was an increase of Orchidaceae and Piperaceae (Fig. 1.1). The authors suggest to separate different groups of terrestrial herbaceous angiosperms in 
order to obtain more clear elevational patterns and that herb layer is more related to bryophyte cover and precipitation.

All of these studies related the diversity and distribution patterns of herbaceous angiosperms with environmental variables (climate or precipitation) present along the elevational gradients. There are few works that include the impact of human influence on the biotic communities, as done by Kessler et al. (2001), which verified that herbaceous species are negatively affected by human disturbance. As well, Jácome-Reyes (2005) related the structure and composition of high montane herbs with temperature and elevation along an elevational gradient in Bolivia. They found that climate change and human disturbance in these zones might lead to variations in the dominance arrangements and an increase of invasive species from neighboring zones.

In studies concerning the anthropic impact on herb diversity (Cicuzza et al. 2011), those studies found that the systems with a high disturbance degree present an increase in total species richness and showed a considerable increase in richness in less disturbed forestuse categories. However, in more disturbed forest-use categories, the richness widespread species was increased. Therefore, herbs were influenced by traits that control their range sizes in response to anthropological events (Lozada et al. 2008). Under extremely degraded environment circumstances, widespread herbs tend to display strong competitiveness, which is the reason why there is a dominance of such herbs in extremely interfered forest-use categories and the most sensitive group to degradation are the species with narrow ranges form (Kessler 2001). It is also known that human-intervened agroecosystems preserve many narrow-ranged species (endemics) and can contribute considerably to general species richness (Lozada et al. 2008).

The above-mentioned works give an overview of the arrangements of herb diversity along elevational gradients in the tropics; however, the available information is not concluding due to the high variation in different organism groups and several world regions (Cicuzza et al. 2013), therefore it is actually not possible to determine a general elevation pattern of herbs (Fig. 1.1). Even as shown in figure 1.1 there are contradictory patterns on elevational gradients, on one hand, there is an increase in species richness with elevation and on the other hand, the contrary occurs on other elevational gradients. Furthermore, 
there is even less information about the impact of human disturbance on the diversity and distribution patterns of herbaceous angiosperms under different biotic and abiotic conditions presents along an elevational gradient.

\subsection{Deforestation as driver of species richness loss due to forest use alteration}

Some of the main contributors to global climate change are the decrease in carbon sinks and forest loss which increase the atmospheric concentration of $\mathrm{CO}_{2}$ (Houghton et al. 2000). After fossil energy combustion, deforestation is one of the most important human causes of increasing $\mathrm{CO}_{2}$ emissions to the atmosphere (approximately 6 to $17 \%$ of world emissions) (van der Werf et al. 2009). Hansen et al. (2013) found that in the period from 2000-2012 there was a loss of 2.3 million $\mathrm{km}^{2}$ (slightly neutralized by an increase of 0.8 million $\mathrm{km}^{2}$ ) of forests worldwide. The tropical rain forest ecozones in Southeast Asia, Africa, and Latin America are the greatest endangered forest portions of the world (Saatchi et al. 2011). The loss of forest area in Latin America is one of the main losses globally (Achard et al. 2002). At the national level, Mexico possesses $2 \%$ of the total carbon deposited in tropical forests but produces too emissions due to forest loss (Baccini et al. 2012). Around $2 \%$ of the total carbon emissions ( $8 \mathrm{Tg} \mathrm{C} \mathrm{yr}^{-1}$ ) of Latin America took place in Mexico, where the current research took place, in the period from 2000-2005 (Harris et al. 2012) and had a total forest cover loss of 24 Mha in the 2000-2012 period (Hansen et al. 2013), which has made Mexico the $11^{\text {th }}$ main worldwide emitter of $\mathrm{CO}_{2}(1.4 \%$ of world emissions) to date (The World Bank 2016). The Yucatan peninsula, Veracruz, and Chiapas are the areas where forest loss is happening to a high rate (Fig. 1.2). 


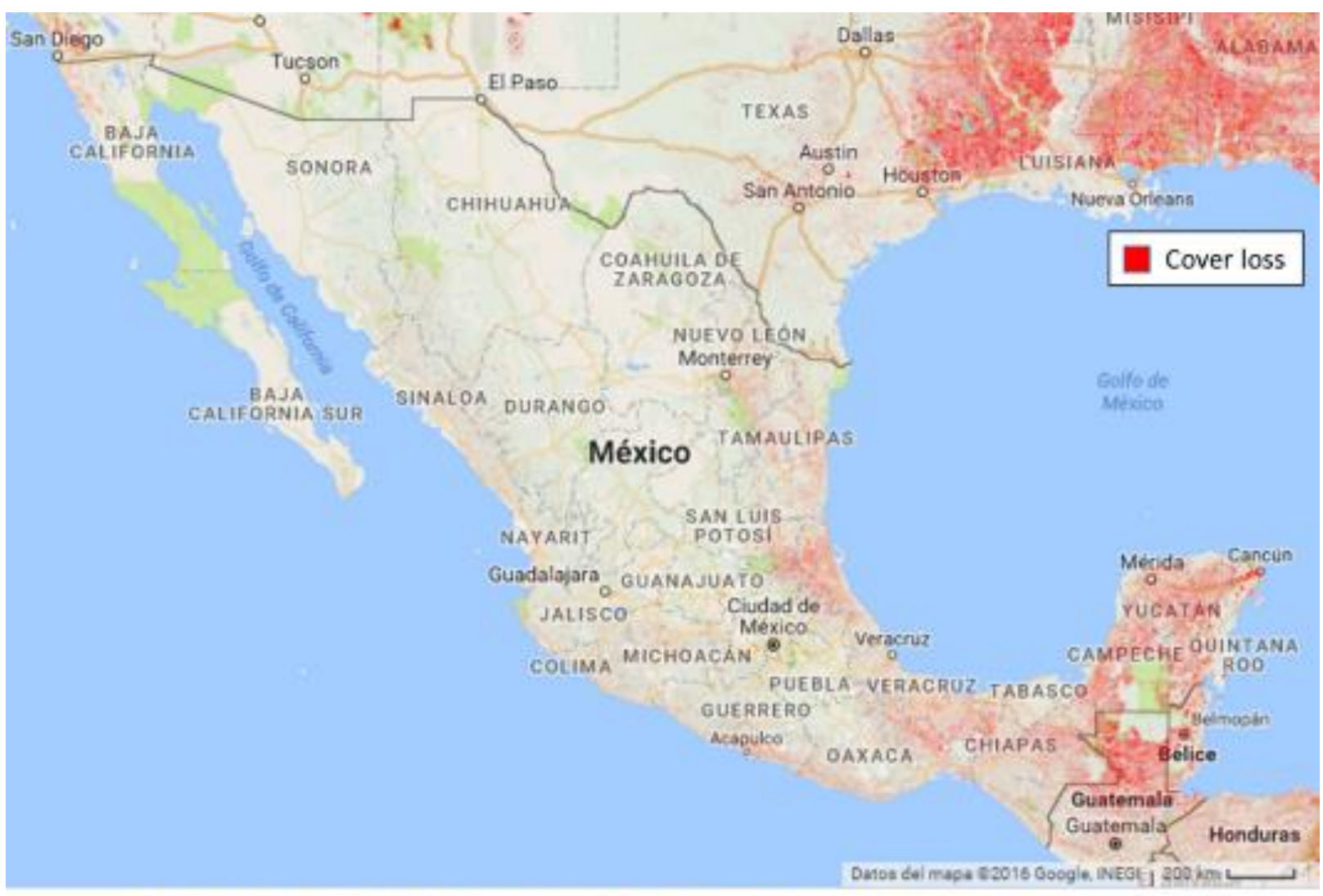

Published by Hansen, Potapov, Moore, Hancher et al. Powered by Google Earth Engine - Help

Figure 1.2 Deforestation in Mexico between 2000 and 2014 (Hansen et al. 2016). Source: Hansen/UMD/Google/USGS/NASA. Data available online from http://earthenginepartners.appspot.com/science-2013-global-forest

Numerous ecosystem services are provided by tropical forests such as regulation of the global climate system, carbon sequestration, and protection of soil. In addition to water filtration, conservation of species richness, renewable energy, and resources (Foley et al. 2005). In general, the logged zones are transformed into agrarian farming schemes (Achard et al. 2002), which causes the alteration on the provision of significant ecosystem services and an enormous loss of species richness in these areas. Tropical forest ecosystems are home to some of the highest concentrations of rare species in the world and have a remarkably high biodiversity (Myers et al. 2000).

Latin America has seven of the 25 global biodiversity hotspots defined by Myers et al. (2000). The state of Veracruz, Mexico, where the present research was done, is located 
in one portion of the Mesoamerican hotspot. Extremely rare species have evolved in Mesoamerica due to its exceptional geological history, as well as its diversity of climates and the confluence of the neotropical and neartic regions (Harvey et al. 2008). However, large areas of natural forests are cleared for agricultural purposes and cattle pasture areas (Fig. $1.3 \mathrm{~A}$ ), which made Veracruz the main producer of cattle inside the country encompassing around $11 \%$ of Mexico's cattle production (INEGI 2007). 




Figure 1.3 Forest cover loss in Veracruz, Mexico. A) Total forest loss from 2001-2014 in Veracruz. B) Yearly deforestation between 2001 and 2014 in the study area central Veracruz, protected areas are shown (green line). Source: Hansen/UMD/Google/UGS/NASA (Hansen et al. 2016). Data available on-line from http://earthenginepartners.appspot.com/science-2013-global-forest 
The region of central Veracruz includes relicts of two rare forest ecoregions within a biodiversity hotspot, i) the humid montane forest with an area of about $4,069 \mathrm{~km}^{2}$ of which only $4 \%$ is part of protected areas (Gillespie et al. 2012, Williams-Linera 2013), and ii) the dry forest with an area of about $372 \mathrm{~km}^{2}$ where only $2 \%$ is protected (Gillespie et al. 2012, López-Barrera et al. 2014) (Fig. 1.3 B). However, increasing forest conversion into cattle pastures and agricultural fields still presents the main pressure to the natural forest in this area. In addition to tropical forest loss and transformation, additional stress on species richness is exerted through landscape homogenization. The previous as result of logging and an increase of current agrarian areas by rises in inputs of fertilizers and herbicides (Benton et al. 2003). Veracruz has one of the highest forest loss rates in Mexico and to date, most of the natural forest has been transformed mainly into agriculture and cattle areas (Table 1.1). It is estimated that if the current tendency continues by the year 2020 only $1 \%$ of the natural forests will remain.

Table 1.1 Changes in land use coverage in Veracruz for the period 1971-2020 (INEGI 2000, Ellis \& Martínez 2010, Gerez-Fernández \& Pineda-López 2011).

\begin{tabular}{|c|c|c|c|c|c|c|c|c|}
\hline Land cover & $\begin{array}{c}1972 \\
(\%)\end{array}$ & $\begin{array}{c}1981 \\
(\%)\end{array}$ & $\begin{array}{c}1984 \\
(\%)\end{array}$ & $\begin{array}{c}1993 \\
(\%)\end{array}$ & $\begin{array}{c}1994 \\
(\%)\end{array}$ & $\begin{array}{c}2000 \\
(\%)\end{array}$ & $\begin{array}{c}2007 \\
(\%)\end{array}$ & $\begin{array}{c}2020^{\star} \\
(\%)\end{array}$ \\
\hline Forests & 41 & 38 & 20 & 19 & 19 & 18 & 9 & 1 \\
\hline Agriculture & 27 & 26 & 37 & 35 & 31 & 28 & 33 & 34 \\
\hline Cattle & 22 & 24 & 34 & 32 & 34 & 47 & 46 & 51 \\
\hline $\begin{array}{l}\text { Secondary } \\
\text { forests }\end{array}$ & 7 & 8 & 6 & 9 & 11 & 4 & 7 & 9 \\
\hline Grassland & 2 & 3 & 2 & 3 & 3 & 2 & 3 & 3 \\
\hline Other & 1 & 1 & 2 & 2 & 2 & 1 & 2 & 2 \\
\hline
\end{tabular}


Considering the huge quantity of carbon deposited and their remarkably high species richness, forest loss in Mesoamerican ecosystems has the potential to promote grave world-wide consequences on species richness and climate (de Albuquerque et al. 2015). There is a continuing discussion whether land should be definitely chosen "for nature" and "for production". Consequently, it can generate a separation (land sparing) through agrarian intensification (high input-high yield) or whether a more combined method to land use should be accepted e.g. following wildlife-friendly agricultural (low input-low yield) (Gilroy et al. 2014, Abou Rajab 2016).

Deforestation and land use change have different consequences on the diversity of herbaceous angiosperms. However, studies on this subject are scarce and to date, there is no research made on the effect of forest use intensity on herbaceous angiosperms in Veracruz.

\subsection{Herbaceous angiosperms as a study model}

Herbaceous angiosperms of the forest understory are defined as non-woody or only slightly woody plants that are rooted on the forest floor (Poulsen 1996), including facultative terrestrial species like hemiepiphytes that are only at ground level for part of their life cycle (Cicuzza et al. 2013). These plants form a functional guild that exploits the same class of resources sharing traits (Stroud et al. 2015). Also, this guild is one of the most widespread angiosperm groups in the world, owing to their plasticity in habitat and reproduction form (Hawkins et al. 2011). This group has the largest number of exclusive families in the angiosperm phylogeny (37\%) with at least 149 families unique to being herbaceous (Hawkins et al. 2011). Furthermore, these plants occur in a variety of habitats, from rainforests to deserts, rugged mountains to savannas, farmlands and even suburban and urban landscapes (Hawkins et al. 2011).

The assemblages of trees and herbs vary considerably on traits, rates of phenotypic and molecular evolution (Smith \& Beaulieu 2009). For example, woody lineages have fewer variations per million years in climatic niche space than associated herbaceous plants and climate space exploited by herbs is higher than parallel lineages composed mostly of 
woody groups (Smith \& Beaulieu 2009). In some cases, the differences on niche between herbs and woods might just be related to geography as in the case of Primulales (Smith \& Beaulieu 2009).

The maximum richness of herbaceous angiosperms can be found in tropics, northern latitudes $\left(45^{\circ}\right)$, mainly in the Nearctic and portions of the North Temperate Region. In general, the average herbaceous angiosperm range sizes have a tendency to be comparatively small in northern California, eastern USA and the tropics (Hawkins et al. 2011). Herb families are younger on average in the north tundra region, Tierra del Fuego, the Australian and Sahara deserts, but are not particularly ancient in the tropics (Hawkins et al. 2011). Herbs are responding adaptively considerable more intensely to present climate than to previous one (Hawkins et al. 2011).

There is no phylogenetic relationship of important traits within herbaceous angiosperms because trait evolution amongst them is occurring so fast (Hawkins et al. 2011). Herbs are adapted to cold climates and had a success on temperate zones due to be annual and the production of underground structures (e.g. rhizomes and stolons) (Hawkins et al. 2011). Assuming that there is no sign of family level niche conservatism with respect to cold climates, it is interesting that the newest families of herbaceous angiosperms had originated in the aridest environments (Hawkins et al. 2011).

Herbaceous clades are evolving rapidly with numerous important traits, this fast process of evolution might reveal a faster rate of adaptation to varying climatic conditions. As an example of this procedure, it can be mentioned the increase of the ecological dominance of $\mathrm{C}_{4}$ grasses in lower latitudes (Edwards et al. 2010).

Furthermore, understory plants in tropical forests comprise around $45 \%$ of the vascular plant species richness (Linares-Palomino et al. 2009, Cicuzza et al. 2013). Terrestrial herbaceous angiosperms are frequently slightly unequally dispersed on the tropical forest floor, and species with underground stems or buds are common (Richards 1996). Furthermore, within the understory herbs monocotyledons (monocots) are the most prominent group, which have some adaptations to drought like diffuse root structures deprived of one or few central roots. This different architecture affects the mode in which the herbs absorb water and nutrients (Robinson 1994). The mean annual precipitation of 
the driest month is negatively linked to dicots diversity, as reported by Cicuzza et al. (2013), explained to their morphological and physiological adaptations (Willinghöfer et al. 2011). The study of Cicuzza et al. (2013) recovered indicator herbaceous angiosperms families that on particular continents play the main role (Table 1.2).

Table 1.2 Indicator herbaceous angiosperms families found in tropical transects worldwide adapted from Cicuzza et al. (2013). Families registered are considerably well represented in respective continent transects than in those of the other two contents ( ${ }^{*}$ Monocots, ${ }^{* *}$ Dicots).

\begin{tabular}{|c|c|c|}
\hline America & Africa & Asia \\
\hline Acanthaceae $e^{\star *}$ & Agavaceae* $^{*}$ & Araceae* $^{*}$ \\
\hline Arecaceae* & Balsaminaceae ${ }^{\star *}$ & Convolvulaceae $^{\star *}$ \\
\hline Bromeliaceae* & Commelinaceae* & Cucurbitaceae $^{* *}$ \\
\hline Costaceae* & Maranthaceae* & Cyperaceae* \\
\hline Dioscoridaceae* & Piperaceae $^{* *}$ & Gesneriaceae $^{\star \star}$ \\
\hline Euphorbiaceae ${ }^{\star *}$ & Poaceae* & Primulaceae ${ }^{\star *}$ \\
\hline Heliconiaceae* & Rubiaceae* & Urticaceae $^{\star *}$ \\
\hline Juncaceae* & & Violaceae ${ }^{* *}$ \\
\hline Malvaceae* & & Zingiberaceae* \\
\hline \multicolumn{3}{|l|}{ Smilacaceae* } \\
\hline Solanaceae ${ }^{* *}$ & & \\
\hline
\end{tabular}

The treeline is the ecological limit of herbaceous species richness with a decrease on richness near of this zone (Wesche et al. 2008). Herbs are more directly influenced by microclimatic environments than by macroclimatic limitations (Wang et al. 2009). Numerous monocot families, instead, have originated in the tropics and have had only restricted success in adjusting to low temperature, particularly frost (Márquez et al. 2006). 
Herbs in tropical forests play a significant role in space antagonism for seedling and young trees due to light restriction (Zivanai et al. 2010), influencing in forest dynamics and tree regeneration (Condit et al. 2000). Also, herbaceous angiosperms are morphologically more flexible in their adaptations to low temperatures and have shorter generation periods than trees, which enables them to diversify more rapidly at higher latitudes (Willinghöfer et al. 2011). For all the previous reasons the species richness patterns of herbaceous angiosperms embody an extremely stimulating field of investigation that might supplement the wide investigation conducted particularly on trees. Given, the current high debate with regard to distributional patterns on herbaceous angiosperms, it is quite surprising that there are not general conclusions. Hence, this dissertation will contribute to filling the knowledge gap on this them.

\subsection{Project framework and study area}

The study was conducted at eight sites along an elevational gradient between 30 and $3540 \mathrm{~m}$ on the Eastern slopes of the Cofre de Perote, an extinct volcano of $4282 \mathrm{~m}$ elevation in the central part of the state of Veracruz, Mexico (Fig. 1.4). This region is located at the junction of the Trans-Mexican volcanic belt and the Sierra Madre Oriental, a mountainous area between $19^{\circ} 25^{\prime} 5.7^{\prime \prime}$ and $19^{\circ} 36^{\prime} 54^{\prime \prime} \mathrm{N}$ and $94^{\circ} 44^{\prime} 43.5^{\prime \prime}$ and $97^{\circ} 9^{\prime}$ 36.9" W. 




Figure 1.4 Location of the eight study sites along the elevational gradient on the Eastern slopes of the Cofre de Perote, the central part of the state of Veracruz, Mexico.

Due to its geomorphological conditions, the study area presents a high variation of climates, from warm at the lower part, over temperate at the mountainous mid-elevations to cold in the higher parts (Soto-Esparza \& Giddings 2011). The temperature shows a linear decrease with elevation, whereas the mean precipitation varies depending on the elevation with a maximum at the mid-elevations and decreasing values at the extremes of the gradient (Fig. 1.5) (SMN 2016). 


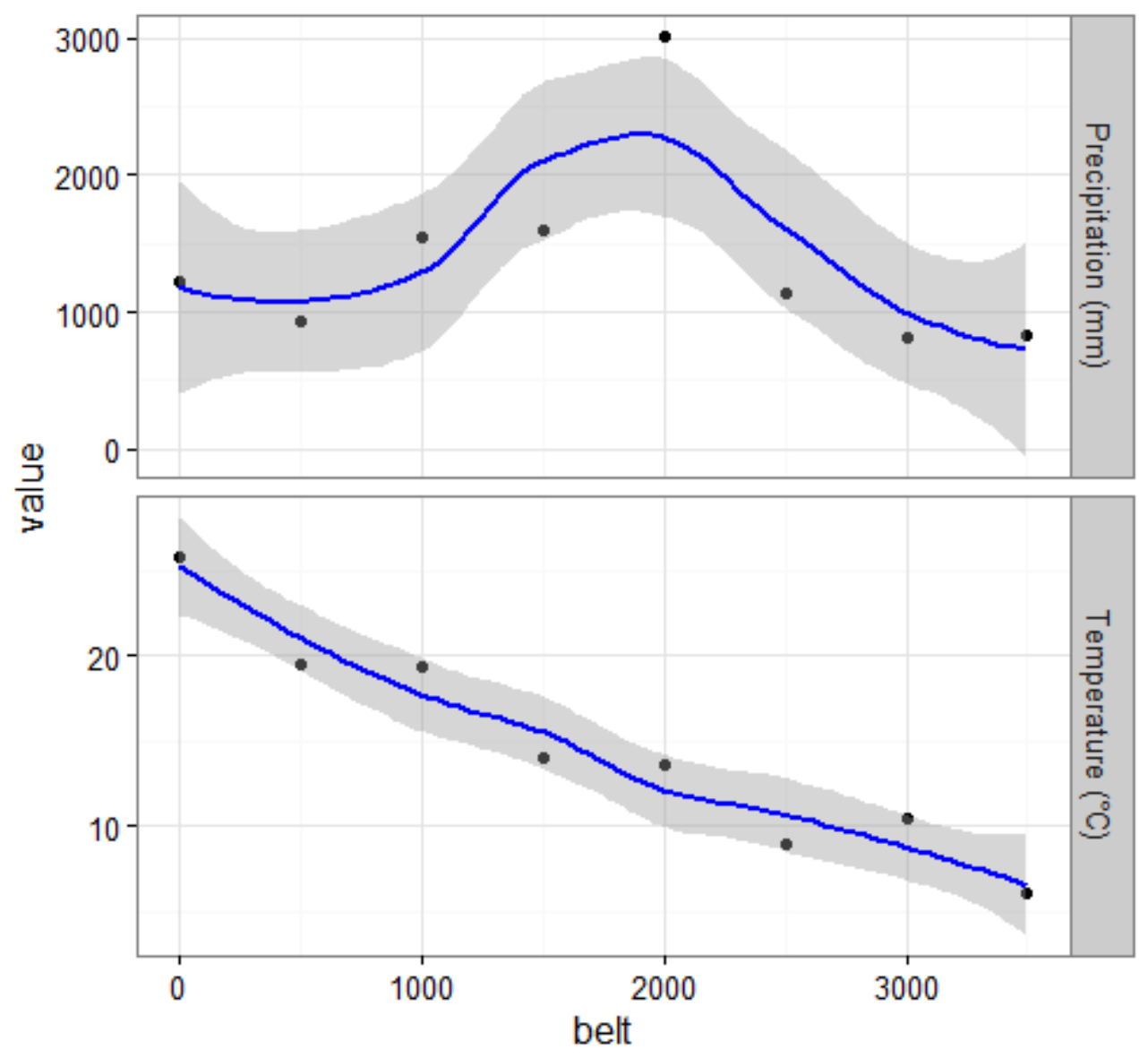

Figure 1.5 Mean annual precipitation and temperature measured in different climatological stations (near to the sampling sites) operating along the elevational gradient during the period 1951-2010 (SMN 2016).

The orographic and climatic differences along the transect allow the presence of different vegetation types, from the dry environments with high temperatures (tropical semideciduous forest and tropical oak) over the humid-temperate (humid montane forest, pineoak forest) to cold and dry at the higher parts of the gradient (pine and fir forest) (Fig. 1.6). According to Lauer (1973), five climate zones can be found in the study area in combination with six vegetation types following Miranda \& Hernández-Xolocotzi (1963). The different vegetation types are described below based on field observations and in accordance with the reported by Castillo-Campos (2011). 


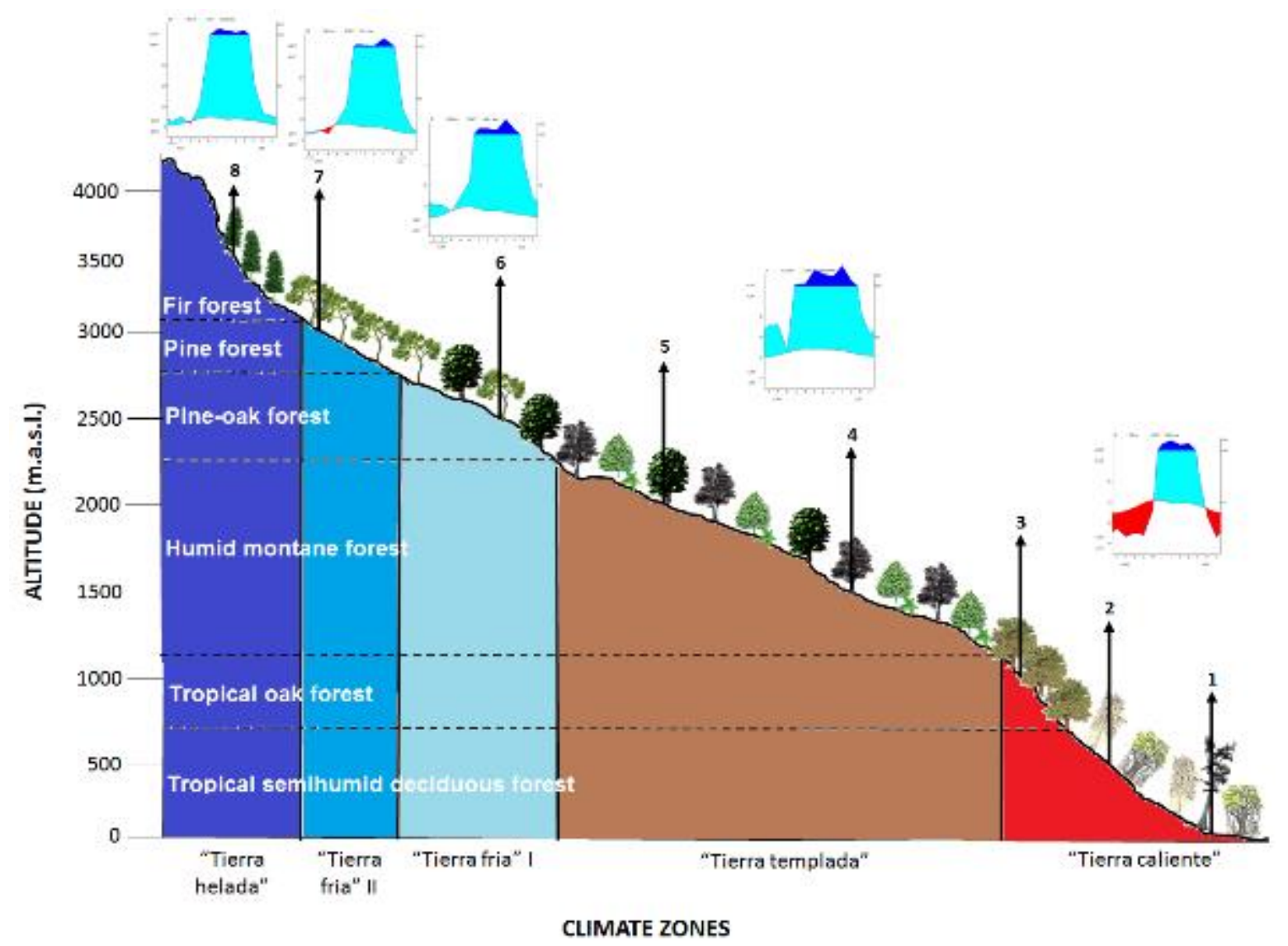

Figure 1.6 Different vegetation types according to Miranda \& Hernández-Xolocotzi (1963) and climate zones (Lauer 1973) along the elevational gradient of the study area.

Tierra caliente $(\mathbf{0}-\mathbf{1 2 5 0} \mathrm{m})$. In this zone, we selected three study sites located in two vegetation types: 1) tropical semi-humid deciduous forest that is found in the localities of La Mancha at $40 \mathrm{~m}$ and Palmarejo at $640 \mathrm{~m}$ (Fig. 1.7) (Castillo-Campos \& Travieso-Bello 2006). The most important trees are Bursera simaruba, Comocladia engleriana, Plumeria rubra and some species of the genus Quercus. The shrub stratum is dominated by Dioon edule, Chusquea sp. and some species of Chamaedorea. The herbaceous stratum is dominated by some ferns of the genera Adiantum and Tectaria. The hemiepiphytes are represented by Monstera and Philodendron (Carvajal-Hernández 2016). 

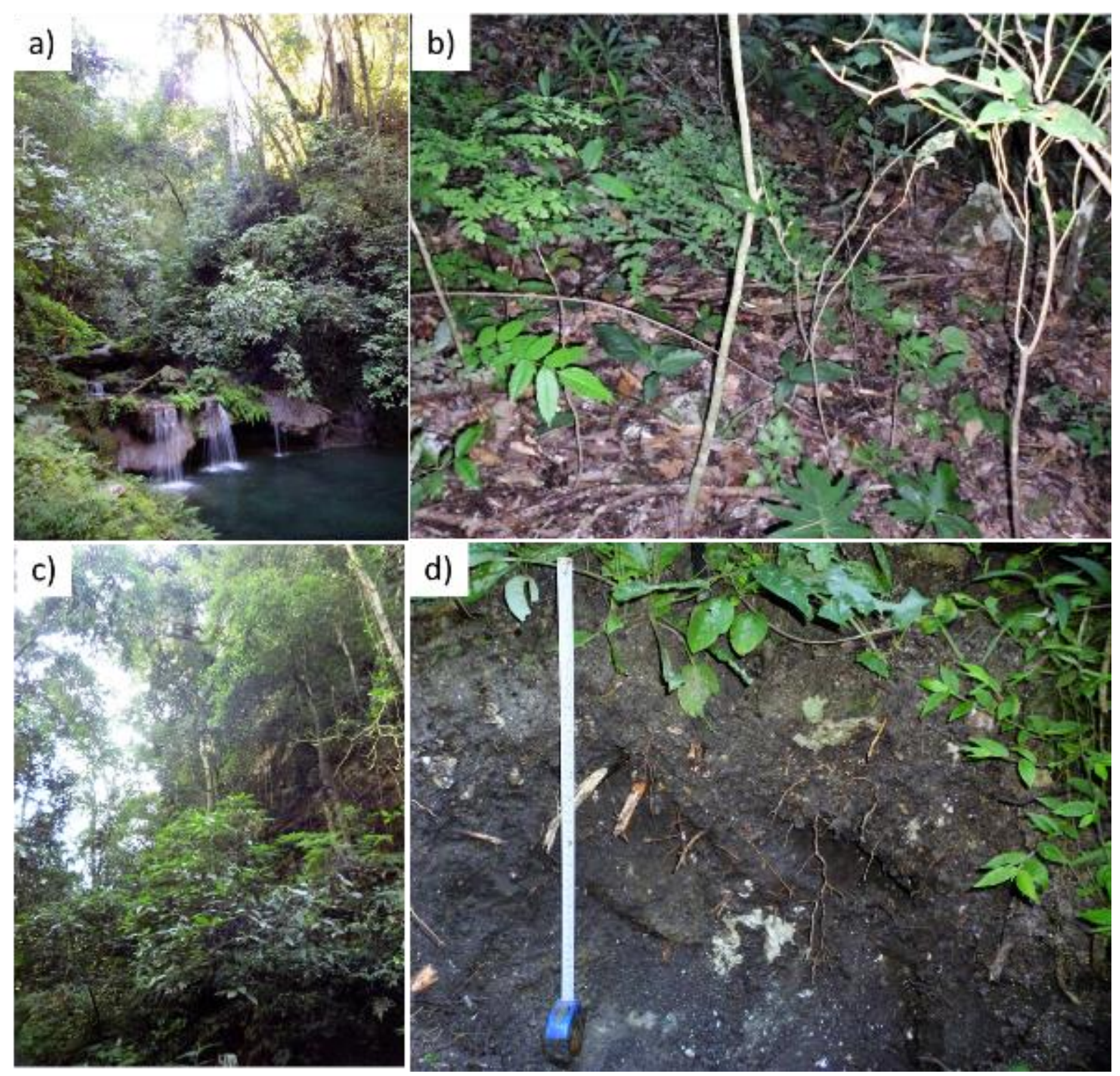

Figure 1.7 Tropical semi-deciduous forest: a) azonal riparian forest, b) herbaceous layer, c) vegetation structure and d) soil profile.

2) Tropical oak forest in the locality of Chavarrillo at $970 \mathrm{~m}$ (Fig. 1.8). This vegetation type is typically dominated by one to three oak species (Quercus oleoides, $Q$. laurina, $Q$. sapotifolia, Q. peduncularis), which do not exceed $15 \mathrm{~m}$ in height, whereas other tree species are scarce (Byrsonia crassifolia, Pouteria campechiana). In the shrub stratum grow Acacia cornigera, A. pennatula and Malvaviscus arboreus. In the herbaceous stratum stand out Bromelia penguin and Blechnum occidentale (Carvajal-Hernández 
2016). Vascular epiphytes, such as xeromorphic bromeliads of the genus Tillandsia and orchids, are abundant (Torres-Cantú 2013).
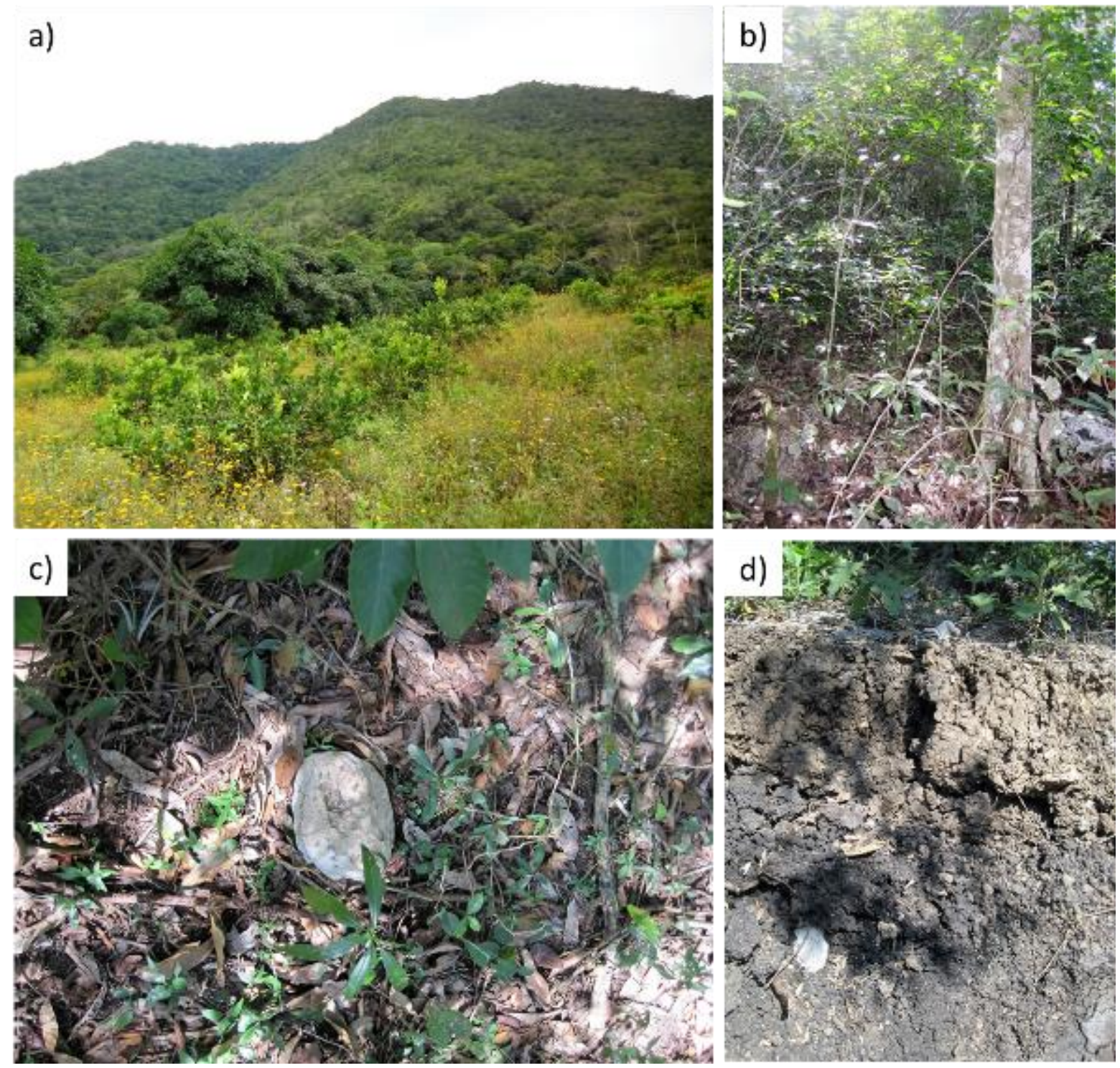

Figure 1.8 Tropical oak forest: a) landscape view of the study site, b) forest structure, c) herbaceous layer and d) soil profile.

Tierra templada (1250-2200 m). In this zone, two study sites within one vegetation type were chosen: 1) humid montane forest, which is found in the localities of Los Capulines 
at $1570 \mathrm{~m}$ and El Zapotal at $2120 \mathrm{~m}$ (Fig. 1.9). One of the most important ecological factors that characterize this kind of forest is the frequency of fog ("bosque de niebla"; ZamoraCrescencio \& Castillo-Campos 1997). In general, this community includes a mix of lower montane forest genera (Quercus spp., Liquidambar sp.) with tropical lowland forest families (Acanthaceae, Rubiaceae, Myrsinaceae). The most common shrubs are Psychotria sp. and tree ferns of the genera Cyathea and Alsophila. The epiphytic herbs stand out in this ecosystem, where the ferns are represented by several families and genera, as well as Bromeliaceae and Orchidaceae stand out for their high species richness and abundance (Carvajal-Hernández 2016). The period of foliar expiration is short and present in the dry cold season (November to March), although the forest is never fully defoliated (Zamora-Crescencio \& Castillo-Campos 1997). There are numerous endemic (22 recorded for Veracruz), endangered and rare species reported in this vegetation (Gómez-Pompa \& Castillo-Campos 2010).
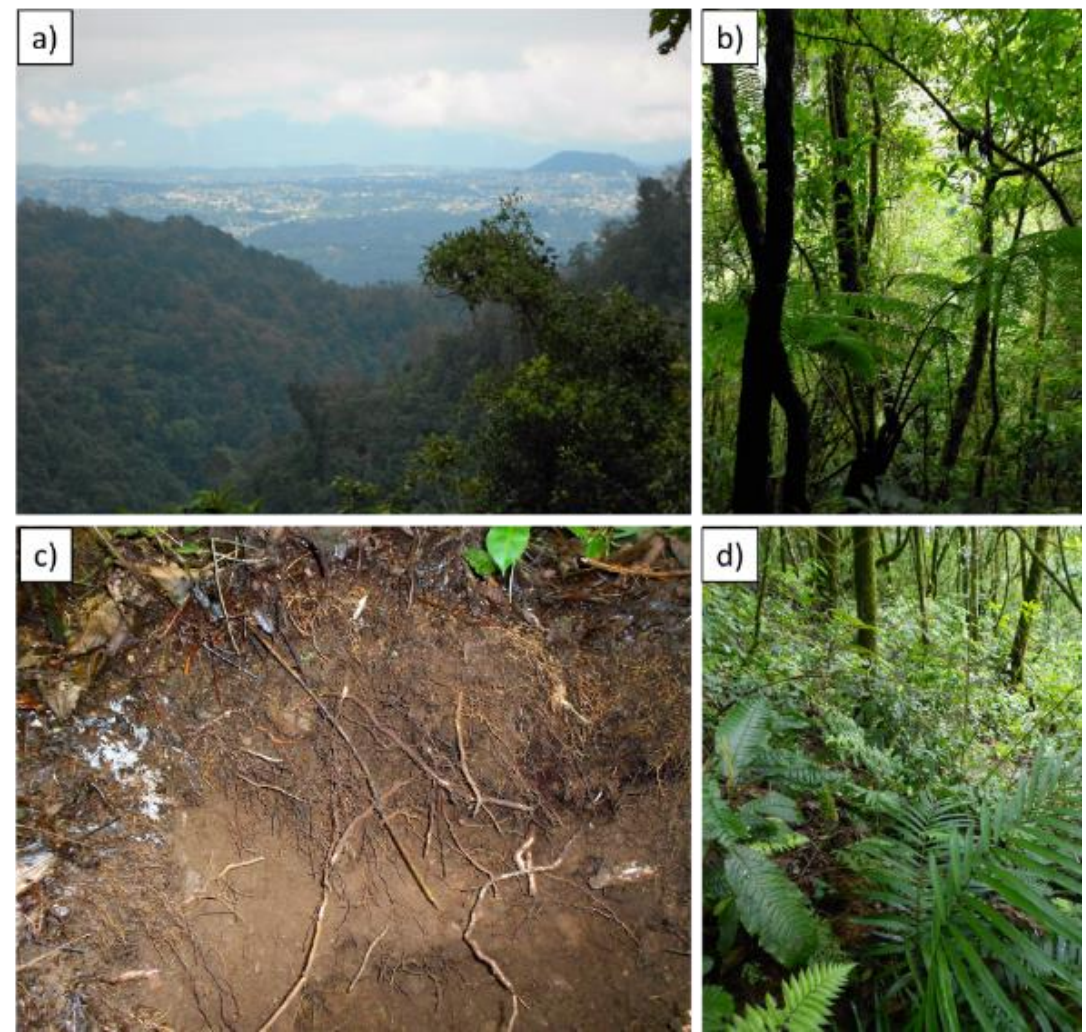

Figure 1.9 Humid montane forest: a) landscape view of the study site, b) forest structure, c) soil profile and d) herbaceous layer. 
Tierra fría I (2200-2700 m). In this zone, one study site within one vegetation type was chosen, the pine-oak forest, which is found in the locality of El Encinal at $2520 \mathrm{~m}$ (Fig. 1.10). This vegetation type comprises a community whose dominant arboreal components belong to the genera Quercus ( $Q$. crassifolia and $Q$. laurina) and Pinus and the shrub stratum is represented mainly by species of the genus Senecio. In the herbaceous stratum dominate species of the family Asteraceae, Poaceae, and ferns of different genera (Carvajal-Hernández 2016). Typically in the afternoons fog occurs, resulting in a high abundance of epiphytic mosses (Narave-Flores 1985, Castillo-Campos 2011).
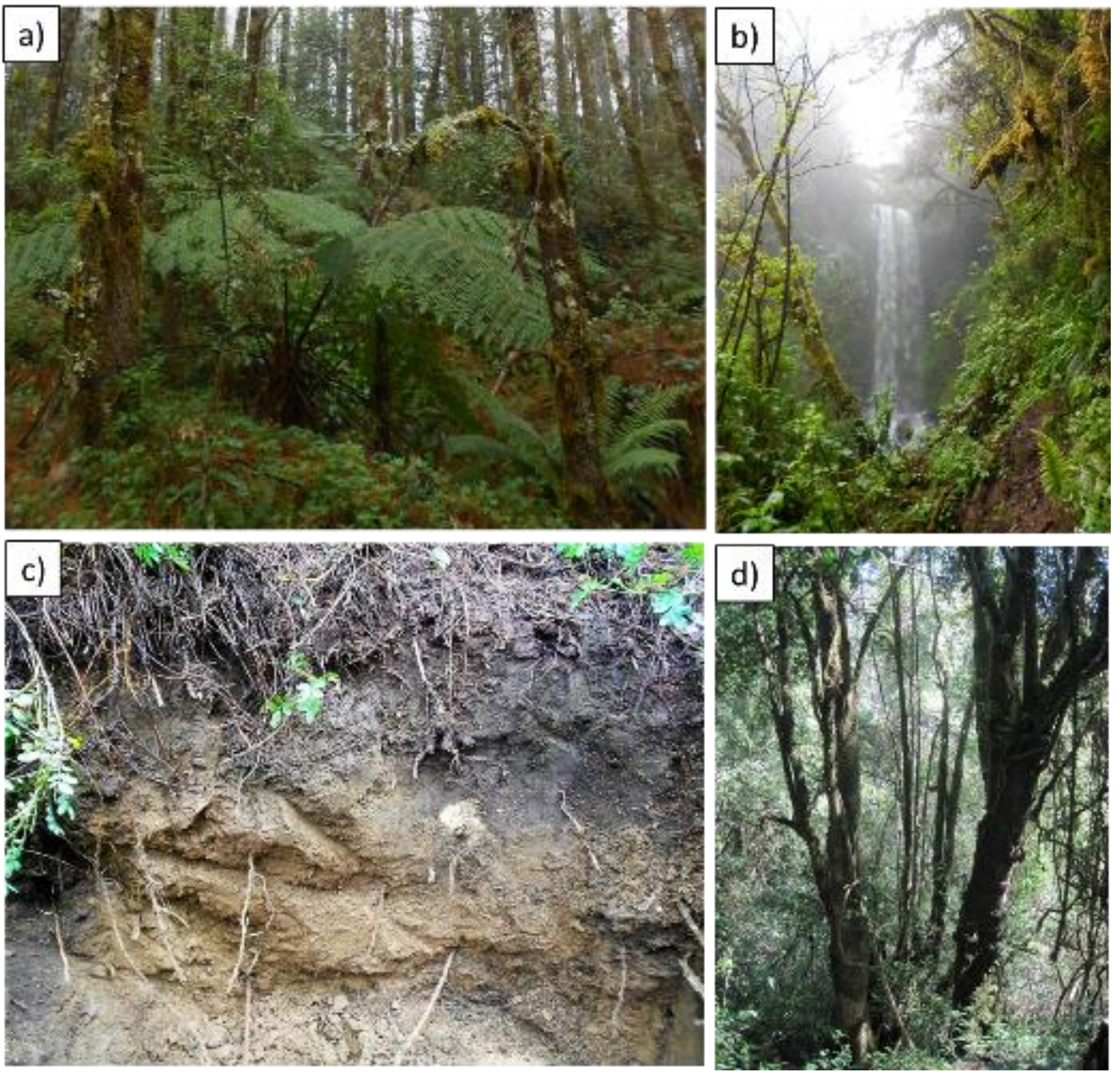

Figure 1.10 Pine-oak forest: a) herbaceous layer, b) azonal forest, c) soil profile and d) forest structure. 
Tierra fría II (2700-3200 m). In this zone, one study site within one vegetation type was chosen, the pine forest, which is found in the locality of Los Pescados at $3110 \mathrm{~m}$ (Fig. 1.11). This vegetation type has a low plant richness, trees are dominated by several species of the genus Pinus (P. montezumae, P. pseudostrobus, P. teocote, and P. patula). The shrub stratum is composed by immature pines of the same species as the arboreal stratum and Baccharis conferta, and the herbaceous stratum is commonly dominated by grasses and species of the families Asteraceae, Crassulaceae mainly from the genus Echeveria and ferns of the genus Dryopteris. Vascular epiphytes are scarce, represented mostly by two species of ferns (Pleopeltis polylepis, Polypodium plebeium) (CarvajalHernández 2016). There are 12 endemic plant species for Veracruz in this forest type (Gómez-Pompa \& Castillo-Campos 2010).
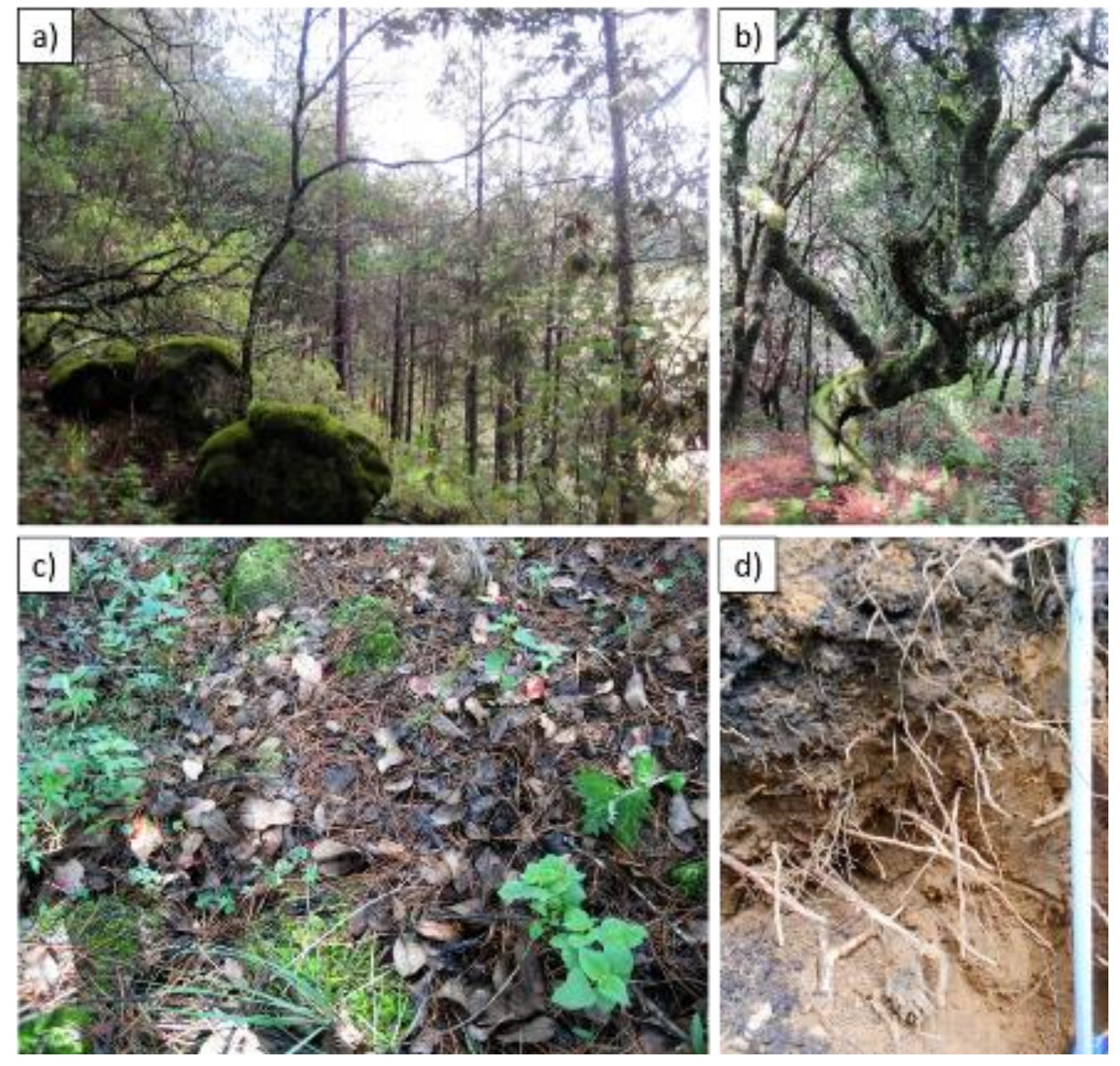

Figure 1.11 Pine forest: a) landscape view of the study site, b) forest structure, c) herbaceous layer and d) soil profile. 
Tierra helada (3200-4282 m). In this zone, one study site within one vegetation type was chosen, the fir forest, which is found in the locality of El Conejo at $3520 \mathrm{~m}$ (Fig. 1.12). This vegetation type is a monospecific Abies religiosa community. These forests are confined to sites of high mountains, between 3,100 and $3,600 \mathrm{~m}$. This plant community is composed of arboreal elements whose height varies between 20 and $40 \mathrm{~m}$, the peculiar characteristic of its dominant elements is the typical triangular shape of its crowns. There are immature individuals of $A$. religiosa forming part of the shrubby and lower arboreal stratum, whereas the herbaceous stratum is dominated by many seedlings of the same species (Narave-Flores 1985).
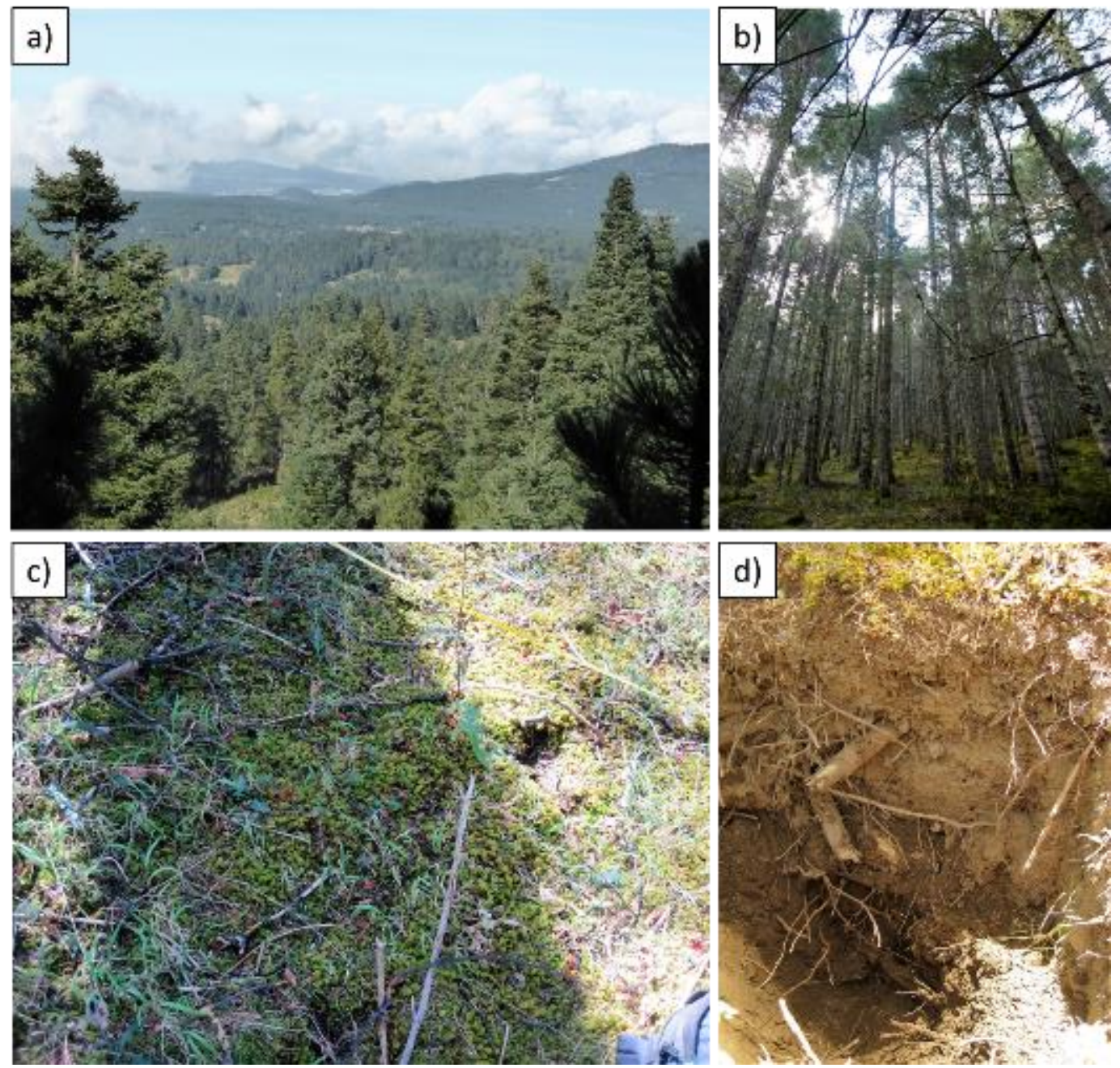

Figure 1.12 Fir forest: a) landscape view of the study site, b) forest structure, c) herbaceous layer and d) soil profile. 


\subsection{Study objectives and general study aim}

Despite the investigations realized on elevational gradients and the effect of land use intensity on plant diversity, relevant research on herbaceous angiosperms is still scarce compared to other groups of vascular plants, such as trees. The study of an elevational gradient proposed in this work provides an opportunity to analyze distributional patterns of herbs in a tropical area with contrasting environmental conditions.

\subsubsection{Research questions}

- What are the patterns of diversity and distribution of herbaceous angiosperms along an elevational gradient in central Veracruz, Mexico, compared with those found in other Neotropical countries and tropical latitudes?

- What is the impact of forest use intensity on the diversity of herbaceous angiosperms?

- What is the current conservation status of forest fragments in central Veracruz, Mexico?

\subsubsection{General hypothesis}

The abiotic factors related to climatic parameters, such as temperature, solar radiation, and relative humidity, have an influence on the species distribution patterns. There is evidence that in presence of anthropogenic disturbance the microclimatic conditions change, which causes pressure on the species diversity. Consequently, it is expected that the present climatic conditions along the studied elevational gradient as well as its modification due to the human disturbance have an influence on the patterns of distribution and diversity of herbaceous angiosperms. Furthermore, it is hypothesized that the fragmentation and degradation of the forests in the study area have been increasing over time, which has also increased the pressure on the herb diversity. Therefore, it is expected that the current spatial distribution of herbs is due to a long history of land use in the study area. 


\subsubsection{Objectives}

- To evaluate the patterns of distribution and diversity of herbaceous angiosperms along an elevational gradient (20 to $3500 \mathrm{~m}$ ) in central Veracruz, Mexico.

- To evaluate the effect of land use intensity on the richness and composition patterns of herb species.

- To analyze the current conservation status of forest fragments in the study area.

\subsection{Thesis structure}

This thesis is divided into three studies concentrating on diverse features of floristics, distributional patterns, diversity and composition of herbaceous angiosperms in different elevations and degrees of land use intensity as well as land use change and forest fragmentation.

\section{CHAPTER 2:}

Richness and distribution of herbaceous angiosperms along gradients of elevation and forest disturbance in central Veracruz, Mexico.

In this chapter, the species richness and floristic composition of herbaceous angiosperms at eight elevational sites were compared with respect to forest use intensities. Furthermore, the role of environmental heterogeneity formed by old-growth, degraded and secondary forests as a reservoir of species richness of herbs was assessed.

The following hypotheses were tested:

1. Species richness of herbaceous angiosperms follows a hump-shaped pattern along the elevational gradient.

2. Species richness of herbaceous angiosperms decreases with land use intensity. 


\section{CHAPTER 3:}

\section{Diversity and composition of herbaceous angiosperms along gradients of elevation and forest use intensity.}

In chapter 3 diversity patterns, as well as floristic composition in six vegetation belts at different elevations and in different habitats, were studied. We analyzed the influence of elevation and forest use intensity on alpha, beta, and gamma diversity.

The following hypotheses were tested:

1. Herb species richness on the plots (a-diversity) increases from old-growth to degraded and decreases in secondary forest.

2. A continuous turnover in species composition from old-growth over degraded to secondary forest.

3. $\beta$-diversity is the most important component of $\gamma$-diversity due to the forest heterogeneity.

\section{CHAPTER 4:}

Deforestation and forest fragmentation in central Veracruz, Mexico since the 1990s.

In this chapter, the deforestation and fragmentation patterns of the study area during three different periods (1993, 2000 and 2014) were examined. We obtained the land-cover classification of the study area, quantified the net change in forest area and the loss of original (gross) forest, and finally quantified and compared the spatial arrangement of native forest fragments, using landscape indexes. Finally, we presented further conclusions for forest conservation strategy in the region.

The following hypotheses were tested:

- There is a continuous deforestation in the study area since 1993.

- The current forest patches in the study area are highly isolated and fragmented. 


\section{CHAPTER 2: Richness and distribution of herbaceous angiosperms along gradients of elevation and forest disturbance in central Veracruz, Mexico}

Jorge A. Gómez-Díaz, Thorsten Krömer, César I. CarvajalHernández, Gerhard Gerold, and Felix Heitkamp.

Accepted in Botanical Sciences.

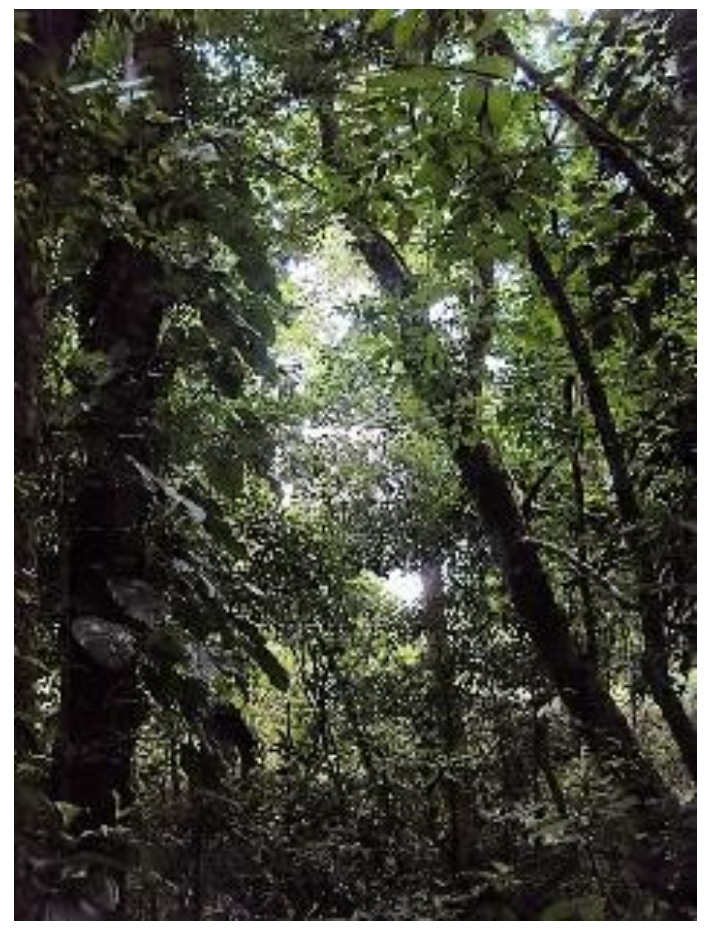

Humid montane old-growth forest in Los Capulines, Veracruz, Mexico at $1500 \mathrm{~m}$. 


\section{Richness and distribution of herbaceous angiosperms along gradients of elevation and forest disturbance in central Veracruz, Mexico}

\subsection{Abstract}

Background: Terrestrial herbs are a significant floristic element of tropical forests; however, there is a lack of research focused on this plant group.

Question: Which are the patterns of species distribution of herbaceous angiosperms along gradients of elevation and forest disturbance at Cofre de Perote, central Veracruz, Mexico?

Studied species: Terrestrial herbaceous angiosperms.

Study site and years of study: Eastern slopes of Cofre de Perote, central Veracruz, Mexico; from 2012 until 2014.

Methods: We established an elevational transect $(40$ to $3,520 \mathrm{~m}$ ), where we realized floristic sampling in eight study sites within elevational belts of about $500 \mathrm{~m}$ each. We recorded the occurrence of terrestrial angiosperm herbs within a total of 135 plots of $20 \mathrm{x}$ $20 \mathrm{~m}$, distributed in old-growth, degraded, secondary forest, as well as azonal vegetation. We analyzed species richness and floristic composition and then compared the resulting data between the different elevational belts and degrees of forest disturbance.

Results: We recorded a total of 264 herb species, 31 endemic to Mexico and three classified as threatened. The total number of species represents $5.7 \%$ of species of the Veracruz' herbaceous angiosperm flora. The elevational belts with highest species richness were 2,500 m (76) and 1,500 m (52). In most of the cases, secondary forests showed the highest species richness along the elevational gradient, whereas old-growth forests had fewer species.

Conclusions: The observed species richness, including endemic elements, highlights the importance for plant conservation of the area which is threatened by land use changes. 
In addition, we suggest that environmental heterogeneity formed by mature, disturbed and secondary forests is acceptable (and unavoidable) and can even increase species richness.

\subsection{Introduction}

Growing human pressure on terrestrial ecosystems represents one of the most important threats to biodiversity, especially in the tropics (Godfray et al. 2010, Melo et al. 2013, FAO 2014b). Therefore, the planet is suffering rapid and dramatic changes across the majority of biomes (Foley et al. 2005). Considering the current high rates of deforestation in most of the tropical countries (Lindenmayer et al. 2006), it is projected that areas with oldgrowth forests will become increasingly scarce and fragmented (Köster et al. 2009, FAO 2014b). Human population growth and the intensification of agricultural practice are the major factors that threaten old-growth forests and their associated biodiversity in the tropics (Wright 2005), due to their conversion into cropland, grassland for cattle and human settlements (Foley et al. 2005). Consequently, complete floristic inventories documenting which species are affected by human interference are urgently needed (DeClerck et al. 2010).

The Mesoamerican region including Mexico is considered as a hotspot of plant diversity, meaning that it is very rich in endemic species, but also highly threatened (Myers et al. 2000). The main reason is the loss of primary vegetation due to high deforestation and urbanization rates (Wright \& Muller-Landau 2006). Within Mexico, the state of Veracruz is considered a priority site for national and global conservation of biodiversity due to its outstanding geographical characteristics, such as the complex topography and the transition between tropical and temperate zones (Olguín 2011). Veracruz covers an area of $72,420 \mathrm{~km}^{2}$ of which less than $20 \%$ consists of natural vegetation, with a high degree of habitat fragmentation (Gómez-Pompa et al. 2010, CONABIO 2011). Nevertheless, Veracruz hosts a large number of angiosperms (6,876 species) that represents about $31 \%$ of the flora of Mexico (Villaseñor \& Ortíz 2012), and thus it is considered as the country's third richest state in angiosperms after Oaxaca and Chiapas (Rzedowski 1993, Villaseñor \& Ortíz 2014). The state is also known for having all vegetation types registered in Mexico 
(Gómez-Pompa \& Castillo-Campos, 2010), according to the classification of Rzedowski (2006). Despite being a region with high species richness, there are still many parts of the state which lack a reliable floristic inventory (Gómez-Pompa et al. 2010), especially in remote montane areas, such as our study area. Until now, no floristic investigation along this elevational gradient was conducted, taking into account terrestrial herbaceous angiosperms, human land use intensity and geoecological conditions.

In the last two decades studies about diversity patterns of tropical vegetation along elevational gradients have received substantial consideration (Vázquez \& Givnish 1998, Colwell et al. 2008, Willinghöfer et al. 2011), but the focus considering different taxonomical plant groups is unevenly distributed because most of the research is concentrated in the most species-rich herbaceous family (e.g., Poaceae, Asteraceae, Araceae) of every study area (Willinghöfer et al. 2011). However, many other herbaceous angiosperm families, such as Orchidaceae, Zingiberaceae, and Begoniaceae, are significant elements in the composition of tropical vegetation (Willinghöfer et al. 2011, Cicuzza et al. 2013). Moreover, terrestrial herbs play an important role in various ecological processes, such as tree regeneration and forest dynamics (Grubb 1977).

Nevertheless, terrestrial forest herbs have been little studied from a floristic and biogeographic point of view. As a result, there is little knowledge about how herbaceous angiosperm associations change along elevational gradients, and if they exhibit similar patterns like other plant groups (Willinghöfer et al. 2011). Only a few relevant studies were realized in pasture (Guevara \& Laborde 2007) and coffee plantations (Ramos et al. 1983) or focusing on single families, such as Poaceae (Hernández et al. 1990, Mejía-Saulés et al. 2002), Orchidaceae (Sosa \& Platas 1998, Salazar 1999) and Asteraceae (Villaseñor et al. 2006). Besides, the lack of specialists and taxonomic literature in different groups of these plants, as well as the seasonality of herb phenology, are important constraints for floristic studies because in lists some representatives of this biotype are omitted.

Further studies on the geographical distribution of the floristic elements of central Veracruz are necessary in order to better understand its complex mix of plant species (Villaseñor 2010). Inventories of specific groups of plants or particular geographic areas contribute to the completion of the national flora of Mexico and form the basis for the 
appropriate management of the natural resources (Martinez-Camilo et al. 2012). This kind of data can also provide information about the degree of endemism and endangered species in specific areas, which allows evaluating protected areas about the richness and uniqueness of their flora (Rzedowski 2006).

The objective of this study was to record the flora of herbaceous angiosperms in central Veracruz, Mexico, along gradients of elevation and human forest use intensity at the slopes of the Cofre de Perote mountain. The study was conducted to gather information about the floristic composition, elevational ranges and geographical distribution of the species, as well as to compare species richness and similarity between elevational belts and forest types. In this way, we provide more detailed information about patterns of species richness and distribution, which presents another step towards defining priority areas for conservation of this complex vegetation mosaic.

\subsection{Materials and methods}

\subsubsection{Study area}

The study was conducted at eight study sites along an elevational gradient of ca. $82 \mathrm{~km}$ between 40 and 3,520 m.a.s.l. on the eastern slopes of the Cofre de Perote, an extinct volcano of 4,282 m elevation in the central part of the state of Veracruz, Mexico (Fig. 2.1). This region is located at the junction of the Trans-Mexican volcanic belt and the Sierra Madre Oriental, a mountainous area between $19^{\circ} 25^{\prime} 5.7^{\prime \prime}$ and $19^{\circ} 36^{\prime} 54^{\prime \prime} \mathrm{N}$, and $96^{\circ} 22^{\prime}$ $36^{\prime \prime}$ and $97^{\circ}$ 09' 36.9" W. According to Lauer (1972), five climate zones can be found in the study area in combination with six forest types as classified by Miranda \& HernándezXolocotzi (1963) (Table 2.1). 




Figure 2.1 Location of the eight study sites along the elevational gradient at the Cofre de Perote, central Veracruz, Mexico. Study locations: 1. La Mancha (50 m); 2. Palmarejo (650 m); 3. Chavarrillo (1,000 m); 4. Los Capulines (1,600 m); 5. El Zapotal (2,100 m); 6. El Encinal (2,500 $\mathrm{m}) ;$ 7. Los Pescados $(3,100 \mathrm{~m}) ; 8$. El Conejo $(3,500 \mathrm{~m})$. The limits of the Neotropics according to Löwenberg-Neto (2014) are shown in light green. 
Table 2.1 Overview of the study sites along the elevational gradient at Cofre de Perote, central Veracruz, Mexico, with information on elevational range, forest type (TSDF= tropical semi-humid deciduous forest, TOF= tropical oak forest, $\mathrm{HMF}=$ humid montane forest, $\mathrm{POF}=$ pine-oak forest, $\mathrm{PF}=$ pine forest, and $\mathrm{FF}=$ fir forest), annual temperature annual precipitation and number of recorded species within the four habitats with different forest use intensities $(O G=$ old-growth, $D E=$ degraded, $\mathrm{SE}=$ secondary, $\mathrm{AZ}=$ azonal).

\begin{tabular}{|c|c|c|c|c|c|c|c|c|c|}
\hline Study site & $\begin{array}{l}\text { Elevational } \\
\text { range }(\mathrm{m})\end{array}$ & $\begin{array}{c}\text { Forest } \\
\text { type }\end{array}$ & $\begin{array}{l}\text { Number } \\
\text { of plots }\end{array}$ & $\begin{array}{l}\text { Temp. } \\
\left({ }^{\circ} \mathrm{C}\right)\end{array}$ & $\begin{array}{l}\text { Prec. } \\
(\mathrm{mm})\end{array}$ & OG & $\mathrm{DE}$ & SE & $\overline{A Z}$ \\
\hline La Mancha & $30-50$ & TSDF & 15 & 26 & 1,221 & 4 & 6 & 8 & - \\
\hline Palmarejo & $610-670$ & TSDF & 20 & 23 & 938 & 12 & 35 & 11 & 20 \\
\hline Chavarrillo & $900-1,010$ & TOF & 15 & 21 & 1,552 & 11 & 13 & 19 & - \\
\hline Los & $1,470-1,650$ & HMF & 20 & 18 & 1,598 & 24 & 21 & 20 & 31 \\
\hline \multicolumn{10}{|l|}{ Capulines } \\
\hline El Zapotal & $2,020-2,230$ & HMF & 15 & 14 & 3,004 & 16 & 18 & 20 & - \\
\hline El Encinal & $2,470-2,600$ & POF & 20 & 12 & 1,142 & 47 & 41 & 38 & 35 \\
\hline Los & $3,070-3,160$ & PF & 15 & 10 & 821 & 22 & 26 & 37 & - \\
\hline \multicolumn{10}{|l|}{ Pescados } \\
\hline El Conejo & $3,480-3,540$ & $\mathrm{FF}$ & 15 & 8 & 829 & 9 & 13 & 10 & - \\
\hline
\end{tabular}

Tierra caliente $(0-1,250 \mathrm{~m})$.- In this climate zone, we selected three study sites located in two forest types (Fig. 2.1, Table 2.1): the tropical semi-humid deciduous forest (TSDF) is found in the localities of La Mancha at $50 \mathrm{~m}$ and Palmarejo at $650 \mathrm{~m}$ (Castillo-Campos \& Travieso-Bello 2006) and characterized by the trees Brosimum alicastrum, Cedrela odorata, Bursera simaruba and Ficus obtusifolia. Canopy trees lose leaves mostly during the prolonged period of drought (October to May). The tropical oak forest (TOF) in the locality of Chavarrillo at $1,000 \mathrm{~m}$ is typically dominated by one to three oak species (Quercus oleoides, $Q$. laurina and/or $Q$. peduncularis), whereas other tree species are 
scarce. The period of leaf fall lasts about four months and it is related with the dry season (February to May).

Tierra templada (1,250-2,200 m).- In this climate zone, two study sites within one forest type were chosen (Fig. 2.1, Table 2.1): the humid montane forest (HMF), which is found in the localities of Los Capulines at 1,500 m and El Zapotal at 2,100 m. One of the most important ecological factors that characterize this kind of forest is the frequent occurrence of fog (bosque de niebla or cloud forests; Zamora-Crescencio \& Castillo-Campos 1997). In general, this community includes a mix of lower montane forest genera (e.g., Quercus and Liquidambar) with tropical lowland forest families (Acanthaceae, Rubiaceae, and Myrsinaceae). The period of leaf fall lasts about four months and is related to the dry season (February to May).

Tierra fría I (2,200-2,700 m). - In this climate zone, one study site within one forest type was chosen (Fig. 2.1, Table 2.1): the pine-oak forest (POF), which is found in the locality of El Encinal at 2,500 m. This forest type comprises a community whose dominant trees belong to the genera Quercus and Pinus. Typically, in the afternoons fog occurs (NaraveFlores 1985, Castillo-Campos 2011), which makes that the temperature and humidity stay constant.

Tierra fría II (2,700-3,200 m).- In this climate zone, one study site within one forest type was chosen (Fig. 2.1, Table 2.1): the pine forest (PF), which is found in the locality of Los Pescados at $3,100 \mathrm{~m}$. This forest type is dominated by several species of the genus Pinus ( $P$. montezumae, $P$. patula, $P$. pseudostrobus, $P$. teocote) causing a high canopy openness.

Tierra helada (3,200-4,282 m). - In this climate zone, one study site within one forest type was chosen (Fig. 2.1, Table 2.1): the fir forest (FF), which is found in the locality of $E I$ Conejo at $3,500 \mathrm{~m}$. This forest type is a monospecific Abies religiosa community with sparse canopy openness.

Along the complete elevational gradient, mean annual precipitation (MAP) ranges from 813 to $3,004 \mathrm{~mm}$, being highest in the humid montane forest at 2,100 $\mathrm{m}$ and lowest in coniferous forests above $3,000 \mathrm{~m}$, whereas mean average temperature (MAT) ranges 
from 9 to $26^{\circ} \mathrm{C}$ (SMN 2016) (Table 2.1). The elevational vertical temperature gradient follows a negative linear pattern with MAT decreasing by $0.55^{\circ} \mathrm{C}$ every $100 \mathrm{~m}\left(r^{2}=0.96, p\right.$ $<0.001)$.

\subsubsection{Sampling and botanical records}

Field sampling was conducted between February 2012 and January 2014 at eight sites within elevational belts of about $500 \mathrm{~m}$ each (Fig. 2.1, Table 2.1). In order to simplify hereafter we will refer to every site as categorical unit $(50,650,1,000,1,500,2,100,2,500$, $3,100,3,500 \mathrm{~m})$.

We studied terrestrial herbaceous angiosperms (excluding epiphytes), whose life form was defined as plants that have no persistent woody stem above ground or plants that are only slightly woody, rooted on the forest floor and have a short height (Moreno 1984, Poulsen 1996). Ferns were not included in this study because their diversity patterns were already described in the work of Carvajal-Hernández \& Krömer (2015). Presence-absence was recorded for all species in each elevational belt within 15 to 20 plots of $20 \times 20 \mathrm{~m}$. The plot size of $400 \mathrm{~m}^{2}$ was selected in order to have a representative study area of the forest fragments, which is small enough to keep abiotic factors and ecological physiognomy uniform within the plot (Kessler \& Bach 1999). The total number of plots for the entire study was 135 , resulting in a total study area of $54,000 \mathrm{~m}^{2}$. For our study, we defined four types of habitat with different forest use intensities following Newbold et al. (2015): old-growth, degraded, secondary and azonal forest (Table 2.2). 
Table 2.2 Classification of habitats with different forest use intensities according to the main physiognomic characteristic, the gap fraction in the canopy, dominance of canopy trees, percentage of shrubs and the presence of lianas (Newbold et al. 2015).

\begin{tabular}{|c|c|c|c|c|c|c|}
\hline Habitat & Characteristic & $\begin{array}{c}\text { Gaps } \\
(\%)\end{array}$ & $\begin{array}{c}\text { Forest use } \\
\text { intensity }\end{array}$ & $\begin{array}{c}\text { Canopy } \\
\text { trees }\end{array}$ & $\begin{array}{c}\text { Shrub } \\
(\%)\end{array}$ & Lianas \\
\hline Old-growth & $\begin{array}{l}\text { No obvious forest use, } \\
\text { dominance of mature } \\
\text { trees }\end{array}$ & $<10$ & Low & High & $<30$ & No \\
\hline Degraded & $\begin{array}{l}\text { Selective logging, grazing } \\
\text { and understory removal }\end{array}$ & $11-25$ & Medium & Low & $30-50$ & Low \\
\hline Secondary & regrown after clear-cut & $>25$ & High & Very low & $>50$ & High \\
\hline Azonal & $\begin{array}{l}\text { Grows in riparian forest } \\
\text { and humid ravines }\end{array}$ & $<10$ & Low & High & $<30$ & No \\
\hline
\end{tabular}

To avoid edge effects, our plots were established at least $50 \mathrm{~m}$ away from the nearest forest edge. An equal number of plots was studied for every forest type, i.e. five were established in each of the following habitats with different use intensities: i) old-growth, ii) degraded and iii) secondary forest. Only in the sites of $650 \mathrm{~m}, 1,500 \mathrm{~m}$ and 2,500 m we were able to add five plots in vi) existing azonal vegetation, causing the uneven numbers of plots per elevational belt (Table 2.1).

\subsubsection{Taxonomic determination}

In each study site (but not in every plot), all terrestrial herbaceous angiosperms species were collected mostly in triplicate and deposited at the following herbaria: Herbario Nacional de México, Instituto de Biología, UNAM, (MEXU, including all unicates), Instituto de Ecología, A.C., (XAL), Centro Interdisciplinario de Investigación para el Desarrollo Integral Regional, IPN (CIIDIR) and/or at the local herbarium of the Facultad de Biología, Universidad Veracruzana (XALU). Collection and processing of botanical specimens were made according to the proposal of Lot \& Chiang-Cabrera (1986). Botanical determinations 
were realized by use of the relevant taxonomic literature (Flora de Veracruz and Flora fanerogámica del Valle de México), by comparison with specimens deposited at MEXU and XAL, and consultation of experts in different plant families (see Acknowledgements). Also, morphospecies which are clearly different were incorporated in the floristic list (Krömer et al. 2013). It was not possible to identify all specimens to species or genus level for two main reasons: i) most of the studied plant groups are not well known and their identification is difficult due to a lack of relevant literature, ii) some individuals were found sterile. Taxa were classified according to the classification of the Angiosperm Phylogeny Group (APG) (Bremer et al. 2009).

\subsubsection{Data analyses}

We used the package "vegan 2.3-4" (Oksanen et al. 2016) in R software 3.2.3 (R Core Team 2014) to calculate the number of unobserved species with the Bootstrap function, which is based on presence-absence data and takes into account rare, unique and duplicated species. This species richness estimator is reliable because it has a sensibility to species aggregation in the initial stage of the sampling when the species distribution is random.

Based on their geographical distribution area, each species was placed in one of the following categories (sensu Rzedowski 1991): i) endemic to Mexico, ii) endemic to the southern United States and Mexico (Megamexico 1), iii) endemic to Mexico and Central America (Megamexico 2), iv) endemic to the southern United States and Central America (Megamexico 3), and v) introduced species (Gómez-Pompa et al. 2010, Espejo-Serna 2012).

Finally, to compare our results with other studies, we calculated the taxonomic diversity index (TDI) (Magurran 2004) for the total number of species and for the three most important families: Asteraceae, Poaceae, and Orchidaceae, with the following equation:

$$
T D I=\frac{\log S}{\log A}
$$

where $S$ is the total species number and $A$ is the entire studied area in $\mathrm{m}^{2}$. 


\subsection{Results}

In 135 plots along the elevational transect, we recorded 264 (morpho-) species of terrestrial herbaceous angiosperms from 152 genera and 54 families (Appendix). Of all recorded species, 201 (76\%) were identified to species level, 42 (16\%) to genus level and $21(8 \%)$ to family level. Monocots contributed $45 \%$ of the species and $28 \%$ of the families, and dicots $55 \%$ of the species and $72 \%$ of the families. Table 2.3 summarizes the most species-rich taxa at family and genus level. The observed species richness varied between 79 and $90 \%$ of the predicted values by the estimator Bootstrap at every elevational belt (Fig. 2.2).

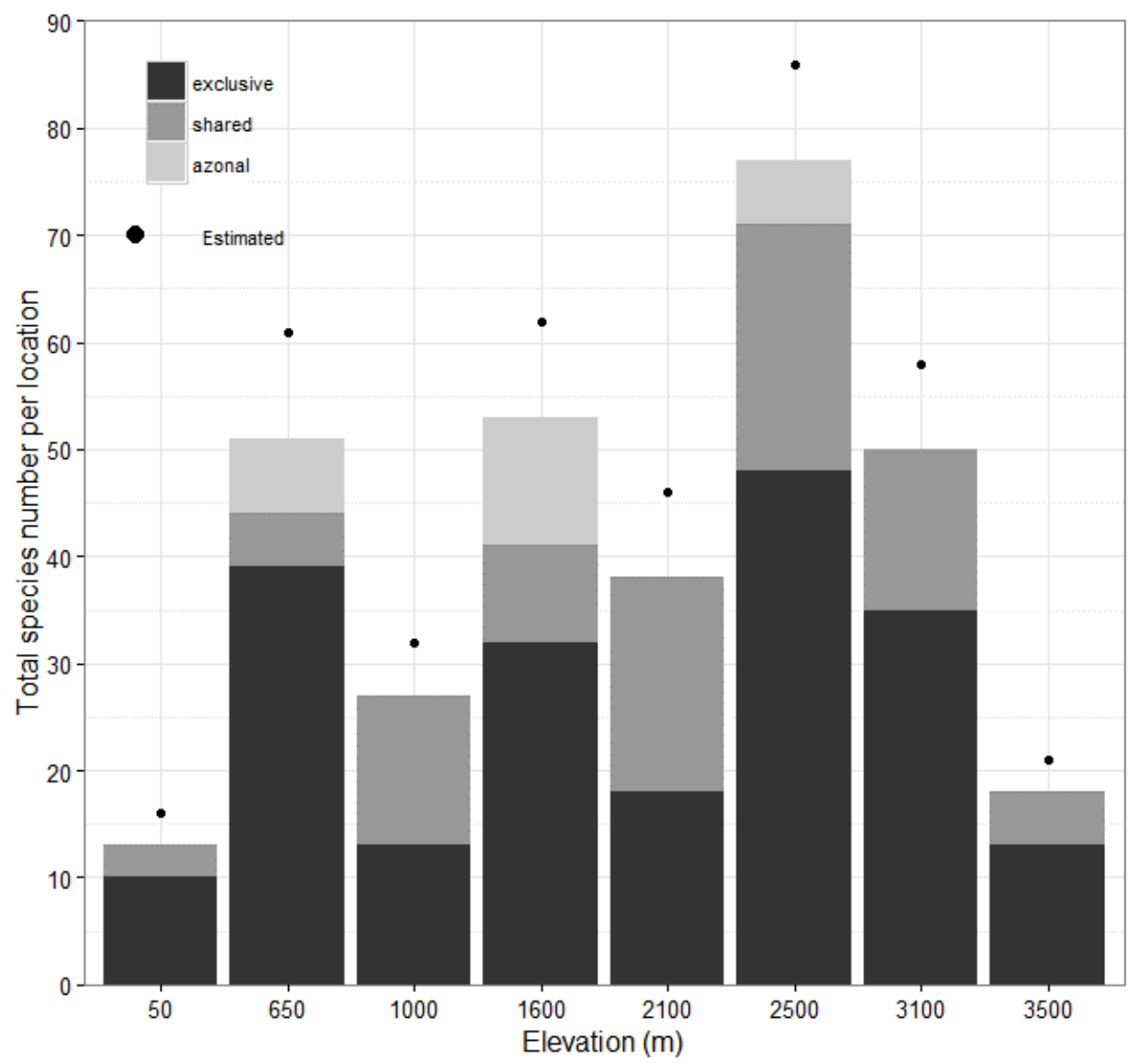

Figure 2.2 Observed and estimated (Bootstrap species richness estimator) species richness of all species together per elevational belt. It is shown the number of exclusive species at each study site, the number of species shared with other sites, and the species that are exclusive for azonal habitats. 
Table 2.3 Most representative families and genera of herbaceous angiosperms along the elevational gradient at the Cofre de Perote, central Veracruz, Mexico.

\begin{tabular}{lrrlrc}
\hline \multicolumn{1}{c}{ Family } & Species number & $\%$ & Genus & Species number & $\%$ \\
\hline Poaceae & 36 & $14 \%$ & Peperomia & 10 & $4 \%$ \\
Asteraceae & 31 & $12 \%$ & Salvia & 8 & $3 \%$ \\
Orchidaceae & 27 & $10 \%$ & Begonia & 6 & $2 \%$ \\
Cyperaceae & 17 & $6 \%$ & Senecio & 6 & $2 \%$ \\
Lamiaceae & 13 & $5 \%$ & Cyperus & 5 & $2 \%$ \\
Araceae & 12 & $4 \%$ & Anthurium & 5 & $2 \%$ \\
Piperaceae & 10 & $4 \%$ & Carex & 5 & $2 \%$ \\
Commelinaceae & 9 & $3 \%$ & Ageratina & 4 & $2 \%$ \\
Rubiaceae & 8 & $3 \%$ & Arenaria & 4 & $2 \%$ \\
Other families & 101 & $38 \%$ & Other genera & 211 & $80 \%$ \\
Total & 264 & $100 \%$ & Total & 264 & $100 \%$ \\
\hline
\end{tabular}

In order to compare overall species richness between the eight study sites, we used the values excluding and including species of azonal vegetation. In the first case, the highest number of species was found on the site of 2,500 (71), followed by 3,100 m (48) and 650


followed by $1,600 \mathrm{~m} \mathrm{(52)}$ and 3,100 m (48) (Fig. 2.2). All habitats of the 2,500 $\mathrm{m}$ site taken separately had the highest species richness of the elevational gradient (Table 2.1), whereas all habitats of $50 \mathrm{~m}$ had the lowest richness. The secondary forest in most of the sites had the highest number of species, whereas old-growth forests had the lowest number of species in most of the sites. In the sites with azonal vegetation, this habitat had more species than old-growth forests, and except for 2,500 m, even more than secondary forests (Table 2.1). TDI was 0.51 for all species and between 0.31 and 0.033 for the three most important families (Table 2.4). 
Table 2.4 Species richness of herbaceous angiosperms recorded in elevational gradient studies realized in Mexico and two different regions of the Neotropics, indicating its elevational range, latitude, area, TDI = taxonomic diversity index (calculated for the total species number and for the most important families Ast= Asteraceae, Poa= Poaceae and Orc= Orchidaceae).

\begin{tabular}{|c|c|c|c|c|c|c|c|c|c|c|c|c|}
\hline Region, Country & $\begin{array}{l}\text { Elevation } \\
\text { (m) }\end{array}$ & Latitude & $\begin{array}{l}\text { Species } \\
\text { number }\end{array}$ & $\begin{array}{l}\text { Area } \\
\text { (ha) }\end{array}$ & TDI & Ast & TDI & Poa & TDI & Orc & TDI & Authors \\
\hline Manaus, Brazil & $70-150$ & $2^{\circ} 37^{\prime} \mathrm{S}$ & 24 & 0.09 & 0.47 & 0 & - & 2 & 0.10 & 0 & - & Costa (2004) \\
\hline Cuyabeno, Ecuador & $250-300$ & $0^{\circ} 00^{\prime} \mathrm{S}$ & 70 & 1.00 & 0.46 & 0 & - & 8 & 0.23 & 0 & - & $\begin{array}{l}\text { Poulsen et al. } \\
(2006)\end{array}$ \\
\hline $\begin{array}{l}\text { Los Tuxtlas, Veracruz, } \\
\text { Mexico }\end{array}$ & $140-1,670$ & $18^{\circ} 43^{\prime} \mathrm{N}$ & 50 & 2.96 & 0.38 & 0 & - & 0 & - & 17 & 0.28 & Krömer et al. (2013) \\
\hline $\begin{array}{l}\text { Jalcomulco, Veracruz, } \\
\text { Mexico }\end{array}$ & $350-900$ & $19^{\circ} 21^{\prime} \mathrm{N}$ & 60 & 0.67 & 0.46 & 2 & 0.08 & 4 & 0.16 & 2 & 0.08 & $\begin{array}{l}\text { Palacios- } \\
\text { Wassenaar et al. } \\
(2014)\end{array}$ \\
\hline Veracruz, & $1,800-2,000$ & $19^{\circ} 29^{\prime} \mathrm{N}$ & 139 & 0.02 & 0.92 & 2 & 0.13 & 4 & 0.26 & 2 & 0.13 & $\begin{array}{l}\text { García-Franco et al. } \\
(2008)\end{array}$ \\
\hline $\begin{array}{l}\text { Sierra de Manantlán, } \\
\text { Jalisco, Mexico }\end{array}$ & $1,500-2,500$ & $19^{\circ} 30^{\prime} \mathrm{N}$ & 181 & 4.30 & 0.49 & ND & ND & ND & ND & ND & ND & $\begin{array}{l}\text { Vázquez \& Givnish } \\
\text { (1998) }\end{array}$ \\
\hline $\begin{array}{l}\text { Central } \\
\text { Mexico }\end{array}$ & $50-3,500$ & $19^{\circ} 31^{\prime} \mathrm{N}$ & 264 & 4.80 & 0.52 & 31 & 0.32 & 36 & 0.33 & 27 & 0.31 & This study \\
\hline Veracruz, & $400-900$ & $19^{\circ} 37^{\prime} \mathrm{N}$ & 300 & 1.20 & 0.61 & 42 & 0.40 & 53 & 0.42 & 2 & 0.07 & $\begin{array}{l}\text { Castillo-Campos } \\
\text { (2007) }\end{array}$ \\
\hline Pacific coast of Mexico & $400-2,860$ & $19^{\circ} 45^{\prime}$ & 1,793 & 140,000 & 0.36 & 333 & 0.28 & 221 & 0.26 & 181 & 0.25 & $\begin{array}{l}\text { Vázquez et al. } \\
\text { (1995) }\end{array}$ \\
\hline $\begin{array}{l}\text { Sierra de Zapalinamé, } \\
\text { Coahuila, Mexico }\end{array}$ & $1,590-3,140$ & $25^{\circ} 25^{\prime} \mathrm{N}$ & 171 & 3.30 & 0.49 & 61 & 0.40 & 27 & 0.32 & 0 & - & $\begin{array}{l}\text { Encina-Dominguez } \\
\text { et al. (2007) }\end{array}$ \\
\hline
\end{tabular}




\subsubsection{Geographical distribution}

Most of the study sites shared only low numbers of species (Fig. 2.2). The highest number of exclusive species was found at 2,500 m, followed by $650 \mathrm{~m}$ and 3,100 m. Concerning biogeography, $70 \%$ of the taxa showed a Neotropical affinity and we recorded 31 species endemic to Mexico, including two species (Begonia multistaminea and Sedum obcordatum) endemic to Veracruz (see Appendix). Furthermore, 20 species were endemic to Mexico and Central America and two to the South of United States of America and Mexico. Three species are listed in Official Mexican Law (SEMARNAT 2010), two of these are threatened and endemic to Mexico (Anthurium podophyllum and Peperomia subblanda), and another was under special protection (Monotropa hypopitys). Additionally, we found 14 introduced species to Mexico that were mostly recorded in secondary and degraded forests (Table 2.5 and Appendix).

Table 2.5 Geographic distribution and life strategy of species found along the elevational gradient at Cofre de Perote, central Veracruz, Mexico, in old-growth habitats and habitats derived from human forest use intensity. $\mathrm{OG}=$ old-growth forest, $\mathrm{DE}=$ degraded forest, $\mathrm{SE}=$ secondary forest, $A Z=$ azonal forest. Total numbers of species in each category are also shown.

\begin{tabular}{lrrrrr}
\hline \multicolumn{1}{c}{ Category } & OG & DE & SE & AZ & Total \\
\hline Under special protection & 1 & 2 & 2 & - & 3 \\
Endemic to Veracruz & 1 & - & - & - & 1 \\
Endemic to Mexico & 11 & 15 & 20 & 9 & 31 \\
South of United States of America and Mexico & 1 & 2 & 1 & - & 2 \\
Mexico and Central America & 9 & 12 & 11 & 9 & 20 \\
Introduced & 5 & 6 & 9 & 2 & 14 \\
Ruderal & 13 & 19 & 27 & 11 & 41 \\
Generalist & 65 & 92 & 73 & 56 & 152 \\
\hline
\end{tabular}




\subsection{Discussion}

\subsubsection{General taxa richness}

A comparison with previous studies on terrestrial angiosperms and other plant groups in the state of Veracruz shows that we recorded a high number of species in our study. Although our sampling area was limited ( $5.4 \mathrm{ha})$, the total number of species recorded was higher than those reported by Cházaro-Basáñez (1992) who focused on a floristic description of the different forest types within the upper part of the same elevational gradient. Cházaro-Basáñez reported only 12 herbs in the humid montane forest, 17 in the pine-oak forest, two in the pine forest and 14 in the fir forest. Carvajal-Hernández \& Krömer (2015) found 155 species of ferns and lycophytes in the same plots of our elevational gradient of which 82 were terrestrial species. Several studies from central Veracruz reported a lower number of terrestrial herbs, e.g., Palacios-Wasenaar et al. (2014) recorded 230 species of vascular plants of which 60 (26\%) were herbs (Table 2.5). García-Franco et al. (2008) found 258 vascular plant species in similar forests, of which 139 (54\%) were herbs. Novelo-Retana (1978) recorded 238 species of vascular plants of which 67 (28\%) were herbs. Zamora \& Castillo-Campos (1997) recorded 390 species of vascular plants of which 225 (58\%) were herbs. The relatively high number of herb species might be explained by the large environmental gradient covered in our study and will be discussed in the next paragraphs.

In contrast, a higher number of herbaceous species has been reported in some studies from central Veracruz, e.g., Castillo-Campos et al. (2007) recorded 580 species of vascular plants of which 369 (64\%) were herbs, and Narave-Flores (1985) recorded 853 species of vascular plants of which 557 (65\%) were herbs. For Southern Veracruz, Ibarra \& Sinaca (1987) recorded 991 species of vascular plants of which $536(54 \%)$ were herbs. However, all these studies were realized in much bigger sampling areas than the present study.

Due to the limited number of similar transect studies in the study area we were only able to compare our results with the following studies realized in Southern Veracruz by Krömer et al. (2013), which however included mainly terrestrial ferns and only a few orchids and bromeliads, Western Mexico (Jalisco) by Vázquez \& Givnish (1998) and Vázquez et al. 
(1995), and Northern Mexico (Coahuila) by Encina-Domínguez et al. (2007). Furthermore, we compared our results with the species numbers of terrestrial angiosperms found along two elevational gradients of Brazil and Ecuador (Table 2.4).

In most of the cases, our study site shows a higher number of species than the other locations. The TDI also shows that excluding the works from central Veracruz, our study has a higher species per area value than the other studies (Table 2.4). These differences among the geographical areas can be explained by environmental factors, such as latitudinal influence, precipitation, temperature, elevation and soil nutrients (Vázquez \& Givnish 1998, Cicuzza et al. 2013). The TDI indicates different patterns for the three most important families, e.g., there is an increase of the values of Asteraceae with elevation (Table 2.4), which is different from the family pattern shown in Mexico (Villaseñor et al. 2005). In the case of the Poaceae, the index shows that at lower latitudes this family is an important component of the flora, whereas in central Veracruz the family has similar values than the Asteraceae, and at the highest latitude there was a decrease in the value. In the case of the Orchidaceae, our study shows the highest value compared to the other locations, which demonstrates that the forest fragments in central Veracruz harbor a high number of orchids (Castañeda-Zárate et al. 2012).

On the other hand, species richness in our study was much lower compared to the numbers presented by Castillo-Campos et al. (2007), which is due to the fact that their work was realized in tropical deciduous forest which is recognized as vegetation type with high diversity of herbaceous angiosperms, as well as a more concentrated and exhaustive sampling effort in only one vegetation type. In general, the tropical deciduous forests occur in environments with high light incidence during the dry season (Chiarucci 1994). Besides, the limitations imposed by the bedrock, such as lack of organic matter in the soil, restrict the establishment of other plant groups (e.g., trees). Therefore, the herbaceous layer is facilitated by excluding competitors due to the physiological and functional traits that are characteristic of this plant group (Castillo-Campos et al. 2007). 


\subsubsection{Patterns of richness along the elevational gradient}

We found a not very pronounced hump-shaped pattern in the overall species distribution along the elevational gradient (Fig. 2.2), which is a pattern found in different groups of vascular plants along tropical elevational gradients, such as ferns (Salazar et al. 2015), terrestrial herbs (Willinghöfer et al. 2011) and shrubs (Chawla et al. 2008). Rahbek (1995) suggested that the distribution of plants in tropical areas is affected by the high variation of environmental factors that can change substantially in small regions, and this causes differences in the form of distributional patterns. We found that the sea level site was less species-rich compared with the other sites. The following sites (from 650 until 2,100 m) have an intermediate species richness (Fig. 2.2). This is probably due to heterogeneity in their landscape in comparison to other areas of the state, such as the coastal plain, caused by the heterogeneous structure of the physiographic discontinuity generated by the union of two regions: Coastal plain of the Gulf of Mexico and Trans-Mexican Volcanic Belt (Narave-Flores 1985, Torres-Cantú 2013).

The highest species richness was found at 2,500 m, which has been also reported from Ecuador for all endemic vascular plant species, endemic species of Acanthaceae, Asteraceae, Lamiaceae, Piperaceae and Scrophulariaceae (Kessler 2002), and for liverworts in the Northern Andes (Wolf 1993). This pattern is based on a contact of different species assemblages within the transition between two climate zones (Lauer 1973, Wolf 1993) and a high level of humidity due to cloud condensation (Rahbek 1995, Hemp 2005). The richness tends to decrease at higher elevations because productivity and temperature decrease with elevation (Currie et al. 2004, Hawkins et al. 2007); both factors affect the competition and growth of plants (Vázquez \& Givnish 1998). Furthermore, the kind of dominant tree species (Pinus spp. and Abies religiosa) at the highest sites $(3,000$ and $3,500 \mathrm{~m})$ has an influence on the herbaceous community because the coniferous litter changes the soil properties (Whittaker 1975, van Wesenbeeck et al. 2003). 


\subsubsection{Forest use intensity effect}

The degraded and secondary forests of the $50 \mathrm{~m}, 650 \mathrm{~m}, 2,100 \mathrm{~m}, 3,100 \mathrm{~m}$ and 3,500 m sites had higher species richness, compared to the old-growth forests. Furthermore, we found introduced and generalist species most frequently in secondary and degraded forest due to the changes in abiotic factors, such as a drier microclimate, change in soil nutrients and higher light incidence (Köster et al. 2009) that allow them to outcompete native species due to specific arrangements of traits (Schultz \& Dibble 2012) (Table 2.1, Appendix). Similarly, Firn et al. (2011) reported that some herbaceous angiosperms are related to human forest use intensity, which allows the establishment of ruderal species. These species increase the richness in anthropogenically influenced habitats, although native biodiversity is affected negatively by introduced plant species. This indicates that modifications in the structure of the old-growth forest affect the species composition of herbaceous angiosperms because changes in abiotic factors due to forest use intensity may increase the richness, especially of Poaceae and Orchidaceae in degraded habitats, whereas Asteraceae increase in secondary habitats. This is due to the ability of ruderal species to survive or even being favored in drier microclimates (Givnish 1995, Pons \& Poorter 2014) with more light in the understory due to the most open canopy of degraded forests (Grime 1977, Lavorel \& Grigulis 2011). Consequently, in North American forests, a higher richness of terrestrial herbs was found in the degraded forest with open canopy gaps compared to mature forests with closed canopies (Meekins \& McCarthy 2001).

However, the richness of species decreases in the degraded and secondary forests of the 1,600 and 2,500 m sites compared to the old-growth humid montane forest. This similar pattern was found for ferns (Carvajal-Hernández et al. 2014, Carvajal-Hernández \& Krömer 2015) and in general for vascular epiphytes (Krömer \& Gradstein 2003, Köster et al. 2009). This loss of species is due to the adaptation of many native species to temperate climate with high humidity (Parry et al. 2007). Furthermore, the changes in the structure of soil due to the forest use intensity leads to a loss of microbial organisms that favor the establishment of some species (Camenzind et al. 2014). On the other hand, it is widely documented that fragmentation has a negative effect on species richness in lowland forest, especially on understory plants (Magrach et al. 2014). For example, in the south of Veracruz, Zambrano et al. (2014) found that seeds of understory plants could be affected 
by altered microclimatic conditions in the fragmented landscape. These species seem to be adapted to moderate conditions of humidity and temperature which, respectively, decrease and increase with forest use intensity (Dale et al. 2001). Peperomia magnoliifolia serves as an example in the $650 \mathrm{~m}$ site, Begonia multistaminea and $P$. cobana in the $1,600 \mathrm{~m}$ site, where these are commonly found in habitats of high humidity and shadow (old-growth forest), but probably cannot tolerate high levels of radiation and low humidity and thus are rare in degraded and secondary forests (Ali 2013, Mathieu et al. 2015).

It was hypothesized that intermediate forest use intensity leads to higher species richness (Connell 1978, Warren et al. 2007) and plant community endemism (Kessler 2001). The mosaic vegetation pattern in our study area is an important shelter for the endemic flora of the region. Since the level of forest use intensity was similar in all sites, the different effects can only be attributed to feedbacks between the specific plant community and the changes in environmental factors, such as microclimate or soil nutrients.

In azonal vegetation (riparian forests), except for the 2,500 $\mathrm{m}$ site, the richness was higher than in old-growth forests, which might be due to stable moist environmental conditions and higher soil moisture. In the case of the $650 \mathrm{~m}$ site, the species richness recorded in azonal vegetation was almost twice of that observed in the old-growth tropical semideciduous forest. This interpretation is consistent with results found by Poulsen and Balslev (1991) in the Amazonian rain forest, who recorded the highest richness of herbs along rivers, which was explained by a mix of species from the border zone to the moist zone next to their study plot and the edaphic and topographic heterogeneity. In the case of terrestrial ferns, Carvajal-Hernández \& Krömer (2015) found the same pattern suggesting that fern richness is favored in areas with the influence of water and high humidity. These results confirm the value of the azonal vegetation as reservoirs of biodiversity.

\subsubsection{Introduced species}

Within the set of introduced species, there is a subgroup known as invasive alien or invasive species, which includes those that survive, are established and reproduce 
uncontrollably outside their natural environment, causing serious damage to biodiversity, economy, agriculture and public health (CONABIO 2016). We found several introduced species recognized as invasive, e.g. Commelina diffusa is a species that invades cultivated parcels and can endure wastelands inundating, meadows and roadsides areas which are problematical mainly in early yields, but can similarly cause a problem in established yields in Mexico due to its extensive behaviour (Boyette et al. 2015). Oeceoclades maculata is competing for the same microhabitat and may displace other native terrestrial orchids (Moreno-Molina et al. 2014). Hedychium coronarium has a negative influence on the recruitment of plants from the plant community, with consequences for the biodiversity of invaded areas (de Castro et al. 2016). Foeniculum vulgare is particularly aggressive in abandoned agricultural fields and grazed areas (Power et al. 2014). Rumex acetosella might interfere with secondary succession processes and gap colonization dynamics of native species, and it has the ability to competitively exclude native tussock grasses (Franzese \& Ghermandi 2014).

\subsubsection{Geographical distribution}

In general, the inventoried species show a phytogeographical affinity with southern latitudes, which can be seen by the high number of taxa also occurring in Central and South America. Nevertheless, many endemic taxa of central Mexico have also been encountered. In this context, Rzedowski (2006) suggests that for the flora of Tierra caliente (from sea level until ca. 1,400 m) the southern Neotropical affinity dominates over the boreal affinity. In addition, in Tierra templada, the most important elements have a southern origin with less boreal elements. In the cooler zones (Tierra fría and Tierra helada), the most important floristic elements are equally of southern and boreal affinity with some being endemic species from North America, such as Ageratina pazcuarensis and Festuca rosei, whereas others, such as Carex melanosperma, Corallorhiza maculata, and Muhlenbergia macroura are species endemic to Central America.

Our results show that species richness patterns of herbaceous angiosperms of forest vegetation in central Veracruz are determined by the large environmental gradient of the region. Moreover, degraded and secondary forests exhibit high species richness 
depending on the elevational belt, which is probably due to the ability of species in several families that compete better under high light conditions. The high richness and turnover of species, including many endemic elements, highlights the importance of this region for plant conservation; however, this area is also highly threatened by land use changes and shows very high deforestation rates (Ellis \& Martínez 2010).

Castillo-Campos et al. (2008) proposed to create a system of many protected reserves distributed throughout the state in order to protect this kind of landscape and its flora under the plan of "archipelago reserves" described by Halffter (2005), where all landscape units are connected by small protected areas. In addition, we suggest that an environmental heterogeneity formed by mature, disturbed and secondary forests is acceptable (and unavoidable) and can even increase species richness. This is an opportunity to develop a sustainable management concept to protect and promote species richness and to take into account the need of the local population for forest ecosystem services, such as timber, water, landslide protection, recreation and tourism. This could be an alternative to the current concept of a protected area, such as a national park, that is only focused on protecting alpha diversity without consideration of species turnover rates (CastilloCampos et al. 2008). Thus, it is necessary to create a conservation and management plan for the study area, which requires taking into account more taxonomic groups, the existing proportions of different habitat types, as well as studies on the socio-economic conditions across the elevational gradient.

\subsection{Acknowledgements}

We thank M. Ruiz-Gómez, F. Calixto-Benites, C. Alavez-Tadeo and V. Guzmán-Jacob for their help during fieldwork, A. Acebey (Araceae), J. Villaseñor-Rios (Asteraceae), G. Salazar-Chávez (Orchidaceae), D. Vergara-Rodriguez (Peperomia), J. Sánchez-Ken and M. Mejía-Saulés (Poaceae), M. Gonzalez-Elizondo (Cyperaceae) and M. CházaroBasáñez (other groups) for species identifications, and $\mathrm{H}$. Kreft for helpful comments on this manuscript. We appreciate the working facilities provided at the Centro de Investigaciones Tropicales (CITRO), Universidad Veracruzana, Xalapa. The first author acknowledges support from the Consejo Nacional de Ciencia y Tecnología (CONACyT 
311672) and the Deutscher Akademischer Austauschdienst (DAAD 91549681) for this research, which is part of his Ph.D. thesis. FH acknowledges a grant from the Deutsche Forschungsgemeinschaft (DFG; HE 6726/4-1). The research of TK was supported by CONACYT. The mobility of researchers was supported by the DAAD with resources of the Bundesministerium für Bildung und Forschung (BMBF, project-ID 57155237, "BIOVERA").

\subsection{Appendix. Species of herbaceous angiosperms recorded along the elevational gradient at the Cofre de Perote, central Veracruz, Mexico.}

Collector: Jorge Gómez Díaz (JGD); Herbaria: MEXU: Instituto de Biología, UNAM; XAL: Instituto de Ecología, A.C., XALU: Facultad de Biología, Universidad Veracruzana, and CIIDIR: Centro Interdisciplinario de Investigación para el Desarrollo Integral Regional, IPN. Data are presented for the minimum ( $\min$ ) and maximum (max) observed elevational distribution range, number of plots $(\mathrm{N})$ in which the species was recorded in a total of 135 plots, and conservation/distribution status: $\mathrm{T}=$ threatened, $\mathrm{P}=$ protected, $\mathrm{V}=$ endemic to Veracruz, $M x=$ endemic to Mexico, Mx1= Megamexico 1, Mx2= Megamexico 2, E=exotic and $\mathrm{R}=$ ruderal. Nomenclature follows Tropicos.org (http://www.tropicos.org, accessed on 24 Mar 2016).

\begin{tabular}{lrrrr}
\hline \multicolumn{1}{c}{ Subclass/Family/Species (voucher, herbarium) } & min & max & N Status \\
\hline LILIIDAE & & & & \\
Amaryllidaceae & & & & \\
Hypoxis sp. 1 (JGD 212, MEXU; XAL) & 1,500 & 1,500 & 1 & \\
Hypoxis sp. 2 (JGD 260, XALU) & 3,100 & 3,100 & 2 & \\
Araceae & & & & \\
Anthurium andicola Liebm. (JGD 329, MEXU) & 2,100 & 2,100 & 2 & Mx2 \\
Anthurium podophyllum (Schltdl. \& Cham.) Kunth (JGD 462, MEXU) & 50 & 50 & 2 & T, Mx \\
Anthurium scandens (Aubl.) Engl. (JGD 175, MEXU) & 1,500 & 1,500 & 3 & \\
Anthurium schlechtendalii Kunth (JGD 319, XAL) & 650 & 1,000 & 17 & \\
Anthurium sp. (JGD 369, XALU) & 1,000 & 1,000 & 1 & \\
Monstera acuminata K. Koch (JGD 444, MEXU) & 650 & 650 & 3 & \\
Monstera deliciosa Liebm. (JGD 170, MEXU) & 1,500 & 1,500 & 6 & \\
Philodendron radiatum Schott (JGD 315, MEXU; XAL) & 650 & 650 & 13
\end{tabular}




\begin{tabular}{|c|c|c|c|c|}
\hline Subclass/Family/Species (voucher, herbarium) & $\min$ & $\max$ & $\mathbf{N}$ & Status \\
\hline $\begin{array}{l}\text { Spathiphyllum cochlearispathum (Liebm.) Engl. (JGD 432, MEXU; } \\
\text { XAL; XALU) }\end{array}$ & 650 & 650 & 2 & Mx2 \\
\hline Syngonium macrophyllum Engl. (JGD 321, MEXU) & 50 & 50 & 1 & \\
\hline Syngonium podophyllum Schott (JGD 312, MEXU) & 50 & 650 & 16 & \\
\hline Syngonium sagittatum G.S. Bunting (JGD 174, MEXU; XAL) & 1,000 & 1,500 & 23 & $M x$ \\
\hline \multicolumn{5}{|l|}{ Arecaceae } \\
\hline Chamaedorea elegans Mart. (JGD 336, XALU) & 650 & 1,000 & 17 & $M \times 2$ \\
\hline Chamaedorea oblongata Mart. (JGD 452, XALU) & 650 & 650 & 1 & \\
\hline Chamaedorea tepejilote Liebm. (JGD 184, MEXU; XALU) & 1,000 & 2,100 & 30 & \\
\hline \multicolumn{5}{|l|}{$\begin{array}{l}\frac{\text { Asparagaceae }}{\text { Maianthemum paniculatum (M. Martens \& Galeotti) La Frankie (JGD }} \\
\text { 381, MEXU; XAL; XALU) }\end{array}$} \\
\hline Maianthemum sp. (JGD 451, XALU) & 2,500 & 2,500 & 5 & \\
\hline \multicolumn{5}{|l|}{ Bromeliaceae } \\
\hline Aechmea bracteata (Sw.) Griseb. (JGD 316, MEXU; XAL) & 650 & 650 & 3 & \\
\hline Bromelia cf. pinguin L. (JGD 314, MEXU) & 50 & 50 & 4 & \\
\hline Cf. Pitcairnia sp. 1 (JGD 268, MEXU) & 3,100 & 3,100 & 5 & \\
\hline Cf. Pitcairnia sp. 2 (JGD 276, MEXU) & 2,100 & 2,500 & 5 & \\
\hline Cf. Pitcairnia sp. 3 (JGD 328, MEXU) & 650 & 650 & 1 & \\
\hline Greigia van-hyningii L.B. Sm. (JGD 330, MEXU) & 2,100 & 3,100 & 22 & $\mathrm{Mx}$ \\
\hline \multicolumn{5}{|l|}{$\underline{\text { Commelinaceae }}$} \\
\hline Callisia fragrans (Lindl.) Woodson (JGD 387, XALU) & 650 & 650 & 3 & $\mathrm{Mx}$ \\
\hline Commelina diffusa Burm. f. (JGD 450, XALU) & 650 & 650 & 1 & $E, R$ \\
\hline Commelina erecta L. (JGD 454, XALU) & 650 & 650 & 1 & $\mathrm{R}$ \\
\hline Gibasis geniculata (Jacq.) Rohweder (JGD 196, MEXU; XAL; XALU) & 1,500 & 1,500 & 11 & \\
\hline Gibasis linearis (Benth.) Rohweder (JGD 320, XAL) & 50 & 50 & 1 & $\mathrm{Mx}$ \\
\hline Tradescantia zanonia (L.) Sw. (JGD 383, MEXU; XAL) & 2,100 & 2,100 & 5 & \\
\hline Tripogandra disgrega (Kunth) Woodson (JGD 243, MEXU; XAL) & 1,000 & 2,100 & 8 & $\mathrm{Mx} 2$ \\
\hline Tripogandra serrulata (Vahl) Handlos (JGD 302, XAL) & 2,100 & 2,100 & 12 & \\
\hline Tripogandra sp. (JGD 443, MEXU) & 650 & 650 & 1 & \\
\hline \multicolumn{5}{|l|}{ Cyclanthaceae } \\
\hline Asplundia sp. (JGD 318, MEXU) & 650 & 650 & 1 & \\
\hline \multicolumn{5}{|l|}{ Cyperaceae } \\
\hline Carex chordalis Liebm. (JGD 286A, CIIDIR) & 2,100 & 2,500 & 2 & \\
\hline Carex cortesii Liebm. (JGD 247, XAL; CIIDIR) & 1,500 & 2,500 & 11 & $\mathrm{Mx} 2$ \\
\hline Carex melanosperma Liebm. (JGD 162, MEXU; XAL; CIIDIR) & 2,500 & 2,500 & 3 & Mx2 \\
\hline Carex sect. longicaules (JGD 286B, CIIDIR) & 2,100 & 2,100 & 1 & \\
\hline Carex thurberi Dewey (JGD 323, XAL; CIIDIR) & 1,500 & 1,500 & 7 & \\
\hline Cyperus articulatus L. (JGD 241, MEXU; XAL; CIIDIR) & 50 & 50 & 1 & $\mathrm{R}$ \\
\hline Cyperus ligularis L. (JGD 286, XAL; CIIDIR) & 2,100 & 3,100 & 12 & \\
\hline Cyperus manimae Kunth (JGD 185, MEXU) & 3,100 & 3,100 & 2 & $\mathrm{R}$ \\
\hline Cyperus seslerioides Kunth (JGD 155, CIIDIR) & 2,500 & 2,500 & 1 & $\mathrm{R}$ \\
\hline Cyperus surinamensis Rottb. (JGD 201, MEXU; CIIDIR) & 1,500 & 1,500 & 1 & \\
\hline
\end{tabular}




\begin{tabular}{|c|c|c|c|c|}
\hline Subclass/Family/Species (voucher, herbarium) & $\min$ & $\max$ & $\mathbf{N}$ & Status \\
\hline Cyperus virens var. minarum (Boeckeler) Denton & 1,500 & 1,500 & 1 & $\mathrm{R}$ \\
\hline $\begin{array}{l}\text { Eleocharis geniculata (L.) Roem. \& Schult. (JGD 188, MEXU) } \\
\text { Eleocharis montana (Kunth) Roem. \& Schult. (JGD 322, XAL; } \\
\text { ClIDIR) }\end{array}$ & 650 & 650 & 1 & $E$ \\
\hline $\begin{array}{l}\text { Kyllinga pumila Michx. (JGD 166, MEXU; CIIDIR) } \\
\text { Rhynchospora radicans (Schltdl. \& Cham.) H. Pfeiff. subsp. radicans } \\
\text { (JGD } 169 \text { \& 460, MEXU; XAL; CIIDIR) }\end{array}$ & 1,500 & 1,500 & 17 & $\mathrm{R}$ \\
\hline Rhynchospora schiedeana Kunth (JGD 303, XAL; CIIDIR) & 2,100 & 2,100 & 3 & \\
\hline Scleria lithosperma (L.) Sw. (JGD 457, CIIDIR) & 650 & 650 & 3 & \\
\hline Uncinia hamata (Sw.) Urb. (JGD 458, XAL; CIIDIR) & 2,100 & 2,500 & 13 & \\
\hline$\underline{\text { Heliconiaceae }}$ & & & & \\
\hline Heliconia adflexa (Griggs) Standl. (JGD 186, MEXU) & 1,500 & 1,500 & 1 & Mx2 \\
\hline $\begin{array}{l}\text { Heliconia schiedeana Klotzsch (JGD 240, XALU) } \\
\text { Iridaceae }\end{array}$ & 1,000 & 1,500 & 6 & Mx2 \\
\hline $\begin{array}{l}\text { Sisyrinchium scabrum Cham. \& Schltdl. (JGD 326, MEXU) } \\
\text { Juncaceae }\end{array}$ & 2,500 & 2,500 & 1 & \\
\hline $\begin{array}{l}\text { Luzula sp. (JGD 190, MEXU) } \\
\text { Orchidaceae }\end{array}$ & 2,500 & 2,500 & 4 & \\
\hline $\begin{array}{l}\text { Beloglottis mexicana Garay \& Hamer (JGD 372, MEXU) } \\
\text { Calanthe calanthoides (A. Rich. \& Galeotti) Hamer \& Garay (JGD } \\
\text { 394, MEXU) }\end{array}$ & $\begin{array}{l}1,000 \\
2,500\end{array}$ & $\begin{array}{l}1,000 \\
2,500\end{array}$ & 1 & Mx2 \\
\hline Calanthe sp. (JGD 466, MEXU) & 2,100 & 2,100 & 1 & \\
\hline Corallorhiza maculata (Raf.) Raf. (JGD 295, MEXU) & 3,500 & 3,500 & 1 & \\
\hline Cyclopogon elatus (Sw.) Schltr. (JGD 406, MEXU) & 2,500 & 2,500 & 1 & \\
\hline Cyclopogon sp. 1 (JGD 337, MEXU) & 650 & 1,000 & 5 & \\
\hline $\begin{array}{l}\text { Cyclopogon sp. } 2 \text { (JGD 373, MEXU) } \\
\text { Cyrtopodium macrobulbon (La Llave \& Lex.) G.A. Romero-Gonzalez } \\
\text { \& Carnevali (JGD 374, MEXU) }\end{array}$ & $\begin{array}{l}650 \\
650\end{array}$ & $\begin{array}{l}650 \\
650\end{array}$ & 1 & Mx2 \\
\hline Epidendrum radicans Pav. ex Lindl. (JGD 244, MEXU) & 1,500 & 1,500 & 1 & \\
\hline Goodyera sp. 1 (JGD 391, MEXU) & 2,100 & 2,100 & 1 & \\
\hline Goodyera sp. 2 (JGD 428, MEXU; XAL) & 3,100 & 3,100 & 1 & \\
\hline Govenia superba (La Llave \& Lex.) Lindl. (JGD 442, MEXU) & 2,500 & 2,500 & 2 & \\
\hline Govenia sp. 1 (JGD 463, MEXU) & 2,100 & 2,100 & 1 & \\
\hline Govenia sp. 2 (JGD 282, MEXU) & 3,100 & 3,100 & 3 & \\
\hline Govenia sp. 3 (JGD 472, MEXU) & 650 & 650 & 1 & \\
\hline Habenaria floribunda Lindl. (JGD 471, MEXU) & 1,500 & 1,500 & 2 & Mx2 \\
\hline Habenaria novemfida Lindl. (JGD 377, MEXU) & 1,500 & 1,500 & 1 & Mx2 \\
\hline $\begin{array}{l}\text { Malaxis excavata (Lindl.) Kuntze (JGD } 390, \text { MEXU) } \\
\text { Malaxis histionantha (Link, Klotzsch \& Otto) Garay \& Dunst. (JGD }\end{array}$ & 2,100 & 2,100 & 1 & \\
\hline 371, MEXU; XAL) & 1,000 & 1,000 & 6 & \\
\hline Malaxis soulei L.O. Williams (JGD 427, MEXU) & 3,100 & 3,100 & 1 & \\
\hline Oeceoclades maculata (Lindl.) Lindl. (JGD 332, MEXU; XAL) & 50 & 1,000 & 7 & $E$ \\
\hline Pelexia funckiana (A. Rich. \& Galeotti) Schltr. (JGD 198, MEXU) & 1,500 & 1,500 & 10 & \\
\hline Prescottia stachyodes (Sw.) Lindl. (JGD 221, MEXU) & 1,500 & 1,500 & 5 & \\
\hline
\end{tabular}




\begin{tabular}{|c|c|c|c|c|}
\hline Subclass/Family/Species (voucher, herbarium) & $\min$ & $\max$ & $\mathbf{N}$ & Status \\
\hline Psilochilus macrophyllus (Lindl.) Ames (JGD 200, MEXU) & 1,500 & 1,500 & 1 & \\
\hline Schiedeella sp. (JGD 464, MEXU) & 2,100 & 2,100 & 2 & \\
\hline Spiranthinae (JGD 465, MEXU) & 2,100 & 2,100 & 2 & \\
\hline Vanilla insignis Ames (JGD 429, MEXU) & 650 & 1,000 & 2 & $M \times 2$ \\
\hline \multicolumn{5}{|l|}{ Poaceae } \\
\hline Aegopogon cenchroides Humb. \& Bonpl. ex Willd. (JGD 199, XAL) & 1,500 & 2,500 & 3 & \\
\hline Agrostis tolucensis Kunth (JGD 296, XAL) & 3,500 & 3,500 & 1 & \\
\hline Andropogon sp. (JGD 310, XAL) & 50 & 50 & 1 & \\
\hline Aristida sp. (JGD 311, XAL) & 50 & 50 & 1 & \\
\hline Bouteloua gracilis (Kunth) Lag. ex Griffiths (JGD 301, XAL) & 2,100 & 2,500 & 6 & \\
\hline Brachypodium mexicanum (Roem. \& Schult.) Link (JGD 258, XAL) & 3,100 & 3,100 & 1 & \\
\hline Brachypodium sp. (JGD 298, XAL) & 2,100 & 2,500 & 8 & \\
\hline Briza minor L. (JGD 299, XAL) & 2,500 & 2,500 & 1 & $\mathrm{E}$ \\
\hline Bromus exaltatus Bernh. (JGD 300, XAL) & 2,500 & 2,500 & 3 & \\
\hline Chusquea glauca L.G. Clark (JGD 362, MEXU) & 2,100 & 2,100 & 6 & Mx \\
\hline Chusquea sp. (JGD 468, MEXU) & 2,500 & 2,500 & 2 & \\
\hline Dichanthelium dichotomum (L.) Gould (JGD 160, MEXU) & 1,500 & 1,500 & 14 & \\
\hline Eragrostis sp. (JGD 306, XAL) & 1,000 & 1,000 & 1 & \\
\hline Festuca amplissima Rupr. (JGD 279, XAL) & 3,100 & 3,100 & 1 & \\
\hline Festuca rosei Piper (JGD 269, XAL) & 3,100 & 3,100 & 11 & Mx1 \\
\hline Festuca sp. (JGD 305, XAL) & 1,000 & 1,500 & 3 & \\
\hline Guadua sp. (JGD 307, XAL) & 650 & 650 & 2 & \\
\hline Hordeum sp. (JGD 234, MEXU; XAL) & 1,000 & 1,500 & 1 & \\
\hline Lasiacis sp. 1 (JGD 441, XAL) & 650 & 650 & 1 & \\
\hline Lasiacis sp. 2 (JGD 161, MEXU) & 1,500 & 1,500 & 6 & \\
\hline Lasiacis sp. 3 (JGD 168, MEXU) & 1,500 & 1,500 & 2 & \\
\hline Melinis sp. (JGD 308, XAL) & 650 & 650 & 2 & \\
\hline Muhlenbergia macroura (Kunth) Hitchc. (JGD 297, XAL) & 3,500 & 3,500 & 10 & $\mathrm{R}, \mathrm{M} \times 2$ \\
\hline Muhlenbergia sp. (JGD 309, XAL) & 650 & 650 & 2 & \\
\hline Oplismenus sp. (JGD 439, XAL) & 650 & 650 & 1 & \\
\hline $\begin{array}{l}\text { Oryza latifolia Desv. (JGD 440, XAL) } \\
\text { Otatea acuminata (Munro) C.E. Calderón \& Soderstr. (JGD 470, } \\
\text { MEXU) }\end{array}$ & $\begin{array}{l}650 \\
650\end{array}$ & $\begin{array}{l}650 \\
650\end{array}$ & 1 & \\
\hline Panicum sp. (JGD 469, MEXU) & 650 & 650 & 1 & \\
\hline Paspalum sp. (JGD 362, XALU) & 650 & 650 & 1 & \\
\hline Pennisetum sp. (JGD 324, XAL) & 650 & 650 & 1 & \\
\hline Phyllostachys aurea Riviere \& C. Riviere. (JGD 214, XAL) & 1,500 & 1,500 & 2 & \\
\hline Schizachyrium condensatum (Kunth) Nees (JGD 304, XAL) & 650 & 1,000 & 17 & \\
\hline Stipa ichu (Ruiz \& Pav.) Kunth (JGD 467, MEXU) & 3,500 & 3,500 & 10 & $\mathrm{R}$ \\
\hline Trisetum spicatum (L.) K. Richt. (JGD 254, XAL) & 3,100 & 3,100 & 14 & \\
\hline Zeugites americanus Willd. (JGD 178, MEXU; XAL) & 1,500 & 1,500 & 2 & \\
\hline Cf. Zeugites sp. (JGD 286C, XAL) & 2,100 & 2,100 & 1 & \\
\hline
\end{tabular}




\begin{tabular}{|c|c|c|c|c|}
\hline Subclass/Family/Species (voucher, herbarium) & $\min$ & $\max$ & $\mathbf{N}$ & Status \\
\hline \multicolumn{5}{|l|}{ Zingiberaceae } \\
\hline Hedychium coronarium J. Koenig (JGD 331, XALU) & 50 & 50 & 2 & $E, R$ \\
\hline \multicolumn{5}{|l|}{ Magnoliidae } \\
\hline \multicolumn{5}{|l|}{ Acanthaceae } \\
\hline Aphelandra scabra (Vahl) Sm. (JGD 449, XALU) & 650 & 650 & 2 & $\mathrm{R}$ \\
\hline Pseuderanthemum alatum (Nees) Radlk. (JGD 453, XALU) & 650 & 650 & 4 & \\
\hline Ruellia sp. (JGD 368, MEXU; XAL; XALU) & 1,000 & 1,000 & 5 & \\
\hline Cf. Ruellia sp. (JGD 405, XALU) & 650 & 650 & 1 & \\
\hline \multicolumn{5}{|l|}{ Amaranthaceae } \\
\hline Iresine diffusa Humb. \& Bonpl. ex Willd. (JGD 233, MEXU; XALU) & 1,500 & 1,500 & 4 & $\mathrm{R}$ \\
\hline Iresine sp. (JGD 433, MEXU; XAL) & 2,500 & 3,100 & 3 & \\
\hline \multicolumn{5}{|l|}{ Apiaceae } \\
\hline Eryngium columnare Hemsl. (JGD 228, XALU) & 2,500 & 2,500 & 1 & Mx \\
\hline Eryngium proteiflorum $\mathrm{F}$. Delaroche (JGD 267, XALU) & 3,100 & 3,500 & 5 & $M x$ \\
\hline Foeniculum vulgare Mill. (JGD 287, MEXU; XALU) & 3,100 & 3,100 & 2 & $E, R$ \\
\hline Sanicula liberta Cham. \& Schltdl. (JGD 211, MEXU; XAL; XALU) & 1,500 & 1,500 & 5 & \\
\hline \multicolumn{5}{|l|}{ Araliaceae } \\
\hline Hydrocotyle mexicana Schltdl. \& Cham. (JGD 422, XALU) & 2,500 & 2,500 & 4 & \\
\hline Hydrocotyle umbellata L. (JGD 213, XALU) & 1,500 & 1,500 & 3 & \\
\hline \multicolumn{5}{|l|}{ Asteraceae } \\
\hline Achillea millefolium L. (JGD 289, XALU) & 2,500 & 3,100 & 4 & $E, R$ \\
\hline $\begin{array}{l}\text { Ageratina chazaroana B.L. Turner (JGD 401, MEXU) } \\
\text { Ageratina pazcuarensis (Kunth) R.M. King \& H. Rob. (JGD 255, }\end{array}$ & 2,500 & 2,500 & 2 & Mx \\
\hline $\begin{array}{l}\text { MEXU) } \\
\text { Aaeratina pichinchensis (Kunth) RM King \& H Rob (JGD } 403\end{array}$ & 2,500 & 2,500 & 1 & $M \times 1$ \\
\hline 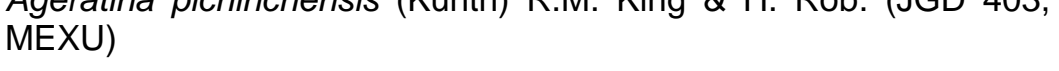 & 2,500 & 2,500 & 2 & \\
\hline Ageratina sp. (JGD 434, XALU) & 2,500 & 2,500 & 1 & \\
\hline Artemisia ludoviciana Nutt. (JGD 274, XALU) & 3,100 & 3,100 & 1 & $\mathrm{R}$ \\
\hline Bidens sp. (JGD 163, MEXU) & 2,500 & 2,500 & 1 & \\
\hline Cirsium conspicuum (G. Don) Sch. Bip. (JGD 351, MEXU; XALU) & 2,500 & 2,500 & 1 & Mx \\
\hline Cirsium ehrenbergii Sch. Bip. (JGD 352, MEXU) & 3,100 & 3,100 & 11 & Mx \\
\hline Cirsium nivale (Kunth) Sch. Bip. (JGD 253, XALU) & 3,500 & 3,500 & 3 & Mx \\
\hline Conyza canadensis (L.) Cronquist (JGD 435; XALU) & 650 & 650 & 5 & $\mathrm{R}$ \\
\hline Conyza coronopifolia Kunth (JGD 227, XALU) & 1,500 & 2,500 & 6 & $\mathrm{R}$ \\
\hline $\begin{array}{l}\text { Elephantopus mollis Kunth (JGD 205, MEXU; XALU) } \\
\text { Hymenoxys integrifolia (Kunth) Bierner (JGD 273, } 293 \text { \& 361, MEXU; }\end{array}$ & 1,500 & 1,500 & 5 & \\
\hline XALU) & 2,500 & 3,500 & 14 & \\
\hline $\begin{array}{l}\text { Laennecia gnaphalioides (Kunth) Cass. (JGD 355, XALU) } \\
\text { Pseudognaphalium liebmannii (Sch. Bip. ex Klatt) Anderb. (JGD 270, }\end{array}$ & 2,500 & 2,500 & 4 & \\
\hline XALU) & 3,100 & 3,100 & 8 & \\
\hline $\begin{array}{l}\text { Roldana angulifolia (DC.) H. Rob. \& Brettell. (JGD 396, XALU) } \\
\text { Roldana aschenborniana (S. Schauer) H. Rob. \& Brettell (JGD } 208,\end{array}$ & 2,500 & 2,500 & 4 & Mx \\
\hline MEXU; XALU) & 1,500 & 1,500 & 4 & \\
\hline Sabazia humilis (Kunth) Cass. (JGD 395, XALU) & 2,500 & 2,500 & 4 & $M x, R$ \\
\hline
\end{tabular}




\begin{tabular}{|c|c|c|c|c|}
\hline Subclass/Family/Species (voucher, herbarium) & $\min$ & $\max$ & $\mathbf{N}$ & Status \\
\hline Sabazia sarmentosa Less. (JGD 285, XALU) & 3,100 & 3,100 & 1 & \\
\hline Senecio callosus Sch. Bip. (JGD 283 \& 359, MEXU; XAL; XALU) & 2,500 & 3,500 & 16 & \\
\hline Senecio cinerarioides Kunth (JGD 436, MEXU; XALU) & 3,500 & 3,500 & 2 & $\mathrm{Mx}$ \\
\hline Senecio deppeanus Hemsl. (JGD 206, MEXU; XALU) & 1,500 & 1,500 & 1 & \\
\hline Senecio roseus Sch. Bip. (JGD 330A, MEXU) & 3,500 & 3,500 & 1 & $M x$ \\
\hline Senecio sp. (JGD 411, XALU) & 2,500 & 2,500 & 1 & \\
\hline Sigesbeckia jorullensis Kunth (JGD 398, XALU) & 2,500 & 3,100 & 6 & $\mathrm{R}$ \\
\hline $\begin{array}{l}\text { Trixis inula Crantz (JGD 446, XALU) } \\
\text { Verbesina robinsonii (Klatt) Fernald ex B.L. Rob. \& Greenm. (JGD }\end{array}$ & 650 & 650 & 3 & \\
\hline 445, MEXU; XALU) & 3,100 & 3,100 & 2 & $\mathrm{Mx}$ \\
\hline Cf. Verbesina sp. 1 (JGD 171, MEXU) & 1,500 & 1,500 & 1 & \\
\hline Cf. Verbesina sp. 2 (JGD 173, MEXU; XALU) & 2,100 & 2,100 & 1 & \\
\hline \multicolumn{5}{|l|}{ Begoniaceae } \\
\hline Begonia fusca Liebm. (JGD 181, MEXU) & 2,100 & 2,100 & 1 & \\
\hline Begonia heracleifolia Schltdl. \& Cham. (JGD 325, MEXU) & 650 & 650 & 1 & \\
\hline Begonia manicata Brongn. ex F. Cels (JGD 376, XALU) & 1,000 & 1,000 & 1 & \\
\hline $\begin{array}{l}\text { Begonia multistaminea Burt-Utley (JGD 187, MEXU) } \\
\text { Begonia nelumbonifolia Schltdl. \& Cham. (JGD 386, MEXU; XAL; }\end{array}$ & 1,500 & 1,500 & 1 & $\mathrm{~V}$ \\
\hline & 2,100 & 2,100 & 2 & \\
\hline Begonia oaxacana A. DC. (JGD 191, MEXU; XALU) & 1,500 & 2,500 & 6 & \\
\hline $\begin{array}{l}\text { Boraginaceae } \\
\text { Hackelia mexicana (Schltdl. \& Cham.) I.M. Johnst. (JGD } 288 \text { MEXU; } \\
\text { XAL; XALU) }\end{array}$ & 3,100 & 3,100 & 1 & \\
\hline Macromeria sp. (JGD 400, XALU) & 2,500 & 2,500 & 2 & \\
\hline Phacelia platycarpa (Cav.) Spreng. (JGD 294, XALU) & 3,100 & 3,100 & 4 & $\mathrm{R}$ \\
\hline Morpho unidentified 1 (JGD 456, MEXU; XAL; XALU) & 3,100 & 3,100 & 2 & \\
\hline Morpho unidentified 2 (JGD 262, XALU) & 2,500 & 2,500 & 1 & \\
\hline \multicolumn{5}{|l|}{ Brassicaceae } \\
\hline Pennellia longifolia (Benth.) Rollins (JGD 409, XALU) & 2,500 & 2,500 & 3 & \\
\hline \multicolumn{5}{|l|}{ Campanulaceae } \\
\hline Centropogon grandidentatus (Schltdl.) Zahlbr. (JGD 249, XALU) & 2,500 & 2,500 & 10 & \\
\hline Morpho unidentified (JGD 278, MEXU) & 3,100 & 3,100 & 2 & \\
\hline \multicolumn{5}{|l|}{ Capparaceae } \\
\hline Morpho unidentified (JGD 437, MEXU) & 3,100 & 3,100 & 3 & \\
\hline \multicolumn{5}{|l|}{ Caryophyllaceae } \\
\hline Arenaria lanuginosa (Michx.) Rohrb. (JGD 420, XALU) & 1,000 & 1,000 & 1 & $\mathrm{R}$ \\
\hline Arenaria lycopodioides Willd. ex D.F.K. Schltdl. (JGD 257, XALU) & 3,100 & 3,100 & 8 & $\mathrm{R}$ \\
\hline Arenaria oresbia Greenm. (JGD 417, XALU) & 2,500 & 3,100 & 2 & Mx \\
\hline Arenaria reptans Hemsl. (JGD 423, XALU) & 2,500 & 2,500 & 14 & $\mathrm{R}$ \\
\hline Cerastium arvense L. subsp. molle (Vill.) Arcang. (JGD 265, XALU) & 3,100 & 3,100 & 1 & $E, R$ \\
\hline Drymaria cordata (L.) Willd. ex Schult. (JGD 384, XAL) & 2,100 & 2,500 & 3 & $\mathrm{R}$ \\
\hline Morpho unidentified (JGD 424, XALU) & 3,100 & 3,100 & 2 & \\
\hline
\end{tabular}




\begin{tabular}{|c|c|c|c|c|}
\hline Subclass/Family/Species (voucher, herbarium) & $\min$ & $\max$ & $\mathbf{N}$ & Status \\
\hline Echeveria mucronata Schltdl. (JGD 272, XALU) & 3,100 & 3,100 & 5 & Mx \\
\hline Echeveria rosea Lindl. (JGD 407, XALU) & 2,500 & 2,500 & 2 & Mx \\
\hline Sedum obcordatum R.T. Clausen (JGD 291, XALU) & 3,100 & 3,100 & 1 & $\mathrm{~V}$ \\
\hline $\begin{array}{l}\text { Cytinaceae } \\
\text { Bdallophyton americanum (R. Br.) Eichler ex Solms. (JGD 358, } \\
\text { XALU) }\end{array}$ & 50 & 50 & 1 & \\
\hline $\begin{array}{l}\text { Ericaceae } \\
\text { Chimaphila umbellata (L.) W.P.C. Barton (JGD 290, MEXU; XAL; } \\
\text { XALU) }\end{array}$ & 3,100 & 3,100 & 4 & \\
\hline Monotropa hypopitys L. (JGD 410, XALU) & 3,500 & 3,500 & 1 & $\mathrm{P}$ \\
\hline Monotropa uniflora L. (JGD 421, MEXU; XAL, XALU) & 2,500 & 2,500 & 3 & \\
\hline Pernettya ciliata (Schltdl. \& Cham.) Small (JGD 431, XALU) & 3,500 & 3,500 & 2 & \\
\hline \multicolumn{5}{|l|}{ Euphorbiaceae } \\
\hline Acalypha arvensis Poepp. (JGD 366, XALU) & 650 & 650 & 1 & $\mathrm{R}$ \\
\hline Euphorbia cyathophora Murray (JGD 447, XALU) & 1,000 & 1,000 & 1 & $\mathrm{R}$ \\
\hline Euphorbia dentata Michx. (JGD 207, MEXU; XAL; XALU) & 1,500 & 1,500 & 3 & $\mathrm{R}$ \\
\hline \multicolumn{5}{|l|}{ Fabaceae } \\
\hline Lupinus mexicanus Cerv. ex Lag. (JGD 399, XALU) & 3,500 & 3,500 & 7 & Mx \\
\hline Lupinus montanus Kunth (JGD 354, XALU) & 3,500 & 3,500 & 1 & Mx2 \\
\hline Trifolium repens L. (JGD 292, XALU) & 2,500 & 3,100 & 17 & $E, R$ \\
\hline \multicolumn{5}{|l|}{ Gentianaceae } \\
\hline 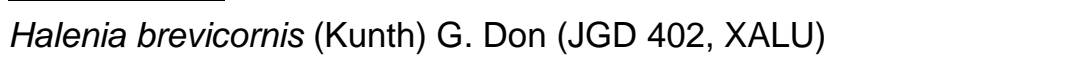 & 2,500 & 2,500 & 2 & \\
\hline \multicolumn{5}{|l|}{ Geraniaceae } \\
\hline Geranium seemannii Peyr. (JGD 263, XALU) & 3,100 & 3,100 & 2 & $\mathrm{R}$ \\
\hline \multicolumn{5}{|l|}{ Gesneriaceae } \\
\hline Achimenes erecta (Lam.) H.P. Fuchs (JGD 339, XALU) & 650 & 650 & 1 & \\
\hline \multicolumn{5}{|l|}{ Gunneraceae } \\
\hline Morpho unidentified (JGD 397, XALU) & 2,500 & 2,500 & 2 & \\
\hline \multicolumn{5}{|l|}{ Lamiaceae } \\
\hline Asterohyptis stellulata (Benth.) Epling (JGD 338, XALU) & 650 & 650 & 1 & $\mathrm{Mx}$ \\
\hline Marrubium vulgare L. (JGD 176, MEXU) & 2,500 & 2,500 & 4 & $E, R$ \\
\hline Prunella vulgaris L. (JGD 426, XALU) & 2,500 & 2,500 & 1 & $E, R$ \\
\hline Salvia carnea Kunth. (JGD 280, XALU) & 3,100 & 3,100 & 9 & $\mathrm{R}$ \\
\hline Salvia coccinea Buc'hoz ex Etl. (JGD 412, XALU) & 2,500 & 2,500 & 3 & \\
\hline Salvia hispanica L. (JGD 364, MEXU; XAL; XALU) & 1,000 & 1,000 & 2 & \\
\hline Salvia iodantha Fernald (JGD 413, XALU) & 2,500 & 2,500 & 6 & Mx \\
\hline Salvia mexicana L. (JGD 375, XALU) & 1,000 & 1,000 & 4 & $M x, R$ \\
\hline Salvia microphylla Kunth (JGD 225, XALU) & 1,500 & 1,500 & 1 & \\
\hline Salvia polystachia Cav. (JGD 414, XALU) & 2,500 & 2,500 & 2 & \\
\hline Salvia tiliifolia Vahl (JGD 385, MEXU; XAL; XALU) & 2,100 & 2,100 & 1 & $\mathrm{R}$ \\
\hline Scutellaria racemosa Pers. (JGD 367, XALU) & 1,000 & 1,000 & 7 & \\
\hline Morpho unidentified (JGD 183, MEXU) & 1,500 & 1,500 & 1 & \\
\hline
\end{tabular}




\begin{tabular}{|c|c|c|c|c|}
\hline Subclass/Family/Species (voucher, herbarium) & $\min$ & $\max$ & $\mathbf{N}$ & Status \\
\hline Linum sp. (JGD 197, MEXU). & 1,500 & 1,500 & 1 & \\
\hline \multicolumn{5}{|l|}{ Lythraceae } \\
\hline Cuphea aequipetala Cav. (JGD 416, XALU) & 2,500 & 2,500 & 1 & $\mathrm{R}$ \\
\hline \multirow{2}{*}{$\begin{array}{l}\text { Cuphea calaminthifolia Schltdl. (JGD 425, MEXU; XAL; XALU) } \\
\text { Cuphea salicifolia Schltdl. \& Cham. (JGD 455, XALU) }\end{array}$} & 2,500 & 2,500 & 1 & Mx \\
\hline & 650 & 650 & 4 & Mx \\
\hline Morpho unidentified (JGD 218, XALU) & 1,500 & 1,500 & 1 & \\
\hline \multicolumn{5}{|l|}{ Malvaceae } \\
\hline Morpho unidentified (JGD 229, MEXU) & 1,500 & 1,500 & 1 & \\
\hline \multicolumn{5}{|l|}{ Moraceae } \\
\hline Dorstenia contrajerva L. (JGD 340, XALU) & 650 & 1,000 & 11 & \\
\hline \multicolumn{5}{|l|}{ Orobanchaceae } \\
\hline Castilleja tenuiflora Benth. (JGD 177, MEXU) & 3,100 & 3,100 & 1 & $\mathrm{R}$ \\
\hline Conopholis alpina Liebm. (JGD 408, XALU) & 2,500 & 2,500 & 3 & \\
\hline \multicolumn{5}{|l|}{$\underline{\text { Oxalidaceae }}$} \\
\hline Biophytum dendroides (Kunth) DC. (JGD 215, XAL) & 1,000 & 1,500 & 2 & \\
\hline \multicolumn{5}{|l|}{ Phytolaccaceae } \\
\hline Petiveria alliacea L. (JGD 333, MEXU; XAL; XALU) & 50 & 50 & 1 & $\mathrm{R}$ \\
\hline \multicolumn{5}{|l|}{$\underline{\text { Piperaceae }}$} \\
\hline Peperomia angustata Kunth. (JGD 392, MEXU) & 2,500 & 2,500 & 1 & \\
\hline Peperomia arboricola C. DC. (JGD 393, MEXU) & 2,100 & 2,500 & 4 & $M \times 2$ \\
\hline Peperomia cobana C. DC. (JGD 461, MEXU) & 1,500 & 1,500 & 1 & Mx2 \\
\hline Peperomia deppeana Schltdl. \& Cham. (JGD 231, MEXU) & 2,500 & 2,500 & 1 & \\
\hline Peperomia donaguiana C. DC. (JGD 189, MEXU; XAL) & 1,500 & 2,500 & 9 & Mx2 \\
\hline Peperomia glabella (Sw.) A. Dietr. (JGD 378, MEXU) & 2,100 & 2,100 & 7 & \\
\hline Peperomia aff. granulosa (JGD 438, MEXU) & 650 & 650 & 2 & \\
\hline Peperomia obtusifolia (L.) A. Dietr. (JGD 242 \& 473, MEXU; XAL) & 650 & 1,500 & 13 & \\
\hline Peperomia peltilimba C. DC. (JGD 245, MEXU) & 1,500 & 1,500 & 1 & Mx2 \\
\hline Peperomia subblanda C. DC. (JGD 380, MEXU; XAL) & 650 & 2,100 & 8 & \\
\hline \multicolumn{5}{|l|}{$\underline{\text { Plantaginaceae }}$} \\
\hline Digitalis purpurea L. (JGD 419, XALU) & 2,500 & 2,500 & 1 & $E, R$ \\
\hline $\begin{array}{l}\text { Penstemon gentianoIdes (Kunth) PoIr. (JGD 430, MEXU; XAL; } \\
\text { XALU) }\end{array}$ & 3,500 & 3,500 & 14 & \\
\hline \multicolumn{5}{|l|}{ Polemoniaceae } \\
\hline Morpho unidentified (JGD 334, XALU) & 50 & 50 & 1 & \\
\hline \multicolumn{5}{|l|}{ Polygalaceae } \\
\hline Morpho unidentified (JGD 370, XALU) & 1,000 & 1,000 & 2 & \\
\hline \multicolumn{5}{|l|}{ Polygonaceae } \\
\hline Rumex acetosella L. (JGD 277, XALU) & 3,100 & 3,100 & 2 & $E, R$ \\
\hline Morpho unidentified (JGD 379, MEXU) & 650 & 650 & 4 & \\
\hline \multicolumn{5}{|l|}{ Portulacaceae } \\
\hline Morpho unidentified (JGD 335, MEXU) & 650 & 650 & 3 & \\
\hline$\underline{\text { Ranunculaceae }}$ & & & & \\
\hline
\end{tabular}




\begin{tabular}{|c|c|c|c|c|}
\hline Subclass/Family/Species (voucher, herbarium) & $\min$ & $\max$ & $\mathbf{N}$ & Status \\
\hline Ranunculus multicaulis var. multicaulis T. Duncan (JGD 261, XALU) & 3,100 & 3,100 & 2 & $\mathrm{Mx}$ \\
\hline \multicolumn{5}{|l|}{ Rosaceae } \\
\hline Lachemilla orbiculata (Ruiz \& Pav.) Rydb. (JGD 357, XALU) & 2,500 & 2,500 & 6 & \\
\hline $\begin{array}{l}\text { Lachemilla procumbens (Rose) Rydb. (JGD 259, XAL) } \\
\text { Lachemilla vulcanica (Schltdl. \& Cham.) Rydb. (JGD 415, MEXU; }\end{array}$ & 3,100 & 3,100 & 12 & \multirow[t]{2}{*}{$\mathrm{R}$} \\
\hline XAL; XALU) & 3,500 & 3,500 & 15 & \\
\hline $\begin{array}{l}\frac{\text { Rubiaceae }}{\text { Bouvardia laevis M. Martens \& Galeotti (JGD 251, MEXU; XAL; }} \\
\text { XALU) }\end{array}$ & 2,500 & 2,500 & 2 & \\
\hline Coccocypselum hirsutum Bartl. ex DC. (JGD 167, MEXU; XALU) & 1,500 & 1,500 & 10 & \\
\hline Crusea coccinea DC. (JGD 350, XALU) & 2,500 & 2,500 & 2 & \\
\hline Deppea grandiflora Schltdl. (JGD 271, XAL) & 2,500 & 3,100 & 3 & \\
\hline Didymaea alsinoides (Schltdl. \& Cham.) Standl. (JGD 388, XALU) & 2,100 & 2,500 & 4 & \\
\hline Galium aschenbornii S. Schauer (JGD 256, XALU) & 2,500 & 3,100 & 18 & \\
\hline Hedyotis sharpii (Terrell) G.L. Nesom (JGD 264, XALU) & 3,100 & 3,500 & 4 & Mx \\
\hline Relbunium hypocarpium (L.) Hemsl. (JGD 474, MEXU) & 2,500 & 2,500 & 2 & \\
\hline \multicolumn{5}{|l|}{ Solanaceae } \\
\hline Cestrum dumetorum Schltdl. (JGD 448, XALU) & 1,000 & 1,000 & 1 & \\
\hline Jaltomata procumbens (Cav.) J.L. Gentry (JGD 209, XALU) & 1,500 & 2,500 & 8 & $\mathrm{R}$ \\
\hline Physalis campanula Standl. \& Steyerm. (JGD 180, MEXU) & 2,100 & 2,500 & 3 & Mx2 \\
\hline Solanum aligerum Schltdl. (JGD 418, XALU) & 2,500 & 2,500 & 3 & \\
\hline Solanum demissum Lindl. (JGD 281, XALU) & 3,100 & 3,100 & 1 & \\
\hline Solanum laxum Spreng. (JGD 404, XALU) & 2,500 & 2,500 & 2 & \\
\hline Solanum tuberosum L. (JGD 284, XALU) & 3,100 & 3,100 & 1 & $E$ \\
\hline \multicolumn{5}{|l|}{ Valerianaceae } \\
\hline Valeriana sorbifolia Kunth (JGD 165, MEXU) & 2,500 & 2,500 & 1 & \\
\hline
\end{tabular}




\section{CHAPTER 3: Diversity and composition of herbaceous angiosperms along gradients of elevation and forest use intensity}

Jorge Antonio Gómez-Díaz, Thorsten Krömer, Holger Kreft, Gerhard Gerold, César Isidro Carvajal-Hernández and Felix Heitkamp.

In revision, Plos One, submission date September 16 2016.

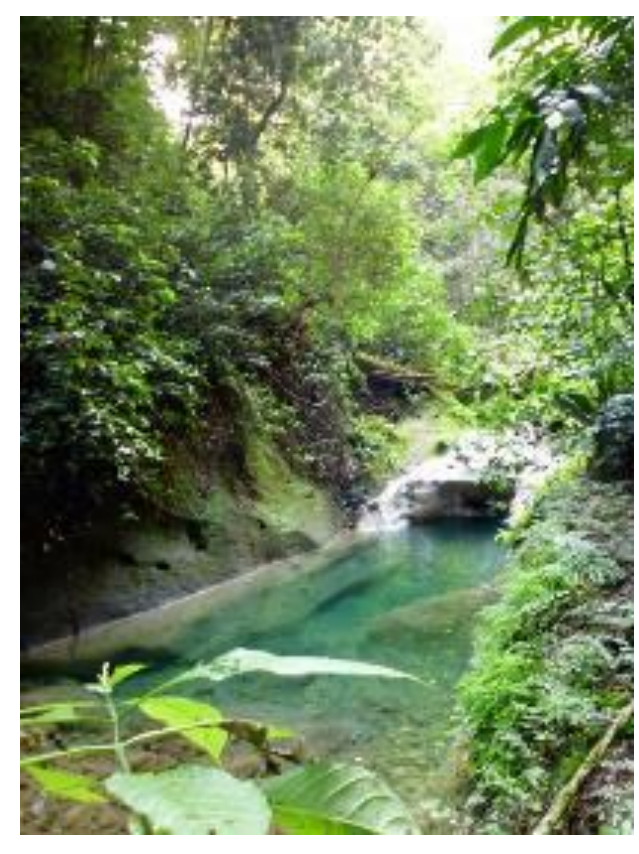

Tropical semi-deciduous azonal forest in Poza azul, Palmarejo, Veracruz, Mexico at $500 \mathrm{~m}$. 


\section{Diversity and Composition of Herbaceous Angiosperms along Gradients of Elevation and Forest Use Intensity}

\subsection{Abstract}

Terrestrial herbs are an important element in tropical forests; however, there is a lack of research on their diversity patterns and how they respond to different forest use intensities. The aim of this study was to analyze the diversity of herbaceous angiosperms along gradients of elevation ( $50 \mathrm{~m}$ to $3500 \mathrm{~m}$ ) and human forest use intensity on the Eastern slopes of the Cofre de Perote, Veracruz, Mexico. We recorded the occurrence of all species of this plant group within 120 plots of $20 \mathrm{~m} \times 20 \mathrm{~m}$. The plots were located in eight study locations separated by ca. $500 \mathrm{~m}$ in elevation and within three different habitats: old-growth, degraded, and secondary forest stands $(n=5)$. We analyzed species richness as well as floristic composition in six vegetation belts at different elevations and in different habitats. In total, we recorded 264 plant species, of which 31 are endemic to Mexico. We found some general elevational trends, such as the increase in $\alpha$ - diversity and $\beta_{b}$-diversity and a decline in $\beta_{w}$-diversity. $\gamma$-diversity follows a hum-shaped pattern with a peak between $2500 \mathrm{~m}$ and $3000 \mathrm{~m}$ and a decrease at the extremes. There was no effect of forest use intensity on $\alpha$-diversity, only $\beta$-diversity was different depending on the change of habitat with the highest values when old-growth forest are transformed into secondary forests. Therefore, a loss of a specific forest area is compensated by the occurrence of a similar assemblage at other areas of the same location. The observed high $\beta$-diversity, including endemic elements, suggests that a mix of different habitats is needed for reaching high $\mathrm{y}$-richness of terrestrial herbs.

\subsection{Introduction}

Our planet is undergoing rapid changes across the majority of biomes, especially in the tropics (Foley et al. 2005). Consequently, growing human pressure on ecosystems poses a marked threat to global biodiversity (Godfray et al. 2010). Considering current rates of deforestation and forest degradation (Lindenmayer et al. 2006), undisturbed forests will 
become scarce and increasingly fragmented (Köster et al. 2009). Conversion of forest for agriculture as well as non-sustainable agrarian and forestry practices increase the demand for new land, and thus the increase in human population is the main driver threatening primary forests and associated biodiversity (Wright 2005). Whereas the effects of forest conversion on plant diversity are comparatively well known (Gibson et al. 2011), there is a lack of knowledge on how anthropogenic forest use intensity affects diversity and composition of plant communities (Flynn et al. 2009). Forest degradation may have different effects on biodiversity, depending on the ecosystem, the kind of degradation (temporal and spatial extent, intensity) and the taxa of interest (Gibson et al. 2011).

A meta-analysis of global patterns of forest degradation found that there is on average a loss of $22 \%$ of terrestrial species richness due to human-mediated forest use (Murphy \& Romanuk 2014). According to the analysis, emerging threats for species richness were land-use change and species invasions, followed by temperature increase, habitat loss and nutrient addition (Murphy \& Romanuk 2014). Opposed to the global losses, most landscapes, however, experienced a local increase in plant species richness mostly because invasions of exotic species tend to exceed native losses locally (Ellis et al. 2012). Therefore, more studies in different ecosystems, e.g. as found along large elevational gradients, are needed to identify the patterns of diversity changes due to forest use intensity (Becker et al. 2007).

Little is known about the specific effects of forest use intensity on herbaceous angiosperms despite being an important element of tropical vegetation (Willinghöfer et al. 2011). Forest use intensity has been reported to have positive, neutral or negative effects on herb diversity (Mayfield \& Daily 2005). Moreover, high numbers of primary forest species and endemic species have been found in naturally regenerating (Barlow \& Gardner 2007) and secondary forests, thus, such habitats can provide conservation services (Marin-Spiotta et al. 2007). Forest use may also lead to an increase in the number of species due to a suppression of competitive herbs (Buscardo et al. 2008). Opposing findings are a consequence of the very different study conditions (biome, ecosystem, taxa of interest), different scales (landscape, plot) and sampling techniques (Naeem et al. 
2001). Therefore, it is important to carry out more empirical research in order to quantify the effects of forest use intensity on herbs using a robust and replicated study design while accounting for different components of herb diversity ( $\alpha, \beta$, and $\gamma$ ).

Despite the remaining uncertainties about forest use intensity effects on species richness, changes in species composition have been reported often with the rarest species found mainly in native communities (Cadotte et al. 2010). Several studies have shown that with increasing forest use intensity, local ( $\alpha$-diversity) and total ( $\gamma$-diversity) species richness declined linearly, whereas species turnover within-plots increased. This shows that anthropogenic forest use intensity in the most intensively used plots made the herb layer more sparse and similarly reduced species richness (Decocq et al. 2014).

Studies on latitudinal and elevational gradients show that effects of forest use intensity on plant diversity may change depending on the ecosystem or ecozone. Several studies of tropical elevational gradients have shown a peak at mid-elevations in species diversity for various plant groups (McCain \& Grytnes 2010). Most works focus on the richest herbaceous families (Krömer et al. 2013) and were conducted in near-natural ecosystems. Considering the ongoing conversion of primary into degraded and secondary vegetation types (Gibson et al. 2011), studies on elevational gradients have to be advanced by focusing on habitats with different anthropogenic influence.

The objective of this study was to investigate the patterns of diversity $(\alpha, \beta$, and $\gamma)$ of herbaceous angiosperms along a combined gradient of elevation and forest use intensity in order to fill the gap on basic information about herbaceous angiosperms along elevational gradients in the tropics and to identify the factors determining its current composition. The study was implemented at the Eastern slopes of the volcano Cofre de Perote in central Veracruz, Mexico. The elevational gradient stretches from sea level up to $3500 \mathrm{~m}$ above sea level and exhibits a large range of environmental conditions on $c$. $80 \mathrm{~km}$ horizontal distance. We established plots at eight different locations (separated by c. $500 \mathrm{~m}$ in elevation) and in three different forest use intensity types (old-growth, degraded, and secondary forest). We hypothesized that (1) forest use intensity affects herb species richness, (2) there is a continuous turnover in species composition from old- 
growth over degraded to secondary forest, and (3) $\beta$-diversity within habitats is lower than $\beta$-diversity between habitats due to the forest heterogeneity.

\subsection{Methods}

\subsubsection{Study area}

The study was conducted at eight sites along an elevational gradient between 30 and $3540 \mathrm{~m}$ on the Eastern slopes of the Cofre de Perote, an extinct volcano of $4282 \mathrm{~m}$ elevation in the central part of the state of Veracruz, Mexico (Fig. 3.1). This region is located at the junction of the Trans-Mexican volcanic belt and the Sierra Madre Oriental, a mountainous area between $19^{\circ} 25^{\prime} 5.7^{\prime \prime}$ and $19^{\circ} 36^{\prime} 54^{\prime \prime} \mathrm{N}$ and $94^{\circ} 44^{\prime} 43.5^{\prime \prime}$ and $97^{\circ} 9^{\prime}$ 36.9 " W. The state of Veracruz covers $72420 \mathrm{~km}^{2}$ and hosts a large number of angiosperms (6876 species) representing about $31 \%$ of the Mexican flora (Luna-Vega \& Espinosa 2013). More than $80 \%$ of Veracruz' primary vegetation has been converted and the remaining parts are highly fragmented (Muñoz-Villers \& López-Blanco 2008). Veracruz is therefore recognized as a priority region for conservation within Mexico (Williams-Linera 2002).

The study locations were selected at the following elevations above sea level: $30-50 \mathrm{~m}$, 610-670 m, 900-1010 m, 1470-1650 m, 2020-2230 m, 2470-2600 m, 3070-3160 m and 3480-3540 m (Table 3.1, Fig. 3.1). To simplify, from now on we will refer to every site as a categorical unit $(50,650,1000,1500,2100,2500,3100,3500 \mathrm{~m})$. Information about geographical reference and elevation were recorded using a Garmin® GPSMAP 60Cx device. 


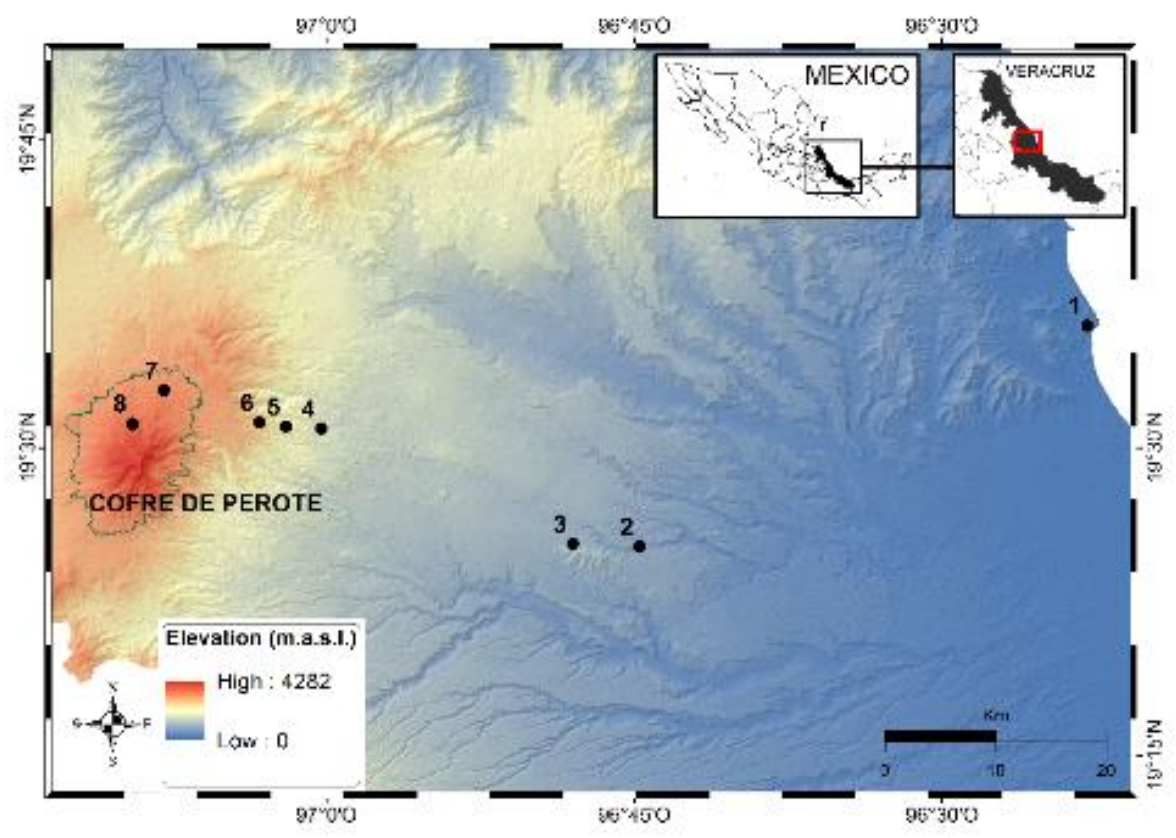

Figure 3.1 Map of the Eastern slopes of the Cofre de Perote in Veracruz State, Mexico. Study locations are shown by black dots. $1=$ La Mancha, $2=$ Palmarejo, $3=$ Chavarrillo, $4=$ Los Capulines, 5 = El Zapotal, $6=$ El Encinal, $7=$ Los Pescados, and $8=$ El Conejo.

Table 3.1 List of the study locations along the elevational gradient at the Cofre de Perote, central Veracruz, Mexico. Information is given on elevational range, vegetation type according to Leopold (Leopold 1950), mean annual temperature (MAT), mean annual precipitation (MAP), days of rain (DR), and days below $0^{\circ} \mathrm{C}$ according to National Meteorological Service of Mexico (data from 1951-2010) (SMN 2016).

\begin{tabular}{lrlrrrr}
\hline \multicolumn{1}{c}{ Location } & $\begin{array}{r}\text { Elevation } \\
(\mathbf{m})\end{array}$ & \multicolumn{1}{c}{ Vegetation type } & $\begin{array}{r}\text { MAT } \\
\left({ }^{\circ} \mathbf{C}\right)\end{array}$ & $\begin{array}{r}\text { MAP } \\
(\mathbf{m m})\end{array}$ & DR & DB \\
\hline La Mancha & $30-50$ & Tropical semi-humid deciduous forest & 26 & 1221 & 81 & 0 \\
Palmarejo & $610-670$ & Tropical semi-humid deciduous forest & 23 & 938 & 86 & 0 \\
Chavarrillo & $900-1010$ & Tropical oak forest & 21 & 1552 & 123 & 0 \\
Los Capulines & $1470-1650$ & Humid montane forest & 18 & 1598 & 145 & 0 \\
El Zapotal & $2020-2230$ & Humid montane forest & 14 & 3004 & 199 & 3 \\
El Encinal & $2470-2600$ & Pine-oak forest & 12 & 1142 & 100 & 12 \\
Los Pescados & $3070-3160$ & Pine forest & 10 & 821 & 113 & 14 \\
El Conejo & $3480-3540$ & Fir forest & 8 & 829 & 112 & 16 \\
\hline
\end{tabular}




\subsubsection{Field sampling}

Fieldwork was conducted between February 2012 and January 2014. We sampled the presence/absence of terrestrial herbaceous angiosperms, which were defined as plants that have no persistent woody stem above ground or plants that are only slightly woody, rooted on the forest floor and have a short height (generally $<1 \mathrm{~m}$ ); vines were excluded (Poulsen 1996). We recorded all species in $20 \mathrm{~m} \times 20 \mathrm{~m}$ plots, without considering seedlings (Carvajal-Hernández \& Krömer 2015). A plot size of $400 \mathrm{~m}^{2}$ was selected because the area is representative for the flora of the herb families in humid tropical forests but small enough to minimize the variation of abiotic factors (Kessler \& Bach 1999). Additionally, this plot size has been used for several comparative studies in the tropics (Cicuzza et al. 2013). Plots were located in the three different habitats subjected to different degrees of forest use intensity: old-growth (OG), degraded (DE), and secondary forest (SE) stands ( $n=5$ plots for each habitat). These categories follow Newbold et al. (2015) and are defined in Table 3.2. Each habitat was present at each of the eight locations resulting in a total number of 120 plots and a sampled area of $48000 \mathrm{~m}^{2}$. A plant collection permit that covered the whole study area and even allowed us the collection of protected species mentioned in the Mexican legislation (NOM-059-SEMARNAT-2010) was issued by the Secretaría de Medio Ambiente y Recursos Naturales (SEMARNAT SGPA/DGVS/2405/14), which is the government agency responsible for regulating matters related to nature. 
Table 3.2 Classification of habitats with different forest use intensities according to the main physiognomic characteristic, the gap fraction in the canopy, dominance of canopy trees, the percentage of shrubs, and the presence of lianas (Newbold et al. 2015).

\begin{tabular}{|c|c|c|c|c|c|c|}
\hline Habitat & Characteristic & $\begin{array}{l}\text { Gaps } \\
(\%)\end{array}$ & $\begin{array}{l}\text { Forest } \\
\text { use } \\
\text { intensity }\end{array}$ & $\begin{array}{l}\text { Canopy } \\
\text { trees }\end{array}$ & $\begin{array}{l}\text { Shrub } \\
(\%)\end{array}$ & Lianas \\
\hline Old-growth & $\begin{array}{l}\text { No obvious forest } \\
\text { use, dominance of } \\
\text { mature trees }\end{array}$ & $<10$ & Low & High & $<30$ & No \\
\hline Degraded & $\begin{array}{lr}\text { Selective } & \text { logging, } \\
\text { grazing } & \text { and }\end{array}$ & $11-25$ & Medium & Low & $30-50$ & Low \\
\hline Secondary & $\begin{array}{l}\text { understory removal } \\
\text { Regrown after clear- } \\
\text { cut }\end{array}$ & $>25$ & High & very low & $>50$ & High \\
\hline
\end{tabular}

Throughout the manuscript, we use specific terms regarding the sampling design, which are defined in figure 3.2 . 


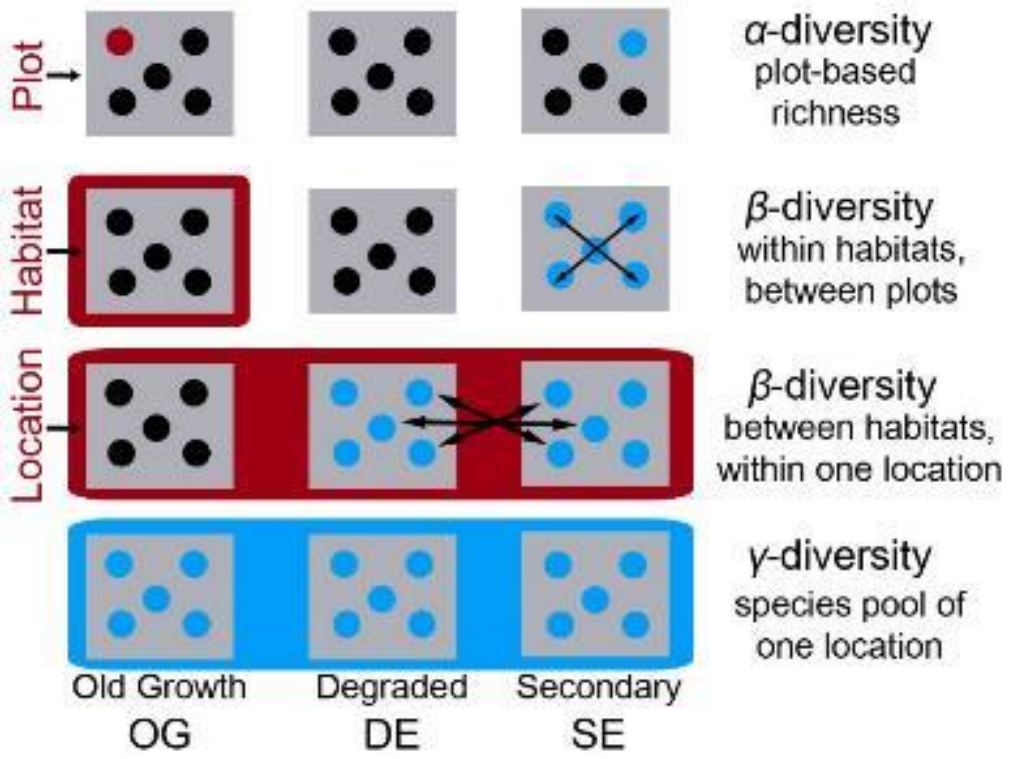

Figure 3.2 Schematic representation of the sampling design. $\alpha$-diversity is measured in plots of $20 \mathrm{~m} \times 20 \mathrm{~m}$ and is given as a mean of five plots. Five plots represent one habitat. Habitat is defined here as a homogenous type of forest use intensity within one location. A location is representative of an elevational belt and harbors three different habitats (OG, DE, and SE). $\beta$ diversity was measured in two ways based on pairs of plots. Within-habitat $\beta$-diversity represents the compositional heterogeneity of a habitat. It is measured as the 1-Sørensen index based on multiple pairwise comparisons of the five plots within each habitat of a specific location. Betweenhabit $\beta$-diversity represents the compositional heterogeneity between different forest use intensity. Measurement is similar to within-habitat $\beta$-diversity, but multiple pairwise comparisons based on the plots between habitats of a specific location. $\gamma$-diversity is defined as the total number of the local species pool across all 15 plots within a location, i.e. three habitats with five plots each.

\subsubsection{Species identification}

At each location, but not in every plot, specimens of all species were collected and prepared if possible in triplicate and deposited at the Mexican herbaria CIIDIR, MEXU, XAL, and XALU. Details about species identifications, geographical distribution, and classification can be found in Gómez-Díaz et al. (accepted). 


\subsubsection{Data analyses}

\subsubsection{Alpha diversity}

Generalized Linear Models (GLMs) were used to assess the effect of the explanatory variables to $\alpha$-diversity. Plot-based species richness ( $\alpha$-diversity) between locations and habitats was used as the response variable. "Elevation" (continuous) and "habitat" (a factor with three levels "OG", "DE", and "SE"), as well as their interaction, were used as explanatory variables in regression models.

a-diversity was modeled as count data using a Poisson error family according to the Shapiro-Wilk normality test $(\mathrm{W}=0.958, \mathrm{p}=0.001)$ and the "descdist" function of the $R$ package "fitdistrplus" version 1.0-7. $\alpha$-diversity presented overdispersion $(z=2, p=0.023$, alpha $=0.341$ ) according to the Test for Overdispersion in the Poisson model (Cameron \& Trivedi 1990) tested with the function "dispersiontest" of the R package "AER" version 1.2-4. Therefore, we used the negative binomial GLM family error with a log-link function, which is a model used for continuous variables, usually with over-dispersion using the $R$ package "MASS" version 7.3-45 (Venables \& Ripley 2002). All analyses were performed in R 3.2.1 (R Core Team 2014).

We fitted several GLMs using the first to fourth order polynomials of the variable "elevation" and used the Akaike Information Criterion (AIC) (Borcard et al. 2011) as the measure of model support, where smaller values indicate a stronger support. We selected the GLM with the fourth order polynomial of "elevation" (AIC $=598.954)$ for additional analyses because it received the strongest support as an explanatory variable for $\alpha$ diversity, whereas all other combinations had a higher AIC or failed in some combination.

\subsubsection{Beta diversity}

In order to have a more intuitive $\beta$-diversity, we used the dissimilarity (1-S) variant of the Sørensen index (Dice 1945):

$\beta$-diversity $=1$-S

Equation 1

where $\mathrm{S}$ is the Sørensen index:

$S=2 C / A+B$

Equation 2 
which is a coefficient of association, where a value of 1 shows that a pair of plots under consideration has exactly the same species. The Sørensen index can be adjusted to measure species turnover (effective or real) (Tuomisto 2010). The index 1-S is also a measure of $\beta$-diversity because if a coefficient is near to 1 , it shows that the units do not share species, and, therefore, they have high $\beta$-diversity (Anderson et al. 2006).

As a measure for landscape-scale $\beta$-diversity, we compared the effect of habitats on floristic composition between $O G$ and DE, OG and SE as well as DE and SE at each site (Chao et al. 2005). The calculation was done plot-by-plot, i.e. each plot of habitat A was compared to five or four (in the case of within $\beta$-diversity) other plots of habitat $B$. Additionally, we calculated the standard errors for the $\beta$-diversity estimator, letting statistically rigorous contrast of two or other similarity index values. Standard errors were calculated by a bootstrap process, which needs resampling the observed data for pairs of samples and recomputing the estimators $N$ times (Chao et al. 2005). All analyses of $\beta$ diversity were performed in EstimateS 9.1.0 (Colwell 2013).

We also computed multiple GLMs to explore explanations for elevational patterns of $\beta$ diversity. The quasi-binomial error family was used for the models which is appropriated for continuous variables that range from 0 to 1 . Therefore, all models were compared by means of an ANOVA test due to the lack of AIC value and log-likelihood in the quasibinomial family error. The AIC is not displayed for quasi-binomial models because there is not explicit log-likelihood to be maximized as in the case of other error families (Rao \& Rao 2014). Also, test statistics from such models should be constructed on F-tests rather than chi-squared tests (Logan 2010). The model with least residual differences and deviation was the quadratic model.

$\beta$-diversity indices were compared with a GLM with a quasi-binomial family error. The independent variables were "location" with seven levels (the $50 \mathrm{~m}$ location was not analyzed due to the lack of species in six plots) and "habitat transition" with six levels ("OG to OG", "OG to DE", "OG to SE", "DE to DE", "DE to SE", and "SE to SE") and the interaction of both variables. Data was checked for normality using the Shapiro-Wilk normality test. Homogeneity of variance was checked using the Bartlett test. All analyses were performed in R 3.2.1 (R Core Team 2014). 
3.3.4.3 Additive gamma partitioning

We used additive partitioning of gamma into alpha and beta components because it has been established as a useful measure to quantify different aspects of communities (Chao et al. 2012), is an intuitive measure of diversity that reflects the species turnover, and represents the specifically species diversity similar as does real gamma diversity (Tuomisto 2011). The total observed diversity Yobs, for each habitat type and location, was partitioned as:

$y=\alpha_{1}+\beta_{b}+\beta_{w}$

Equation 3

where $\alpha$ is the mean $\alpha$-diversity per location, $\beta_{b}$ is the between-habitat $\beta$-diversity, $\beta_{w}$ the mean within-habitat $\beta$-diversity. These values can be obtained as follows:

$\alpha_{i}=\sum_{j=1}^{n i} \mathrm{D}_{i j}$

Equation 4

where $D_{i j}$ are the diversity metrics recorded in each sample $j=1,2,3 \ldots n_{\mathrm{i}}$ is the number of samples taken at level $i$ of the hierarchical sampling design.

$\beta_{b}=\alpha_{i+1}-\alpha_{i}$

Equation 5

$\beta_{w}=\gamma-\alpha_{m}$

Equation 6

to extend across multiple scales, we have a hierarchical design with $i=1,2 \ldots m$ levels of sampling. Samples in the lowest hierarchical level $i=1$ represents the smallest sampling unit nested within samples at $\mathrm{i}=2$, and samples at $i=2 \ldots m$ are formed by pooling together the appropriate groups of nested samples from each level $i-1$ (Crist et al. 2003). Analysis of additive diversity partitioning was done using the "hierDiversity" package (Marion et al. 2015).

\subsection{Results and Discussion}

\subsubsection{Alpha diversity}

Elevation was the only significant predictor of $\alpha$-diversity of herbaceous angiosperms and explained almost two third of the variance $\left(G L M, R^{2}=0.59, p=0.003\right)$. $\alpha$-diversity followed 
a bimodal pattern, showing a first peak at $650 \mathrm{~m}$ and another at $2500-3100 \mathrm{~m}$, followed by a decline towards the extremes of the gradient (Fig. 3.3).



Figure 3.3 $\alpha$-diversity of herbaceous angiosperms along gradients of elevation and forest use intensity at the Cofre de Perote, central Veracruz, Mexico. The lines were fit from a negative generalized linear model (GLM), the shaded area marks confidence intervals $(\mathrm{Cl}=1.96$ times standard error). Difference to zero is not significant for the intercept ( $x y, O G$ at $50 \mathrm{~m}, \mathrm{p}=0.766$ ) neither for the effect of habitat (DE: $p=0.081$, SE: $p=0.422$ ). All the effects are estimated in relation to $O G$. Elevation significantly $\left(R^{2}=0.59, p=0.003\right)$ affected $\alpha$-diversity. Observed species richness on $20 \mathrm{~m} \times 20 \mathrm{~m}$ plots along the elevational gradient for OG (green), DE (blue), and SE (red). 
Bimodal diversity patterns have been reported for different groups of vascular plants (McCain \& Grytnes 2010), such as palms, Acanthaceae, Bromeliaceae and woody plants along tropical mountains (Lovett et al. 2006, Eiserhardt et al. 2011, Salas-Morales \& Meave 2012). However, our results show differences in previous findings as the peak in species richness shifted towards higher, instead of mid-elevations (Kluge \& Kessler 2006). Our transect is located near the border of the tropics, whereas most other studies were located within the moist inner tropics.

Lower elevations in Veracruz are subject to prolonged dry seasons (Table 3.2). With increasing elevation, precipitation increases while potential evapotranspiration decreases with lower temperatures. Species richness of ferns has been reported to be positively related to humidity (Salazar et al. 2015). In our study, angiosperm richness peaked between $2500 \mathrm{~m}$ and $3100 \mathrm{~m}$, where precipitation and number of rainy days already decrease. However, the pine-oak forests at $2500 \mathrm{~m}$ are often subject to fog, whereas in pine forests $(3100 \mathrm{~m})$ light transmission to the forest floor is high (Holeksa et al. 2007), which likely increases the ground cover of angiosperms and thus also their diversity.

Surprisingly, forest use intensity had no significant effect on a-diversity (Fig. 3.3). The lack of a detectable net-change in a-diversity might indicate that the level of forest use intensity is still relatively moderate; however, other life forms (e.g. trees, epiphytes, and ferns) might show contrasting patterns. It is quite well documented that forest herbs profit from better light conditions in DE or SE. Newbold et al. (2015) found that the richness of vascular plant species can increase by $40 \%$ due to the conversion of old-growth forests to secondary vegetation, but more severe habitat conversion, e.g. from forest to intensive cropland, decreases species richness.

\subsubsection{Beta and gamma diversity}

Instead of richness, forest use intensity affected the floristic composition. Community composition was markedly affected by habitat transitions (Table 3.3). Within-habitat $\beta$ diversity was generally lower $(0.42-0.52)$ than between-habitat $\beta$-diversity $(0.58-0.66)$. Not surprisingly, the highest dissimilarity was found in the transition from OG to SE, whereas the most homogenous species pool was within OG. Wider environmental differences are 
indicated by the high $\beta$-diversity between habitats (Wang et al. 2003), than the heterogeneity of plots within the same habitat type.

Table 3.3 Average effects of the habitat change. Mean $\beta$-diversity at every habitat transition, letters in superscript differences in groups after Tukey posthoc test $(H S D=0.138)$.

\begin{tabular}{lr}
\hline Habitat transition & $\begin{array}{r}\boldsymbol{\beta} \text {-diversity } \\
(\mathbf{1 - S})\end{array}$ \\
\hline Old-growth to secondary & $0.66^{\mathrm{a}}$ \\
Degraded to secondary & $0.61^{\mathrm{ab}}$ \\
Old-growth to degraded & $0.58^{\mathrm{ab}}$ \\
Degraded to degraded & $0.52^{\mathrm{bc}}$ \\
Secondary to secondary & $0.48^{\mathrm{bc}}$ \\
Old-growth to old-growth & $0.42^{\mathrm{c}}$ \\
\hline
\end{tabular}

There was a marked effect of elevation on $\beta$-diversity (Fig. 3.4). Within-habitat $\beta$-diversity showed a clear humped-shaped pattern for OG and SE with peaks between $1500 \mathrm{~m}$ and $2500 \mathrm{~m}$. DE, however, had their highest $\beta$-diversity at $650 \mathrm{~m}$ with a subsequent decline. Obviously, DE at lower elevations exhibits a different response to environmental conditions compared to OG and SE. Maybe degradation leads to a higher heterogeneity of environmental conditions and, consequently, offers diverse niches triggering differences in community assemblage (Warren et al. 2007). $\beta$-diversity between-habitat was generally high but varied with the type of habitat transition. During the transition from OG to SE ca. $50 \%$ of species were exchanged at both extremes of the elevational gradient. Between $1500 \mathrm{~m}$ and $2500 \mathrm{~m}$, however, even $75 \%$ of the species were different after conversion from OG to SE. Habitat transitions related to degradation (OG-DE, DE$\mathrm{SE})$ showed highest $\beta$-diversity between $650 \mathrm{~m}$ and $1500 \mathrm{~m}$ and declined afterward. Especially at $3100 \mathrm{~m}$ and $3500 \mathrm{~m}$, the change in species composition with the transition from $O G$ to $D E$ is relatively low. This indicates that present environmental conditions favor a spectrum of adapted species (Sánchez-González \& López-Mata 2003), which thrive regardless of the habitat type. Above $3100 \mathrm{~m}$ there are fewer species, which are adapted 
to extreme climate events, such as days below $0^{\circ} \mathrm{C}$, lower temperature, and precipitation (Table 3.1).
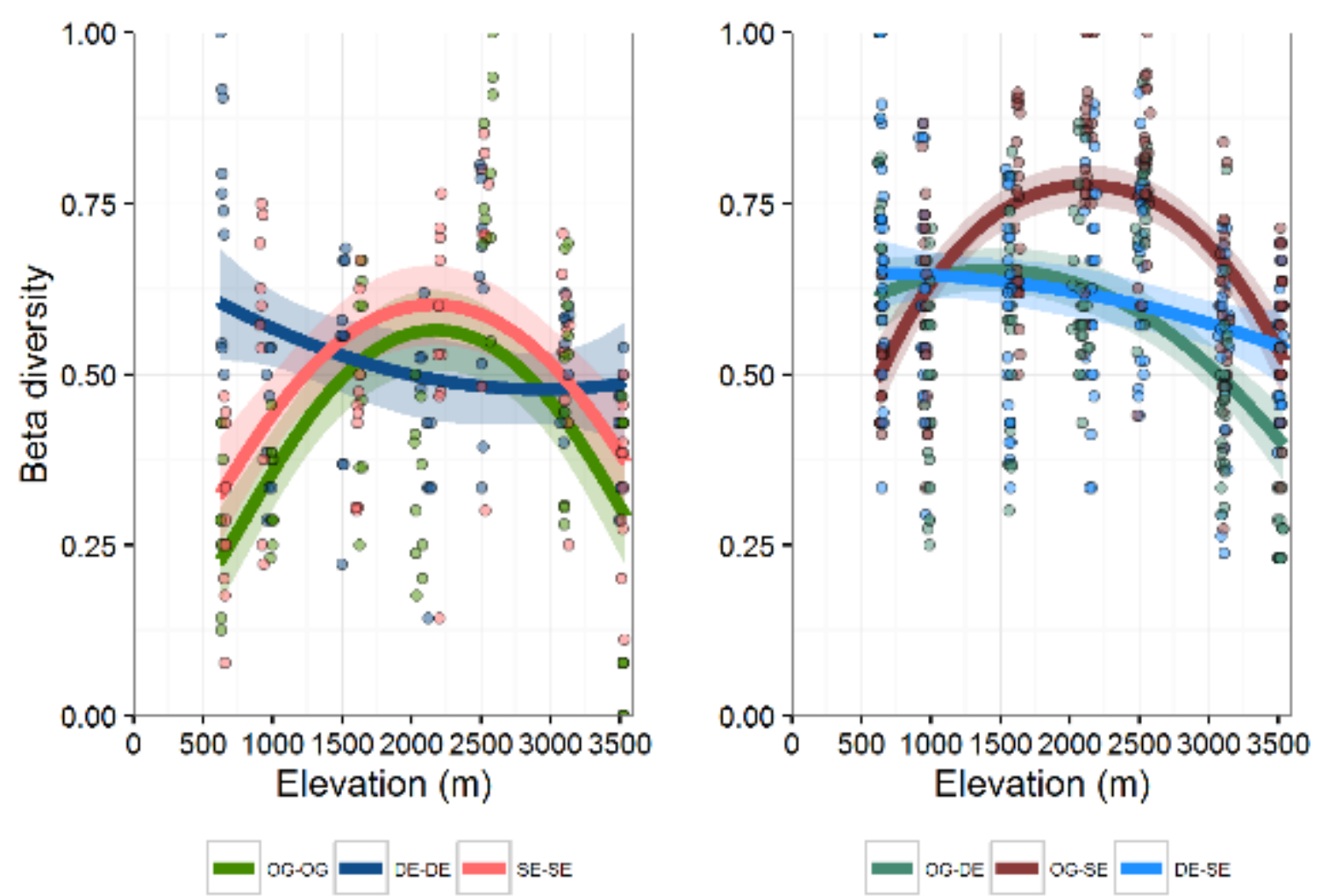

Figure 3.4 Compositional heterogeneity (as a measure for $\beta$-diversity) between different changes in forest habitats along the elevational gradient at the Cofre de Perote, central Veracruz, Mexico. Values are 1-Sørensen values as means across all plots. Error bars are standard errors computed by a GLM with quasibinomial error family.

The relative contribution of $\alpha$, within-habitat $\beta$, and between habitats $\beta$-diversity to $y$ was revealed by using the additive partitioning approach (Fig. 3.5). The contribution of $\alpha$ diversity was only between $12 \%$ and $32 \%$ (Fig. 3.5). The majority of entire species richness was accounted for $\beta$-diversity. In general, the values of $\beta$-diversity are higher between-habitat $\left(\beta_{b}\right)$ than within-habitat $\left(\beta_{w}\right)$. At the landscape scale, plant species diversity is typically accumulated (equal to the location-scale in the current study), this outcome verifies similar preceding results (Chandy et al. 2006, Clough et al. 2007, Wang et al. 2014). Diverse forest habitats support high species diversity and lead to high $\beta$ - 
diversity between-habitat $\left(\beta_{b}\right)$ confirming the importance of these habitats. There are some general elevational trends, such as the increase in $\alpha$-diversity and $\beta_{b}$-diversity as well as a decline in $\beta_{w}$-diversity. The increase of $\alpha$-diversity with elevation could be due to the adaptation of some herbs to cold climates (Hawkins et al. 2011), which is similar to the pattern found by Cicuzza et al. (2013). A similar pattern of increasing $\beta$-diversity was found by Yang et al. (2016), which is due to changes in climatic variables since elevationrelated vegetation zones reflect climatic zones. This can be also observed in our pattern since the most remarkable changes in values of $\beta_{b}$-diversity are located between different climatic zones (Fig. 3.5), which according to with Yang et al. (2016) "shows the effects of an elevation-related climate gradient on $\beta_{\mathrm{b}}$-diversity patterns". The decline in $\beta_{\mathrm{w}}$-diversity is consistent with the pattern found by Akhtar \& Bergmeier (2015), which is explained by the increasingly controlling effect of climate over other environmental factors (e.g. soil factors) and the decrease of forest heterogeneity at higher elevations.

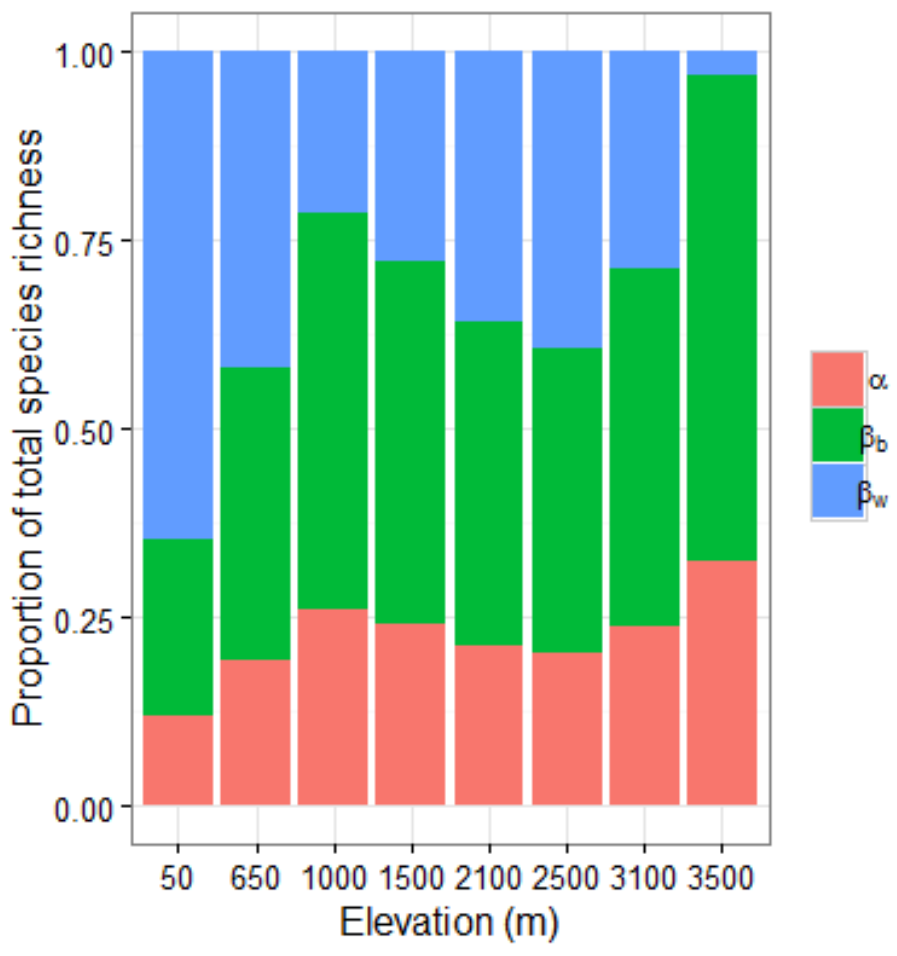

Figure 3.5 Additive gamma partitioning. The total observed diversity partitioned at each habitat type and location $\left(\alpha=\alpha\right.$-diversity, $\beta_{b}=\beta$-diversity between habitats, and $\beta_{w}=\beta$-diversity within habitats). 
The most remarkable effect of forest use intensity was on $\beta$-diversity and it was highest between $2100 \mathrm{~m}$ and $2500 \mathrm{~m}$ (Fig. 3.4). It has been reported that forest use intensity decreases $\beta$-diversity due to the propagation of exotic and opportunist species that can lead to a 'biotic homogenization' (Vellend et al. 2007). $\beta$-diversity is, on average, in our sample of landscapes, lower within habitats than between habitats (Table 3.3 and Fig. 3.4 and 3.5). Also, the a-diversity in our study did not change, but the dissimilarity between habitats was high (0.594 to 0.665) (Table 3.3).

Here, we argue that man-made habitats markedly contribute to the herbaceous angiosperm richness in our study region. It is, of course, important to note that our study does not include spatially weighted information about the abundance of different forest habitats. Pressure on the primary or $O G$ forest is often higher than their ability to regenerate. Therefore, there is the risk that $O G$ or even DE will be converted into SE (Brown \& Lugo 1990). Although different successional stages of SE may also harbor high species richness (Valencia et al. 2016), our results indicate that OG species are particularly threatened by habitat conversion. A homogenization of habitats will consequently lead to species homogenization by decreasing $\beta$-diversity.

The most vulnerable location is the pine-oak forest at $2500 \mathrm{~m}$ because high $\beta_{b}$-diversity implies that there is a loss of many OG species during forest degradation. This means that conversion of a certain area increases the chance that a unique flora is changed in composition and invasive species appear. In addition, this elevation contains the largest number of endemic species compared to the rest of locations (Gómez-Díaz et al. accepted), leading to increased vulnerability. Therefore, the pine-oak forest at $2500 \mathrm{~m}$ should be considered as a priority for conservation, especially because according to Mittermeier et al. (Mittermeier et al. 2005) this vegetation type in Mexico has the lowest levels of protection (Gómez-Mendoza \& Arriaga 2007). For the herbaceous angiosperm group, however, it seems that a well-designed management plan instead of pure conservation would be beneficial because high habitat heterogeneity is required to achieve high species richness. 


\subsection{Conclusions}

Understanding how forest use intensity and elevation affect the species diversity and community composition of herbs is a complex question and needs a frame that allows understanding the different patterns at the landscape level. Therefore, we focused on the three components of diversity ( $\alpha, \beta$, and $\gamma$ ). We did not find significant differences in $\alpha$ diversity among the three forest systems, a finding that is not in accordance with previous studies. However, forest use intensity affected the floristic composition, which varied markedly between habitats. The most important component driving $\mathrm{Y}$-diversity was the $\beta$ diversity between habitats. Thus, different forest use intensities, which coexist, increased the species richness in the landscape.

Some elevations, and especially the location at $2500 \mathrm{~m}$, were shown to be vulnerable, whereas species richness still depends on a certain degree of forest use intensity. Our findings clearly showed that $O G$ at mid-elevations contributed more to regional diversity than DE. At least for the group of herbaceous angiosperms, sustainable forest management, such as forest certification instead of strict protection may be a good way to conserve herbaceous forest plants in the region. The important influence of $\beta$-diversity to regional species richness should be considered in forest protection systems rather than put emphasis completely on the protection at local scale ( $\alpha$ ) diversity.

\subsection{Acknowledgements}

We thank M. Ruiz-Gómez, F. Calixto-Benites, C. Alavez-Tadeo, and V. Guzmán-Jacob for their help during fieldwork. We appreciate the working facilities provided at the Centro de Investigaciones Tropicales (CITRO), Universidad Veracruzana, Xalapa. 


\section{CHAPTER 4: Long-term changes in the forest cover in central Veracruz, Mexico since the 1990s}

Jorge Antonio Gómez-Díaz, Kristina Brast, Jan Degener, Thorsten Krömer, Gerhard Gerold and Felix Heitkamp.



Habenaria floribunda Lindl. in humid montane secondary forest in Los Capulines, Tlalnelhuayocan, Veracruz, Mexico. 


\section{Long-term changes in the forest cover in central Veracruz, Mexico since the 1990s}

\subsection{Summary}

Forest fragmentation and deforestation are important threats for the conservation of species that have severe consequences for ecosystem functions. The focus of this study is to empirically elucidate forest land cover transformations by determining deforestation rates between 1993 and 2014 and recognizing forest types that have the main conversion rates. Our study area is located between $96^{\circ}-97^{\circ} \mathrm{W}$ and $19^{\circ}-20^{\circ} \mathrm{N}$ in "La Antigua" and "Actopan" drainage basins, which is in the state of Veracruz, Mexico. Historical land cover information for the years 1993, 2000 and 2014 were obtained from image data of Landsat. We applied a supervised classification using maximum likelihood estimation and quantified both the net change in forest area and the loss of original forest area. Landscape metrics were established to measure the spatial shape of the forest fragments. Our results show that the area covered by original forests decreased during the period studied by approximately $57 \%$. The annual net forest change rate for the first period (19932000) was $-0.44 \%$; and increased significantly to $0.11 \%$ for the second period (20002014). The old-growth forests of Central Veracruz have suffered high land use change rates throughout the last twenty years with a reduction of this process during the last decade. We found that fragmentation patterns varied considerably between different time periods. In the first period, forest patches increased in irregularity, isolation, and amount, with a reduction in the dimension of patches reflecting the continuing fragmentation of forest habitats. The second period (2000-2014) experienced a slightly recovering of forest cover $(+0.11 \%)$. Our paper provides a thorough analysis of the forest transformations in Central Veracruz that will increase the consciousness of stakeholders for proper planning and management to maintain biological integrity of the area. 


\subsection{Introduction}

Two critical components of global change are forest fragmentation and deforestation (Tapia-Armijos et al. 2015). Thus, together with the degradation of tropical forests, those are the major threats for the conservation of species and have severe consequences for ecosystem functioning (Malhi et al. 2008). Some of the consequences of deforestation are changes in habitat quality and structure of ecosystems (Collinge 1996), an increase of greenhouse emissions (Crutzen 2006), degradation of ecosystem services (Chazdon 2008) and species extinctions (Whitmore \& Sayer 1992). Forest landscape structure is affected by deforestation due to the decrease of forest area (Foley et al. 2005). Most of the forest patches are reduced in size and connectivity due to fragmentation (Andrén 1994). Fleshing out the dynamics of forest transformations within the tropics and subtropics will make aware stakeholders on improving carbon storage in existing forest estates.

Half of Mexico's natural forest cover has been lost unevenly in the previous 50 years (Barsimantov \& Kendall 2012). However, during the last 20 years, Mexico has decreased deforestation rates (yearly rates of $0.56 \%$ for the $1990-2000$ period and $0.21 \%$ for the 2001-2010 period) (FAO 2014a, Skutsch et al. 2014). As in other tropical countries, the main drivers of continuing land cover changes are agricultural expansion, pasture expansion, growing economic inequality and population numbers, timber production, the absence of well-defined property rights, maize cultivation, cattle grazing, highway building and the harvesting of timber (Cortina-Villar et al. 2012, Bonilla-Moheno et al. 2013). Recently, the Mexican deforestation rates have been reduced due to protection efforts in communal forests (ejidos) (Bonilla-Moheno et al. 2013) and improving in protection initiatives (Pfaff et al. 2014). However, there still some inconsistencies in the available literature for example there some authors that show that the decrease in Mexico's deforestation rates is just a result of methodology inconsistencies (Skutsch et al. 2014).

In Mexico, tropical forests and pine-oak forests (mainly found in mountainous regions) have the highest deforestation rates stated to date (Barsimantov \& Kendall 2012). Central Mexico is assumed to play a leading role in deforestation in the country (López-Barrera et al. 2014). However, with the exception of the studies of López-Barrera et al. (2014) and 
Galicia et al. (2013) data on deforestation rates in this area are scarce. Though, the aforementioned studies were only focused on one vegetation type. Furthermore, this area is of specific value and attention for biodiversity preservation (Sarukhan et al. 2014).

The biodiversity of Veracruz has a high degree of endemism and poses a very specific flora, which varies evidently from the rest of the country (Sosa et al. 1998). Unfortunately, deforestation and poaching had extirpated some species from Veracruz such the harpy eagle (Harpia harpyja) (Vargas G et al. 2006) and the thick-billed parrot (Rhynchopsitta pachyrhyncha) (Sánchez Mateo 2007). The mountainous region of Central Veracruz hosts very important ecosystems, such as humid montane and pine-oak forests, which are very rich in biodiversity and offer a variety of ecological services (Williams-Linera et al. 2007). This region has an outstanding high regional plant diversity resulting from a characteristic high beta diversity or species turnover (Williams-Linera et al. 2007). Also, this region has been proposed to be protected as a natural reserve, an archipelago reserve, which should promote the conservation and restoration of biological landscape corridors connecting forest fragments through riparian forests, and biodiversity-friendly agricultural land, such as shade coffee plantations (Williams-Linera et al. 2007).

High rates of deforestation have been reported by current studies on small zones in this area (López-Barrera et al. 2014, Muñiz-Castro et al. 2015). Species richness and floristic composition are affected by the effects of deforestation and fragmentation (e.g. ArmentaMontero et al. 2015; Lopez-Barrera et al. 2014; Meyer et al. 2016; Rueda-Hernandez et al. 2015; Gomez-Diaz et al., accepted). Therefore, the aim of this study is to describe land cover change and variations in forest spatial configuration in the highly diverse montane forest area of Central Veracruz since 1993 by 1) determining deforestation rates in the area throughout two periods (1993-2000 and 2000-2014), 2) classifying which are the old-growth forest types that have suffered the highest change rates, and 3) assessing the variations in the spatial patterns of forest cover over time by designated landscape metrics. 


\subsection{Methods}

\subsubsection{Study area}

Our study area is located between $96^{\circ}-97^{\circ} \mathrm{W}$ and $19^{\circ}-20^{\circ} \mathrm{N}$ in the drainage basins of "La Antigua" and "Actopan" rivers. It covers approximately $6,987 \mathrm{~km}^{2}$ located mainly in the central region of the state of Veracruz (Fig. 4.1), whereas a small fraction (ca. 7\%) belongs to the state of Puebla. Our study area was chosen due to the outstanding species richness of angiosperms (6,876 species) representing about $31 \%$ of the Mexican flora (Luna-Vega \& Espinosa 2013). A great portion of the state of Veracruz is located inside the Mesoamerican biodiversity hotspot, which is considered the sixth richest hotspot in the world (Myers et al. 2000, Mittermeier et al. 2005). Besides, the area has been identified as a center of biodiversity (Williams-Linera 2013) at the junction of the Neotropical and the Nearctic regions (Olson et al. 2001, Morrone 2005).

However, more than $80 \%$ of Veracruz' primary vegetation has been converted and the remaining parts are highly fragmented (Muñoz-Villers \& López-Blanco 2008). This area is therefore recognized as a priority region for conservation within Mexico (Williams-Linera 2002). The elevation of Central Veracruz ranges from 0 to $4,282 \mathrm{~m}$, which turns it into a climatically and topographically varied area (Castellón et al. 2008), including several climatic zones (Lauer 1973) (Appendix 4.1). These are favored by numerous geographical factors, such as orography with elevation, distance to the Gulf of Mexico and continental air masses from the North (Delgado De Cantú 2003, Holwerda et al. 2010). The rainy season can be observed between May-June and September-October, (Lauer 1973), and a dry season between October and May (López-Barrera et al. 2014). The mean annual temperature gradient ranges from $2^{\circ} \mathrm{C}$ to $25^{\circ} \mathrm{C}$, whereas the precipitation ranges from 600 $\mathrm{mm}$ to 2,000 $\mathrm{mm}$ per year; although the upper part of the mountainous area receives less than $500 \mathrm{~mm}$ of annual precipitation and in winter, above $3,400 \mathrm{~m}$ even snowfall is possible (Hietz \& Hietz-Seifert 1995, Holwerda et al. 2010) (Appendix 4.1). The differences in climate, elevation, and the rock layer create extremely variable soil conditions (e.g. Muñoz-Villers et al. 2012) with the main soil types being calcic kastanozem, dystric folic andosol, eutric folic vitric andosol and eutric skeletic folic andosol (Bumiller 2015). 
Along the altitudinal gradient, we found six vegetation belts: i) the tropical semi-deciduous forest (TSD), which is characterized by the trees Brosimum alicastrum, Cedrela odorata, Bursera simaruba and Ficus obtusifolia (Castillo-Campos \& Travieso-Bello 2006), ii) the tropical oak forest (TOF) is typically dominated by one to three oak species (Quercus oleoides, $Q$. laurina and/or $Q$. peduncularis), whereas other tree species are scarce, iii) the humid montane forest (HMF) features frequent occurrences of fog as one of the most important characterizing ecological factors in this kind of forest (bosque de niebla or cloud forests) (Zamora-Crescencio \& Castillo-Campos 1997), iv) the pine-oak forest (POF), which comprises a community whose dominant trees belong to the genera Quercus and Pinus, v) the pine forest (PF), which is dominated by several species of the genus Pinus (P. montezumae, P. patula, P. pseudostrobus, P. teocote) causing a high canopy openness, and vi) the fir forest (FF), which is a monospecific Abies religiosa community with sparse canopy openness. For a detailed description of the vegetation belts see Gómez-Díaz et al. (accepted). 


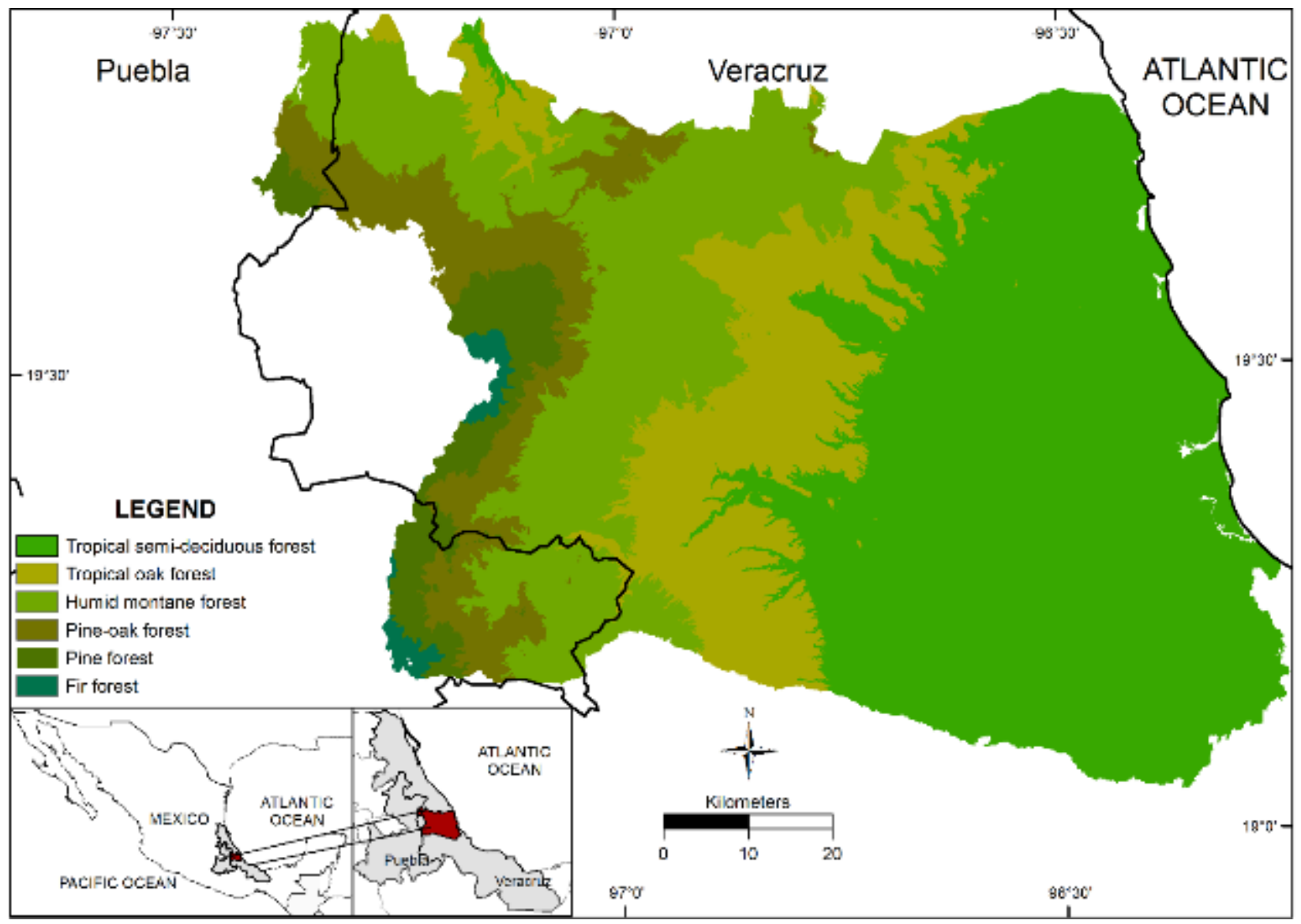

Figure 4.1 Study area in Central Veracruz, Mexico. Overview on the potential natural vegetation belts in the states of Veracruz and Puebla.

\subsubsection{Land cover data}

Historic land cover data for a period of 21 years, from the years 1993, 2000 and 2014 were obtained from image data of Landsat 5 TM, Landsat 7 ETM + and Landsat 8 OLI / TIRS, respectively. The scene selection was limited to the months of June to October in the rainy season, in order to be comparable with phenology or tree crown density in the partly deciduous forests. Due to the rainy season, there was an increased cloud cover within the selected scenes. Furthermore, due to the size and location of the study area, four Landsat scenes for each year were used to ensure full site coverage (Table 4.1). 
Table 4.1 Overview of the Landsat satellite scenes used for forest change analysis and the most important information about the scenes (information refers to the total scene) taken from the metadata set.

\begin{tabular}{|c|c|c|c|c|c|c|}
\hline Year & Sensor & $\begin{array}{l}\text { Number of } \\
\text { channels }\end{array}$ & $\begin{array}{c}\text { Panchromatic } \\
\text { channel (15 m } \\
\text { resolution) }\end{array}$ & $\begin{array}{c}\text { Date of } \\
\text { recording }\end{array}$ & $\begin{array}{c}\text { Scene } \\
\text { (path/row) }\end{array}$ & Projection \\
\hline \multirow[t]{8}{*}{1993} & Landsat LT & 7 & - & $04 / 09 / 1993$ & $24 / 46$ & WGS84 \\
\hline & $5 \mathrm{TM}$ & & & & & UTM $15 \mathrm{~N}$ \\
\hline & Landsat LT & 7 & - & 04/09/1993 & $24 / 47$ & WGS84 \\
\hline & $5 \mathrm{TM}$ & & & & & UTM 14 N \\
\hline & Landsat LT & 7 & - & 26/08/1993 & $24 / 46$ & WGS84 \\
\hline & $5 \mathrm{TM}$ & & & & & UTM $14 \mathrm{~N}$ \\
\hline & Landsat LT & 7 & - & 26/08/1993 & $24 / 47$ & WGS84 \\
\hline & $5 \mathrm{TM}$ & & & & & UTM 14 N \\
\hline \multirow[t]{8}{*}{2000} & Landsat LT & 7 & - & $23 / 09 / 2000$ & $24 / 46$ & WGS84 \\
\hline & $5 \mathrm{TM}$ & & & & & UTM $15 \mathrm{~N}$ \\
\hline & Landsat LT & 7 & - & 23/09/2000 & $24 / 47$ & WGS84 \\
\hline & $5 \mathrm{TM}$ & & & & & UTM 14 N \\
\hline & Landsat LE & 8 & Yes & 06/09/2000 & $25 / 46$ & WGS84 \\
\hline & 7 ETM & & & & & UTM 14 N \\
\hline & Landsat LE & 8 & Yes & 06/09/2000 & $25 / 47$ & WGS84 \\
\hline & 7 ETM & & & & & UTM 14 N \\
\hline \multirow[t]{8}{*}{2014} & Landsat LC & 11 & Yes & $13 / 08 / 2014$ & $24 / 46$ & WGS84 \\
\hline & 8 OLI TIRS & & & & & UTM $15 \mathrm{~N}$ \\
\hline & Landsat LC & 11 & Yes & 13/08/2014 & $24 / 47$ & WGS84 \\
\hline & 8 OLI TIRS & & & & & UTM 14 N \\
\hline & Landsat LC & 11 & Yes & 19/07/2014 & $25 / 47$ & WGS84 \\
\hline & 8 OLI TIRS & & & & & UTM 14 N \\
\hline & Landsat LC & 11 & Yes & $19 / 07 / 2014$ & $25 / 46$ & WGS84 \\
\hline & 8 OLI TIRS & & & & & UTM 14 N \\
\hline
\end{tabular}

Total belt area (TBA) was estimated based on previous studies conducted in the same study area by Carvajal-Hernández \& Krömer (2015), Gómez-Díaz et al. (accepted) and Gómez-Díaz et al. (in revision). 


\subsubsection{Land-cover classification}

We applied a supervised classification to level 1 Landsat data land cover types using maximum likelihood estimation (de Lange 2013). Therefore, training data for each mosaic dataset was created individually. For land cover classifications we tried to get at least 60 or 80 training pixels per land cover type. The land cover classes in the scenes of 1993 were interpreted largely visually. If uncertainties regarding forest or plantation inventory were detected, we used further vector data of 1997 with information about the vegetation types of Veracruz. The data are freely available for several decades on the server of the National Institute of Statistics, Geography and Statistics of Mexico (INEGI 2000). Another source was the classification for the upper drainage basin of "La Antigua" by Muñoz-Villers \& López-Blanco (2008). Besides, there was a further classification made in 2003 (INEGI 2000), which was used for comparison and selection of appropriate training data of the scenes from 2000. Furthermore, we considered a classification from Ellis \& Martínez (2010), for the total land cover of Veracruz.

The scenes from the year 2014 are only with ground truth data, i.e. vegetation surveys that have been mapped locally (Carvajal-Hernández \& Krömer 2015). These vegetation surveys were based solely on different forest stands and have been raised in the course of a research project from 2012 to 2014. In order to facilitate the differentiation of difficult cover classes, we used the conditions detailed in Table 4.2.

Table 4.2 Description of the cover classes used for the land use classification.

\begin{tabular}{ll}
\hline \multicolumn{1}{c}{$\begin{array}{c}\text { Cover } \\
\text { class }\end{array}$} & Description \\
\hline Forest & We did not discriminate between primary and secondary forest due to the central \\
& satellite image resolution and quality scene differences from the period 1993- \\
& 2014. Additionally, we were concerned in discriminating the forests with \\
& anthropogenic disturbance from the forests lacking such interference. Therefore, \\
& we considered a total of 140 (non-randomly distributed) ground control points \\
& available from previous field work in the study area and we used this GPS \\
& evidence to support the classification of different forest types.
\end{tabular}


Plantations The plantation land cover class refers to fruit, vegetable and coffee plantations. Plantations are mostly recognizable for being parcelled, but also have a different land cover and different vegetation band color. In this case, coffee can only be classified as "plantation" if it is cultivated unshaded and/or as shaded monoculture because these kinds of plantations with few tree species may be differentiated from dense, high-growing tree stands to occur in the forest. Furthermore, disturbed surfaces as scrubby structures of pasture have been integrated into this class.

Other In this category, we included the actual cloud surfaces and their shadows, water classes bodies, farmland, poor vegetation to vegetation-free areas as sand structured coastline and open rock formations in the mountainous area and coastal and hydro vegetation, which includes vegetation types that have been proven to be particularly adapted to the coasts (Leopold 1950).

Build-up Under this category fell both residential and industrial areas, as well as paved areas roads. Suitable training data were cities like Xalapa at higher elevations, as well as José Cardel in the coastal lowlands.

\subsubsection{Accuracy assessment}

Before we conducted the land cover classifications for further analysis, we applied an Accuracy Assessment. According to Congalton (2004), we established a sample number of at least 50 training points per land cover class. To determine the classification accuracy of the reference pixels we created a confusion matrix with pixels of the grid.

The Producer's Accuracy is the percentage of reference points of a class, which was correctly classified within the grid and provides the classification information on the quality of its raster data. The calculation accuracy total serves to assess the quality of the raster data and to correct the possible classification problems in a given case, by revising the training areas (Congalton 2004).

The values obtained in the global accuracy, producer's accuracy, and user's accuracy measures, as well as the Kappa index, revealed the resulted accuracy assessment. The Kappa index was obtained with the Eq. (1) where по is and the observational probability of agreement and $\pi e$ is a hypothetical expected probability of agreement under an 
appropriate of baseline constraints such as total independence of observer classifications (Landis \& Koch 1977).

$\kappa=\frac{\pi_{0} \pi_{e}}{1-\pi_{e}}$

Eq. 1

\subsubsection{Deforestation for the diverse forest types and at area level}

We counted together with the loss of original (gross) forest area ignoring zones of renewing or secondary forests and the net change in forest area in difference to other studies (e.g. Aide et al. 2013). We conducted two levels of deforestation analyses: i) the changes in the natural cover area were used to calculate the mean annual deforestation rates for each period $(1993-2000 ; 2000-2014)$ at the regional level, and ii) the annual deforestation rates for the main old-growth forest types in the area were calculated. Both analyses were applied to the total area and on each vegetation type. The classification map for Veracruz proposed by Ellis \& Martínez (2010) was used to obtain spatial information on vegetation belts. Then, we simplified the categories according to the classifications proposed by Carvajal-Hernández et al. (2015) and Gómez-Díaz et al. (accepted). We used the compound-interest-rate formula Eq. (2) proposed by Puyravaud (2003) to obtain annual net forest change and annual gross-forest rates. This formula has been used in similar studies (López-Barrera et al. 2014, Tapia-Armijos et al. 2015), where $A 1$ and $A 2$ are the area cover by natural forest at time $t 1$ and $t 2$, respectively and $P$ is the annual deforestation rate.

$P=\frac{100}{t_{2}-t_{1}} \ln \frac{A_{2}}{A_{1}}$

Eq. 2

\subsubsection{Fragmentation analysis}

In order to count and associate the spatial configuration of old-growth forest fragments, we used the landscape metrics proposed by Tapia-Armijos et al. (2015), taking into justification that the designated metrics were not redundant in the data achieved (Tapia- 
Armijos et al. 2015). We used the program FRAGSTATS 4.2 (McGarigal et al. 2012) to calculate the following parameters as proposed by Tapia-Armijos et al. (2015): i) area of each individual patch (PA: Patch area); ii) the number of fragments of natural forest (NP: Number of patches); iii) the number of patches per $\mathrm{km}^{2}$ (PD: Patch density); iv) the percentage of the landscape occupied by the largest fragment of natural forest (LPI: Largest patch index); v) the sum of the lengths ( $m$ ) of all edge segments in the landscape, divided by the total landscape area in ha (ED: edge density); vi) the mean size of natural forest patches (MPS: mean patch size); vii) the total patch size remaining after removing a specific buffer edge (TCA: Total core area); and viii) the degree of isolation of natural forest patches resulting from measure the ratio between the size and proximity of all patches whose edges are within $1 \mathrm{~km}$ of the focal patch (MPI: Mean proximity index).

\subsection{Results}

\subsubsection{Accuracy assessment}

A confusion matrix was used for the corroboration of the land cover maps (Appendix 4.2). Our results showed an overall accuracy of $82.5 \%$ for the year $1993,88.9 \%$ for the year 2000 and $84.3 \%$ for the year 2014 , which means that the pixels with forest cover were correctly distinguished from those with other covers (plantations, other classes, and buildup) in the three years of land cover classification. For this study, the Kappa index was 0.81 for the year $1993,0.88$ for 2000 and 0.83 for 2014 , which means that according to with Cook (2005), we had a good performance on the land cover classification for the three years (Appendix 4.2).

\subsubsection{Deforestation and land cover change patterns}

The land cover maps of 1993, 2000 and 2014 (Fig. 4.2) were used to derive variations in land cover (Table 4.3). Throughout the entire study period, the zone covered by old-growth vegetation was reduced by approximately 57\%. For the first period (1993-2000) the annual net forest change rate in central Veracruz' extent was $-0.44 \%$; then in the second period (2000-2014) it increased significantly to $+0.11 \%$. For the whole study period $(21$ 
years) the mean net-forest change rate was $-0.17 \%$. Throughout the entire study period, the vegetation types that suffered the main conversion rates were fir forest and tropical oak forest (Fig. 4.3). For the first period (1993-2000), the annual gross forest loss rate was $-1.17 \%$, which was reduced significantly to $-0.14 \%$ in the second period (2000-2014). Overall, tropical sub-deciduous forest and tropical oak forest were the vegetation types that suffered the highest gross forest loss (Fig. 4.3).

Table 4.3 Area covered by different natural forest types (FO), plantations, arable and grassland (AG) and other covers in 1993, 2000 and 2014 at different vegetation belts in Central Veracruz, Mexico. Total belt area (TBA) is also shown.

\begin{tabular}{|c|c|c|c|c|c|c|c|c|c|c|}
\hline VEGETATION & \multicolumn{2}{|l|}{ TBA } & \multicolumn{2}{|l|}{1993} & \multicolumn{3}{|c|}{2000} & \multicolumn{3}{|c|}{2014} \\
\hline BELT & $\left(\mathrm{km}^{2}\right)$ & FO & AG & Other & FO & AG & Other & FO & $\mathbf{A G}$ & Other \\
\hline $\begin{array}{l}\text { Tropical sub- } \\
\text { deciduous forest }\end{array}$ & & & & & & & & & & \\
\hline (TSD) & 3242 & $25 \%$ & $69 \%$ & $6 \%$ & $21 \%$ & $73 \%$ & $5 \%$ & $26 \%$ & $68 \%$ & $6 \%$ \\
\hline Tropical oak forest & & & & & & & & & & \\
\hline (TOF) & 1192 & $43 \%$ & $56 \%$ & $1 \%$ & $29 \%$ & $68 \%$ & $3 \%$ & $40 \%$ & $53 \%$ & $7 \%$ \\
\hline Humid montane & & & & & & & & & & \\
\hline forest (HMF) & 1595 & $54 \%$ & $43 \%$ & $3 \%$ & $45 \%$ & $48 \%$ & $7 \%$ & $51 \%$ & $37 \%$ & $12 \%$ \\
\hline Pine-oak forest & & & & & & & & & & \\
\hline (POF) & 604 & $44 \%$ & $53 \%$ & $3 \%$ & $37 \%$ & $57 \%$ & $6 \%$ & $47 \%$ & $45 \%$ & $8 \%$ \\
\hline Pine forest (PF) & 296 & $41 \%$ & $51 \%$ & $8 \%$ & $31 \%$ & $51 \%$ & $19 \%$ & $49 \%$ & $41 \%$ & $10 \%$ \\
\hline Fir forest (FF) & 58 & $36 \%$ & $37 \%$ & $27 \%$ & $22 \%$ & $43 \%$ & $35 \%$ & $34 \%$ & $25 \%$ & $40 \%$ \\
\hline
\end{tabular}



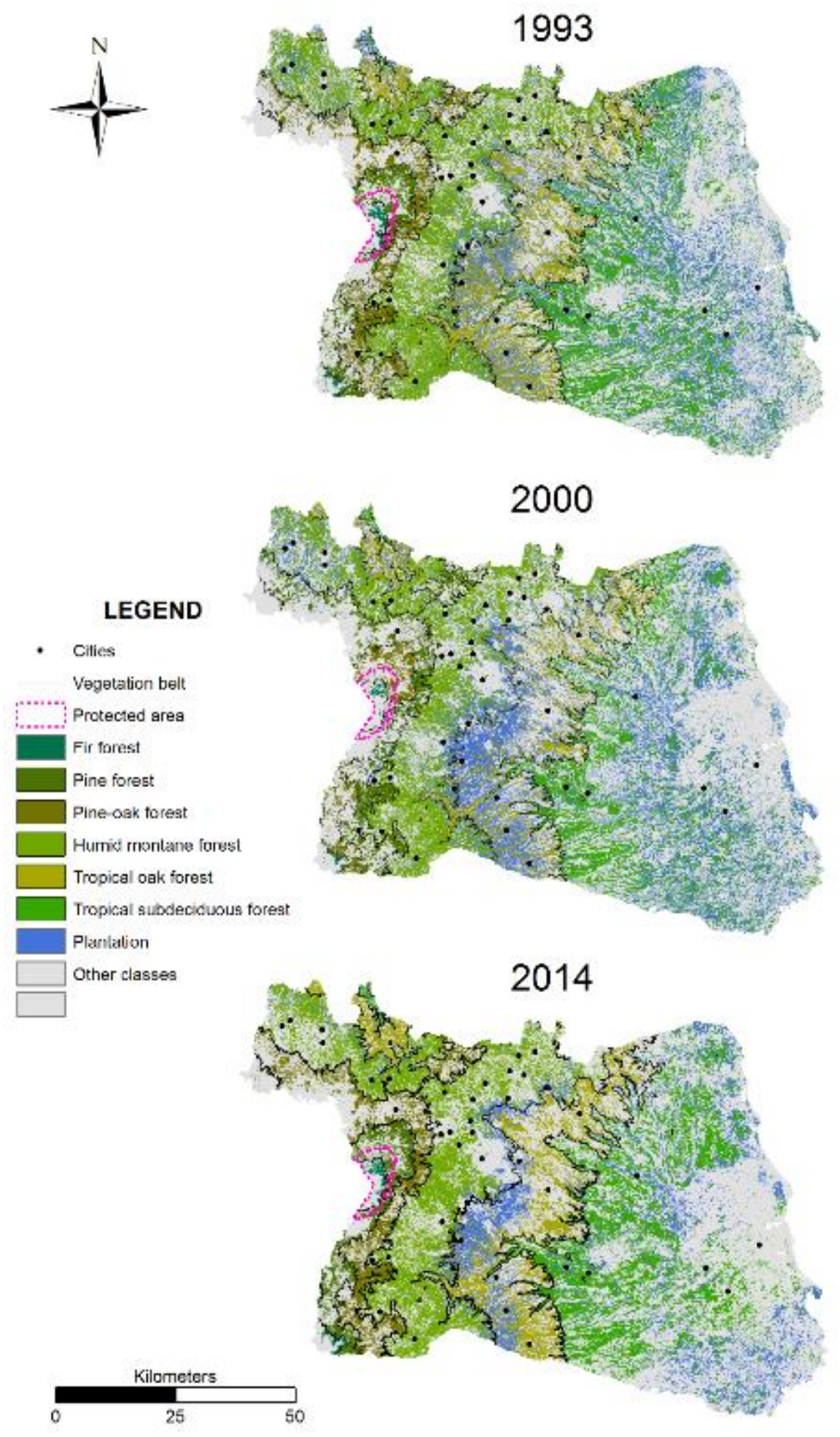

Figure 4.2 Land cover maps for the studied years (1993, 2000 and 2014). The spatial distribution patterns of the land cover types in Central Veracruz, Mexico is shown on the maps. The limits of the protected area are displayed in pink dashed polygons. The continuous lines show the border of each vegetation type. 

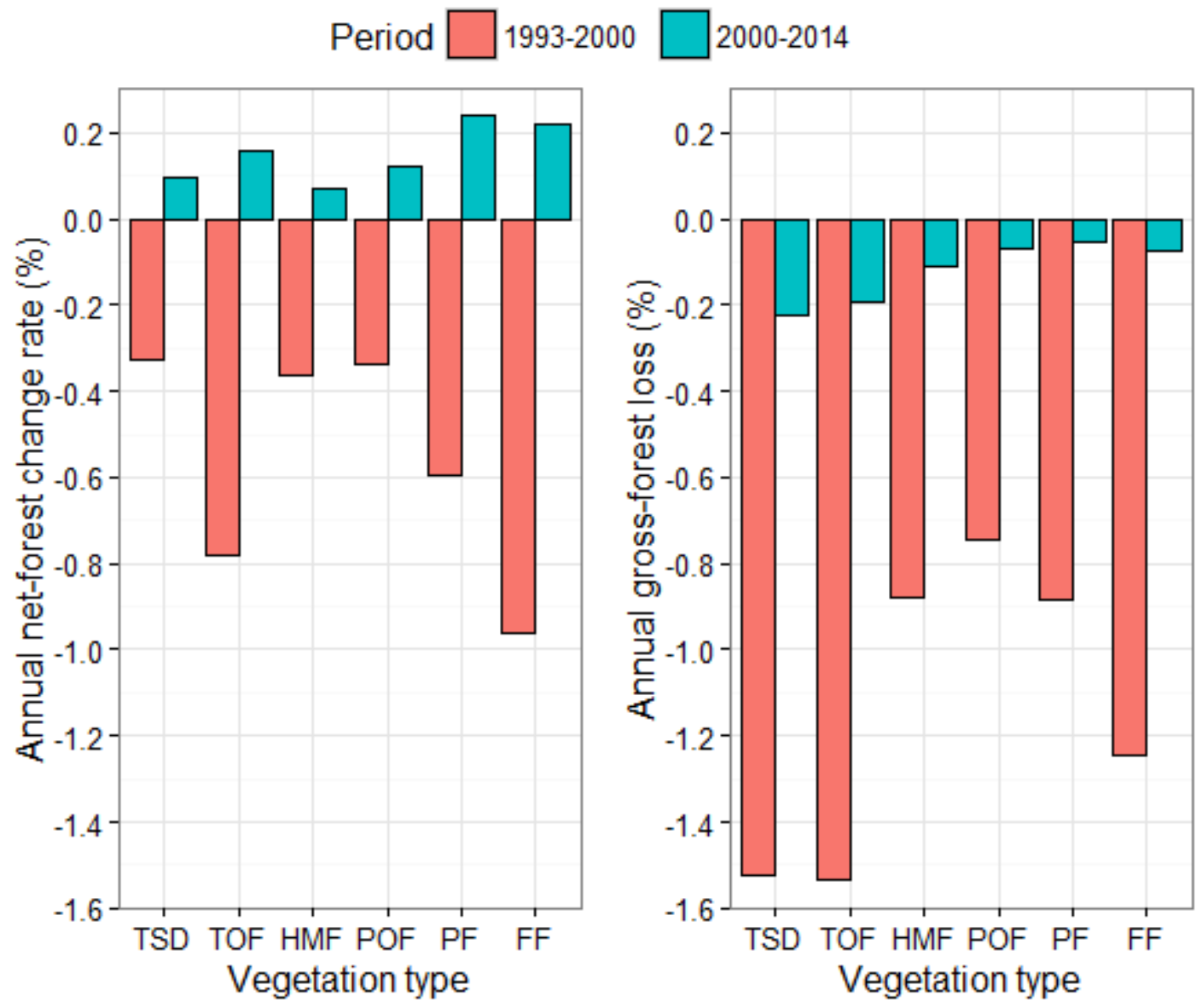

Figure 4.3 Annual net-forest change and gross forest loss rates (\%) in four natural vegetation types in Central Veracruz, Mexico for the periods 1993-2000 and 2000-2013.

During the 21 years of the study period, $271 \mathrm{~km}^{2}$ of the initial 2,586 $\mathrm{km}^{2}$ of natural forest have been converted to plantations, another $592 \mathrm{~km}^{2}$ has been transformed to grasslands, and additional $135 \mathrm{~km}^{2}$ to non-natural covers. Tropical sub-deciduous forest and tropical oak forest were converted to plantations, grassland $(68 \%$ and $53 \%$ of the initial area, respectively), and the fir forest and humid montane forest were converted to non-natural covers (40\% and $12 \%$, respectively) (Table 4.3$)$. 


\subsubsection{Fragmentation patterns}

The entire amount of forest patches increased from 76,983 to 100,831 in 2000 and decreased to 63,273 in 2014 demonstrating an 18\% decrease in relation to the number of fragments existing in 1993 (Fig. 4.4 and Table 4.4). Mean forest fragment size increased from $0.03 \mathrm{~km}^{2}$ in 1993 to $0.04 \mathrm{~km}^{2}$ in 2014 . The patch density decreased from 1,102 to 906 patches per $100 \mathrm{~km}^{2}$ (Table 4.4). The decreasing total edge length and the decreasing mean shape index value indicate decreasing irregularity in the shape of old-growth forest patches and a slightly decrease of vulnerability to edge effects. Considering a buffer region of $300 \mathrm{~m}$, the entire core area of lasting old-growth forest increased by $573 \%$ from 1993 to 2014 to $18 \mathrm{~km}^{2}$ today (Table 4.4 ).

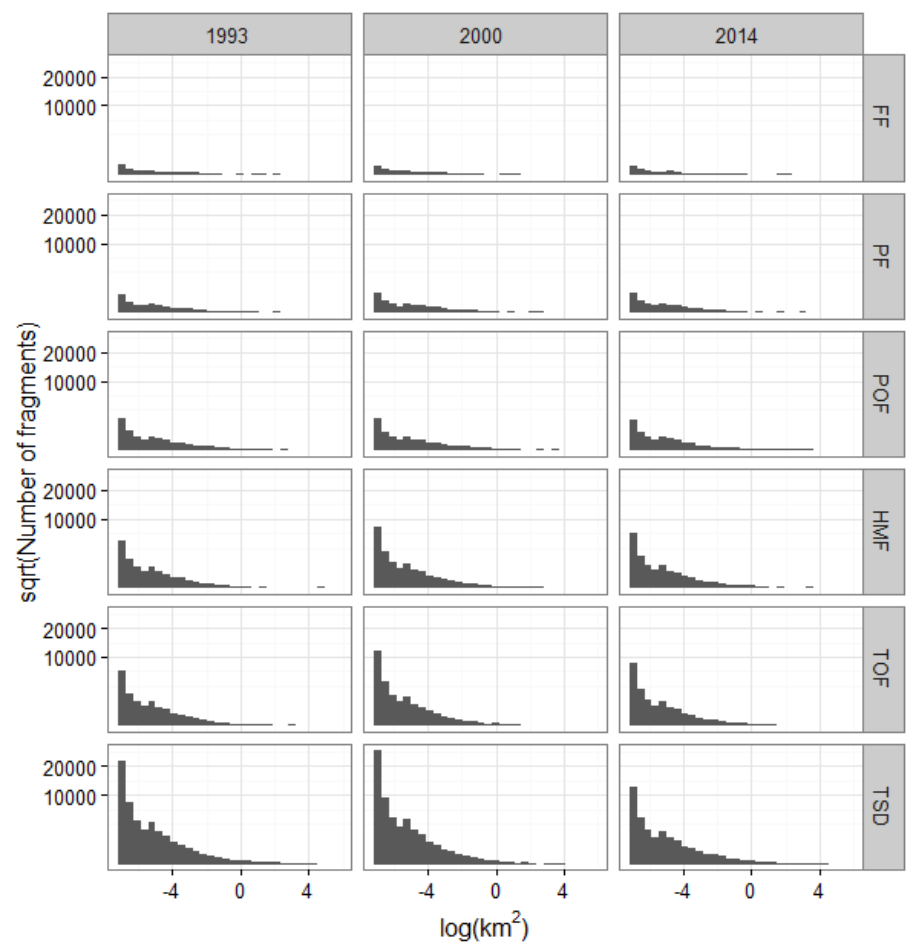

Figure 4.4 Variation of forest fragment size for 1993, 2000 and 2014 at the different vegetation belts $(\mathrm{FF}=$ fir forest, $\mathrm{PF}=$ pine forest, $\mathrm{POF}=$ pine-oak forest, $\mathrm{HMF}=$ humid montane forest, $\mathrm{TOF}=$ tropical oak forest, $T S D=$ tropical sub-deciduous forest). The change in a number of forest fragments is displayed in the figure. The y-axis is the square root of the number of fragments and $x$-axis is the logarithmic area of the patches, we transformed the values in order to normalize the pattern and make it comparable. 
Table 4.4 Variations in the spatial conformation of old-growth forests in Central Veracruz, Mexico throughout the period from 1993 to 2014 . Metrics are: $\mathrm{PA}=$ total area of forest $\left(\mathrm{km}^{2}\right), \mathrm{NP}=\mathrm{number}$ of patches, $\mathrm{PD}=$ patch density (number of patches $/ \mathrm{km}^{2}$ ), $\mathrm{LPI}=$ largest patch index (\%), $\mathrm{ED}=$ edge density $(\mathrm{m} / \mathrm{ha})$, AREA_MN= mean patch size $(\mathrm{ha}), \mathrm{TCA}=$ total forest core area $\left(\mathrm{km}^{2}\right)$ and PROX_MN= mean proximity index ${ }^{b}$.

\begin{tabular}{|c|c|c|c|c|c|c|c|c|c|}
\hline Forest & Year & PA & NP & PD & LPI & ED & AREA_MN & TCA & PROX_MN \\
\hline \multirow[t]{3}{*}{ FF } & 1993 & 21 & 494 & 24 & 40 & 245 & 4.16 & 0.00 & 263 \\
\hline & 2000 & 13 & 463 & 36 & 28 & 310 & 2.77 & 0.00 & 125 \\
\hline & 2014 & 20 & 397 & 20 & 41 & 238 & 4.99 & 0.01 & 404 \\
\hline \multirow[t]{3}{*}{ PF } & 1993 & 121 & 1748 & 14 & 53 & 187 & 6.93 & 1.09 & 1598 \\
\hline & 2000 & 91 & 2082 & 23 & 16 & 240 & 4.35 & 0.38 & 367 \\
\hline & 2014 & 144 & 2144 & 15 & 34 & 186 & 6.74 & 3.06 & 1692 \\
\hline \multirow[t]{3}{*}{ POF } & 1993 & 263 & 5310 & 20 & 15 & 258 & 4.96 & 0.20 & 946 \\
\hline & 2000 & 223 & 4894 & 22 & 15 & 238 & 4.56 & 0.92 & 466 \\
\hline & 2014 & 282 & 4839 & 17 & 14 & 218 & 5.82 & 2.03 & 973 \\
\hline \multirow[t]{3}{*}{ HMF } & 1993 & 852 & 10872 & 13 & 30 & 306 & 7.84 & 0.02 & 14140 \\
\hline & 2000 & 714 & 17013 & 24 & 24 & 282 & 4.19 & 0.79 & 3169 \\
\hline & 2014 & 816 & 13767 & 17 & 29 & 245 & 5.93 & 2.99 & 7924 \\
\hline \multirow[t]{3}{*}{ TOF } & 1993 & 510 & 14819 & 29 & 22 & 427 & 3.44 & 0.00 & 3950 \\
\hline & 2000 & 348 & 24644 & 71 & 5 & 488 & 1.41 & 0.00 & 215 \\
\hline & 2014 & 472 & 17466 & 37 & 13 & 319 & 2.70 & 1.38 & 1264 \\
\hline \multirow[t]{3}{*}{ TSD } & 1993 & 815 & 47524 & 58 & 8 & 457 & 1.71 & 0.00 & 620 \\
\hline & 2000 & 695 & 55517 & 80 & 8 & 481 & 1.25 & 0.00 & 320 \\
\hline & 2014 & 836 & 28027 & 34 & 9 & 291 & 2.98 & 1.97 & 995 \\
\hline
\end{tabular}

a We measured a buffer region of $300 \mathrm{~m}$ length for the calculation of forest core area.

${ }^{b}$ For the calculation of the mean proximity index, we considered a search radius of $300 \mathrm{~m}$ width.

In 2000, it happened that the mean proximity index was reduced due to the fact that the vicinity was less occupied by old-growth forest patches (Table 4.4). 


\subsubsection{Old-growth forest}

We identified $1,100 \mathrm{~km}^{2}$ of forest that had not been changed since 1993. These old-growth forests are located mostly at mid elevations in the transition of humid montane forest and pine-oak forest (Fig. 4.5 and 4.6). There are also small corridors in the tropical oak forest belt located at the ravines (Fig. 4.5 and 4.6). At the extremes of the altitudinal gradient, there are almost no patches of old-growth forest left (Fig. 4.5 and 4.6). The area of the regenerating forest after 2000 is $1,474 \mathrm{~km}^{2}$, which represents $21 \%$ of the total study area and $57 \%$ of the forest area at 2014 (Fig. 4.2 and 4.6).



Figure 4.5 Sites with high conservation value. Fragments of forests without change since 1993. 


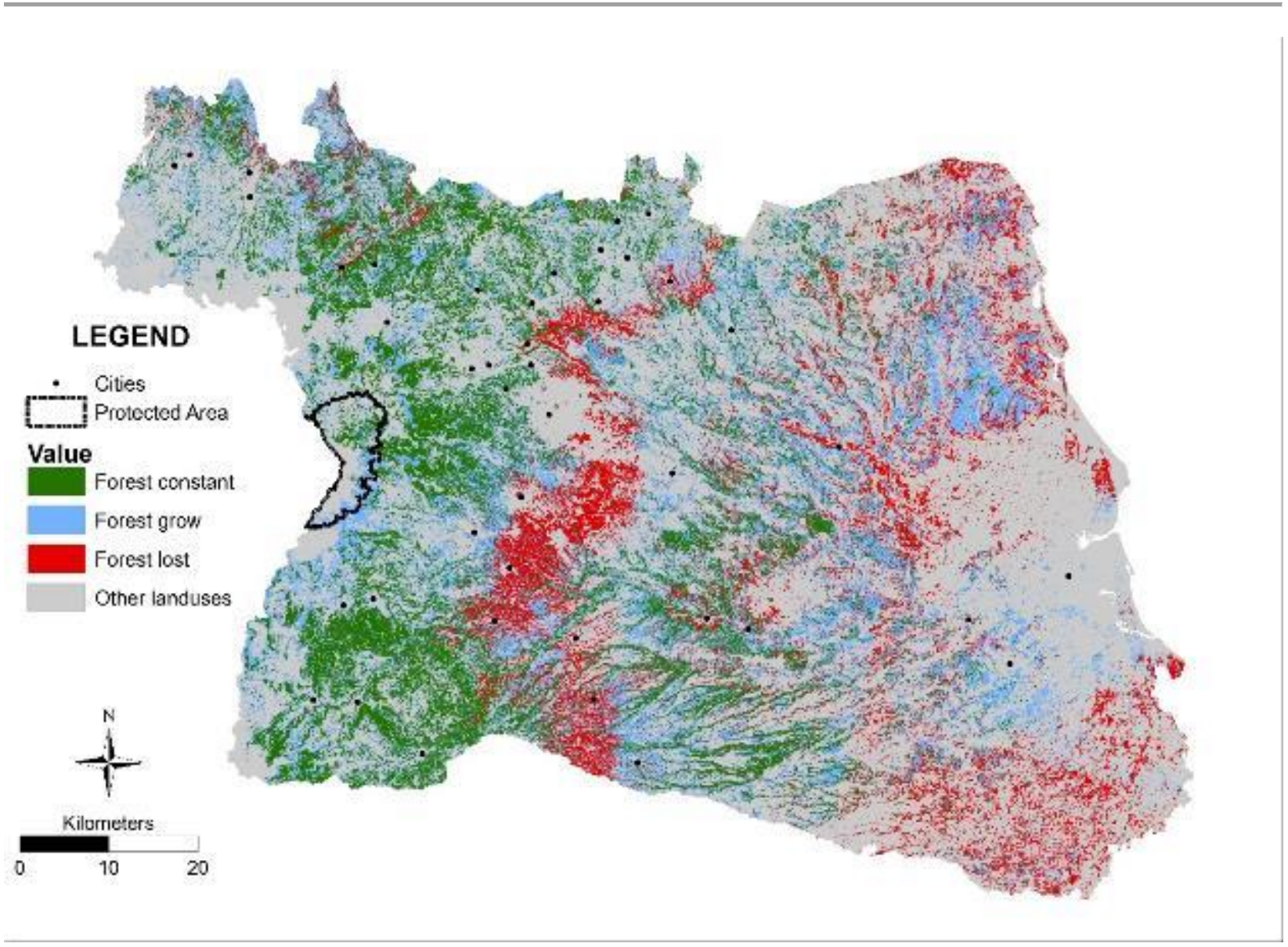

Figure 4.6 Change use analysis. Fragments of forests without change since 1993, forest grow since 1993 and forest loss since 1993.

\subsection{Discussion}

\subsubsection{Deforestation patterns and fragmentation configurations}

The old-growth forests of Central Veracruz have suffered high change rates throughout the most recent twenty years, although in the course of the most recent decade there is a reduction of this process. Throughout the period of 1993 to 2000, the annual net forest change rate $(-0.44 \%)$ was lower compared to the one estimated for the whole country for the same period (-2.02\%) (Masera et al. 1997) and even lower than the rate of Latin America (-2.5\%) (Achard et al. 2002).

The public strategy on land uses of the Mexican government has an important contribution to the transformation of natural forest to other land uses. In the 1990s in Mexico, forest 
deteriorations were related to the application of influential national motivations (e.g. PROCAMPO) by the Secretariat of Agriculture (SAGARPA) since 1994. These programs intended to encourage the establishment of livestock grasslands and agrarian parcels, which were causing the change of forest cover (Klepeis \& Vance 2003). Another example is the forest loss and land degradation encouraged by the Idle Land Law (Ley de tierras ociosas) in the region of Los Tuxtlas, Southern Veracruz (Negrete-Yankelevich et al. 2013). For example, due to the arrival of different colonizers and probable parcel claims, local population could not leave any forest parcel unplanted. In consequence, important portions of forest cover were transformed to pastures and farmland throughout the 1960s and 1970s and unplanted wooded areas were changed. At national (Carabias et al. 2007) and state level (Gonzalez-Montagut 1999), similar arrangements of deforestation produced by legal reforms have been documented.

The accelerated destruction of the regional forest in Central Veracruz is a recent phenomenon. Data on territorial and population growth indicate that the explosion of urban growth soared from the 1960s. According to Marchal \& Palma (1985), this growth was due to migration flows and Xalapa classified as a center of attraction of very high immigration. According to the INEGI (2000), the study area has been extensively used for agriculture and cattle. A substantial stress on old-growth forests is applied by the previous actions and the increase in human population, which has produced the decline of the lasting forests and the vanishing of vegetation cover (López-Barrera et al. 2014).

In addition to the overall reduction of forest area, we found that fragmentation patterns varied considerably between different time periods. In the first period from 1993 to 2000, the constant fragmentation of forest habitats was reflected in the reduction of the dimension of patches and the intensification in amount, irregularity, and isolation of forest patches. The growing isolation of old-growth forest patches due to the replacement by additional land cover types is a consequence of fragmentation. Gustafson and Parker (1994) suggested that a measure of the status of isolation is the mean proximity index. A rise in forest isolation, high amount of loss and degradation of forest extent and a reduction in entire core area was involved in this initial phase of fragmentation. Therefore, the preservation importance of the remaining forest fragments can be affected negatively due 
to i) reduced plant-animal interactions (Tewksbury et al. 2002); ii) decays in vegetation and wildlife populations in remainder forest fragments (Laurance et al. 2002), and iii) reduced pollen movement and genetic diversity (Kwak et al. 1998).

The second period (2000-2014) experienced a slight recovery of forest (0.11\%) (Fig. 6); similarly, (López-Barrera et al. 2014) reported an increase in forest cover $(0.69 \%)$ in the period of 2000-2007 in Central Veracruz. Furthermore, there was an improvement in the connectivity of the landscape as several fragments that were isolated in the former period than were connected. One factor that can explain this recovery is the abandonment of agricultural land due to high rates of emigration (Tuirán 2002), which have recently accelerated in Veracruz State. The NAFTA free-trade arrangements were improved over the last decade (Pascual \& Barbier 2007) augmenting rivalry from the US producers that led to reduced subventions for farming and livestock ranching coupled with the drop in international coffee prices (Hausermann \& Eakin 2008) caused many farmers to abandon agrarian lifestyle in the study area.

In our study area, the deforestation and forest fragmentation are concentrated at the tropical semi-deciduous forest and tropical oak forest (Fig. 4.2 and 4.3), which are the vegetation belts at lowest elevations and with flat areas. These areas have been under human pressure since pre-Hispanic times (Sluyter \& Siemens 1992). After the Spanish conquest, these areas were used for cattle and crops (Cortés et al. 2013). In the next centuries, they were extensively used to a degree that almost destroyed the original vegetation because of overexploitation and conversion to agricultural land (GómezPompa \& Castillo-Campos 2010). López-Barrera et al. (2014) explored the forest cover a few kilometers south of our study area, where they found that most deforestation happened more than a century ago and generalized rates of forest loss between 1973 vs. $2000(-2.02 \%)$ and 1973 vs. $2007(-0.59)$ were moderate to low. However, among different time periods, rates of forest loss varied significantly with minor reforestation (1.55\%) during the period of $1973-1990$, followed by a noticeable deterioration $(-8.08 \%)$ in the period of 1990-2000, and lastly an obvious rise in forest cover (4.92\%) in the period of 2000-2007 that matches with tendencies in population migration and modifications in public policy. They also found that the main factors that promote forest alteration were the 
hydraulic infrastructure for yield irrigation, livestock grasslands and the nearness to mild hills.

\subsubsection{Value of old-growth forests}

It is important to distinguish between the value of the old-growth forest and secondary forests due to the ecological value of old-growth forests. In our study area, we found that deforestation has reduced the size of old-growth forests (Fig. 4.2 and 4.3). We found that the second period of our study (2000-2014) was characterized by a regrowth of new forests (Fig. 4.2 and 4.3) and an increase in the connectivity of the patches (Table 4.4). However, it is important to notice that those are young secondary forests, which are at most 14 years old and do not preserve the structure, biodiversity, and function of oldgrowth forests (Martin et al. 2013)).

According to Williams-Linera et al. (2016), there is a potential that secondary forest regrowth to old-growth forest in richness and diversity of trees in 15 and 25 years. Respectively, the average canopy height recovers after 35 years, and maximum height, basal area and density of trees after 80 years from clear cut logging. According to their results, active restoration suggests that the successional process on recently abandoned pastures and secondary forests (10 years), can be accelerated by the introduction of intermediate and late succession tree species.

There is only one formally protected area in our study area (National park "Cofre de Perote) that comprises only about $2 \%$ of the total surface (about $117 \mathrm{~km}^{2}$, Fig. 4.2), and of this only $57 \%$ corresponds to core areas in which human activity is restricted (GarcíaRomero et al. 2010). Besides, this park only protects two vegetation types (pine forest and fir forest), which are the vegetation belts with fewest species in our study area (CarvajalHernández \& Krömer 2015; Gómez-Díaz et al. accepted) (Gómez-Díaz et al. in review).

According to the models of island biogeography (MacArthur \& Wilson 1976), 50\% of species can be lost only with a decrease to $10 \%$ of the original area. Therefore, preservation actions are an urgent task in the study area as indicate by our main results of forest gross loss. Furthermore, an extra issue to be considered is the extreme 
fragmentation of these forests. The remaining original forest area would possibly constitute minor vegetation islands detached from each other (Fig. 4.5), a phenomenon that may have important consequences at the genetic, ecological and ecosystem functioning levels (Naeem et al. 2001). This condition is mainly perturbing since Veracruz is one of the most important states in Mexico regarding total plant species diversity and its flora is characterized by a high level of endemism (Gómez-Pompa et al. 2010, Villaseñor 2016).

According to Tscharntke et al. (2012), the capacity to re-organize an ecosystem service after disturbance is related to the landscape complexity. The species pool and the level of biological control is improved due to the increasing landscape complexity, as in the second period of our study (2000-2014), therefore after a disturbance, there is a rapid recovery in biological diversity. More species are maintained in complex landscapes, mostly due to the higher beta diversity, but also due to higher alpha diversity (Tscharntke et al. 2012).

Discriminating amongst the effects of habitat fragmentation versus degradation is an extra challenge in a landscape such as Central Veracruz since both processes may act together synergistically and often co-occur with adverse influences on the fauna and flora existing in fragments of natural vegetation. In this area, a high beta diversity among patches of the diverse forest has been detected (Gómez-Díaz et al. n.d., Carvajal-Hernández \& Krömer 2015)(Gómez-Díaz et al. in review), which makes finding a reference forest for such comparisons particularly challenging.

Williams-Linera et al. (2007) proposed an enlargement of protected areas in Central Veracruz, especially where remnants of HMF old-growth forests can be found. Finally, on January 5, 2015, this area was decreed as a Natural Protected Area (ANP) under the category of Multifunctional Biological Corridor in seven fragments with environmental value, located in the municipalities of Xalapa, Banderilla, Coatepec, Emiliano Zapata and Tlalnelhuayocan (Gobierno del Estado de Veracruz 2015). The ANP is called "Archipelago of forests in the Capital Region of the State of Veracruz" and has seven fragments with a total area of $55.8 \mathrm{~km}^{2}$. This archipelago reserve should promote the conservation and restoration of biological landscape corridors connecting forest fragments through riparian 
forests, and biodiversity-friendly agricultural land, such as shade coffee plantations. Conservation has to be made compatible with sustainable economic activities and the preservation of the ecological environmental services that benefit the people living in the region.

\subsection{Conclusions}

In biologically diverse zones like Central Veracruz a better consciousness of the patterns, dynamics and spatial degree of forest fragmentation and deforestation is desirable. According to our study, this area demands an urgent attention on preservation initiatives because only $2 \%$ of the surface extent is below federal protection and $0.8 \%$ is under State protection due to the new reserve. It is important to protect the larger forest areas left in the pine-oak forest belt particularly as new construction plans will rapidly destroy the forest. The pressures to most of the studied environments are possibly even bigger than expected from our land use trajectory, for example through growing atmospheric nutrient deposition and upcoming climatic change.

As an outlook, we can expect in the future for Veracruz a recovery and regrowth of some areas if the current deforestation rates continue. It is important to plan and design corridors that connect the old-growth forest with the young forest in order to promote the protection and development of biodiversity. It is important to preserve the young forest fragments because it takes at least 80 years to recover from disturbance. If special efforts will be done in protecting the forests of Central Veracruz it will take a lot of time on its cover will reach the same amount as 23 years ago.

\subsection{Acknowledgments}

We want to thank C. Carvajal-Hernández, M. Ruiz-Gómez, F. Calixto-Benites, C. AlavezTadeo and V. Guzmán-Jacob fieldwork assistance. The first author acknowledges support from the Consejo Nacional de Ciencia y Tecnología (CONACyT 311672) and the 
Deutscher Akademischer Austauschdienst (DAAD 91549681) for this research, which is part of his Ph.D. thesis.

\subsection{Appendix}

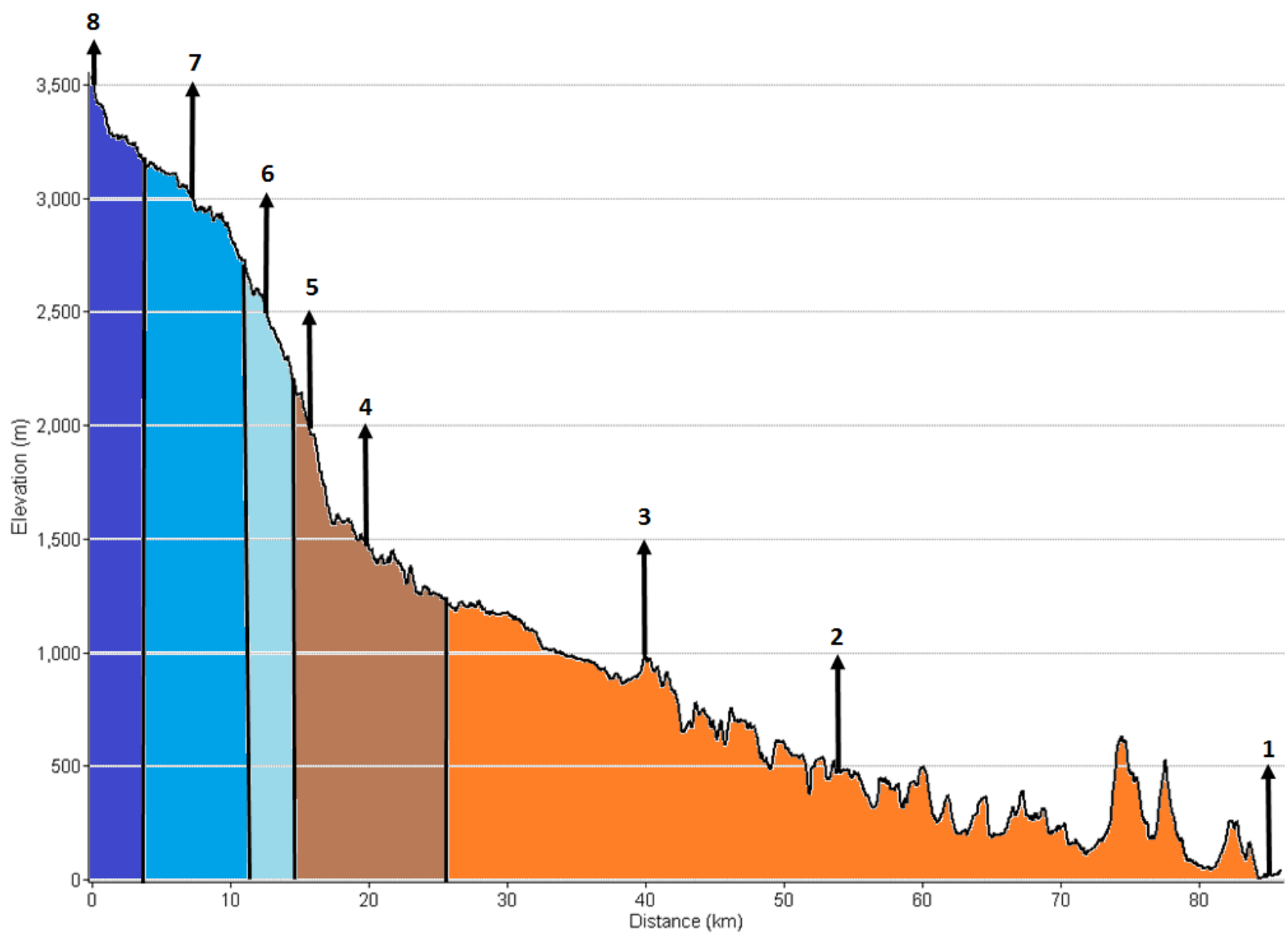

Appendix 4.1 Elevational gradient. Study sites and climate zones according to Lauer (Lauer 1973) are shown (dark blue= "tierra helada", blue= "tierra fria II", light blue= "tierra fria I", brown= "tierra templada" and orange="tierra cálida". 
Appendix 4.2 Confusion matrix achieved from the accuracy assessment of the land cover map of Central Veracruz, Mexico. Other classes (arable, grassland, open country, coast and hydro).

\section{REFERENCE}

\begin{tabular}{|c|c|c|c|c|c|c|c|}
\hline \multirow[b]{2}{*}{ Year } & \multirow[b]{2}{*}{ Classified } & \multicolumn{5}{|c|}{ Other } & \multirow{2}{*}{$\begin{array}{c}\text { User's } \\
\text { accuracy (\%) }\end{array}$} \\
\hline & & Forest & Plantations & classes & Build-up & Total & \\
\hline \multirow[t]{8}{*}{1993} & Forest & 59 & 16 & 6 & 3 & 84 & 70.24 \\
\hline & Plantations & 6 & 20 & 10 & 5 & 41 & 48.78 \\
\hline & Other classes & 1 & 8 & 245 & 8 & 262 & 93.51 \\
\hline & Build-up & 1 & 5 & 10 & 49 & 65 & 75.38 \\
\hline & Total & 67 & 49 & 271 & 65 & 452 & \\
\hline & Producer's & & & & & & \\
\hline & accuracy (\%) & 88.06 & 40.82 & 90.41 & 75.38 & & \\
\hline & Overall accuracy & 82.52 & & & & & \\
\hline \multirow[t]{8}{*}{2000} & Forest & 52 & 17 & 2 & 0 & 71 & 73.24 \\
\hline & Plantations & 8 & 43 & 2 & 1 & 54 & 79.63 \\
\hline & Other classes & 3 & 0 & 226 & 5 & 234 & 96.58 \\
\hline & Build-up & 0 & 0 & 7 & 41 & 48 & 85.42 \\
\hline & Total & 63 & 60 & 237 & 47 & 407 & \\
\hline & Producer's & & & & & & \\
\hline & accuracy (\%) & 82.54 & 71.67 & 95.36 & 87.23 & & \\
\hline & Overall accuracy & 88.94 & & & & & \\
\hline \multirow[t]{8}{*}{2014} & Forest & 83 & 17 & 2 & 1 & 103 & 80.58 \\
\hline & Plantations & 4 & 41 & 1 & 5 & 51 & 80.39 \\
\hline & Other classes & 2 & 10 & 234 & 15 & 261 & 89.66 \\
\hline & Build-up & 2 & 5 & 11 & 45 & 63 & 71.43 \\
\hline & Total & 91 & 73 & 248 & 66 & 478 & \\
\hline & Producer's & & & & & & \\
\hline & accuracy (\%) & 91.21 & 56.16 & 94.35 & 68.18 & & \\
\hline & Overall accuracy & 84.31 & & & & & \\
\hline
\end{tabular}




\section{CHAPTER 5: Synthesis}

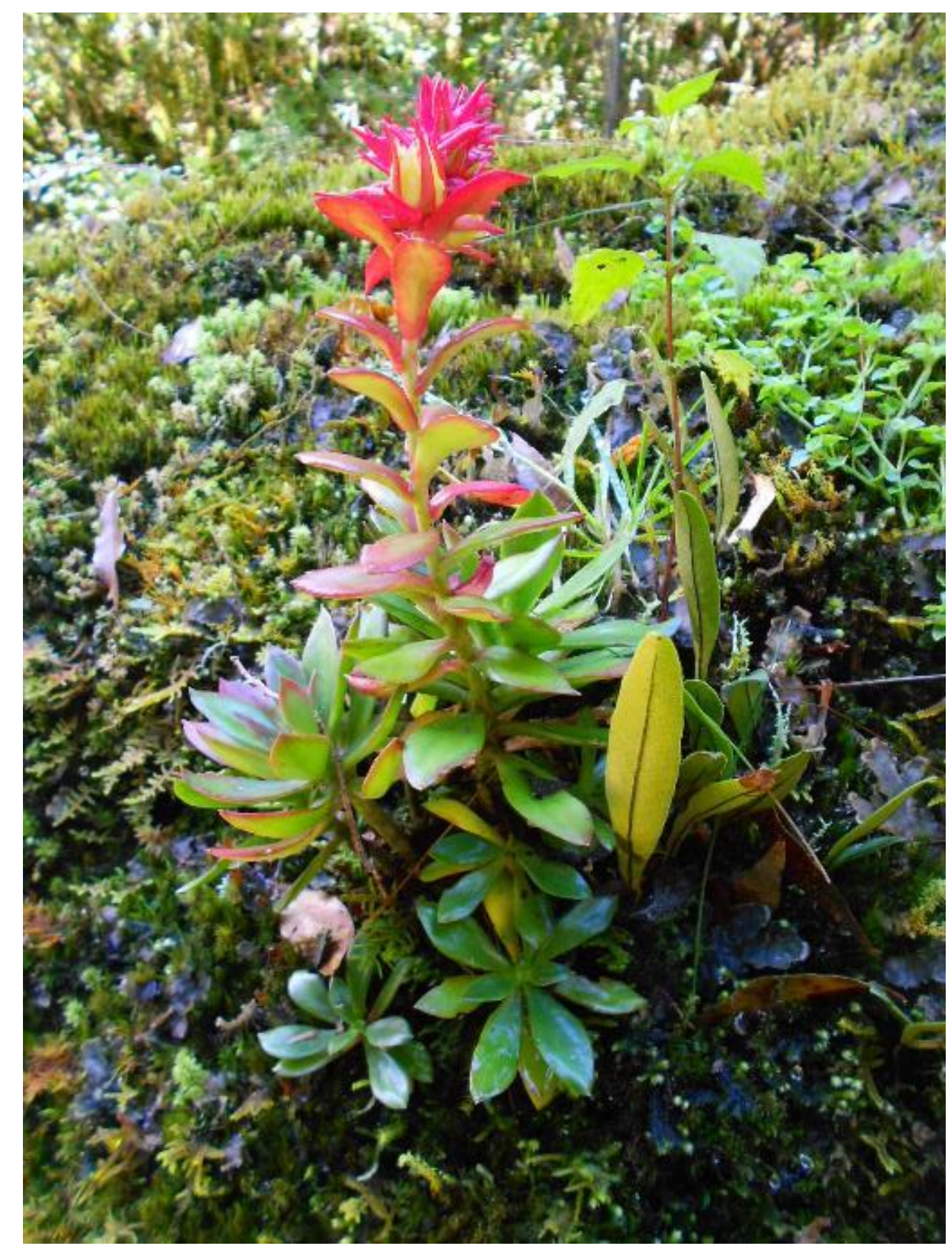

Echeveria rosea Lindl. in humid montane azonal forest in El Encinal, Acajete, Veracruz, Mexico. 


\section{Synthesis}

At present, existing old-growth forests are becoming increasingly affected by forest use intensity and forest fragmentation. In order to investigate the effects that these pressures induce on herbaceous angiosperms, different vegetation types and habitats along an elevational gradient in Central Veracruz, Mexico were studied. Besides the influence of elevation, varying degrees of land use intensity were analysed, focusing on species richness, distribution and composition of herbaceous angiosperms (Chapter 2), their patterns of alpha, beta and gamma diversity (Chapter 3) as well as deforestation and fragmentation patterns of the different vegetation types (Chapter 4). Overall, this study pretends to contribute to the understanding of how forest use intensity affects a specific functional guild of plants and the old-growth forests in general.

\subsection{Objective 1: Evaluation of distributional and diversity patterns of herbaceous angiosperms along an elevational gradient}

In the area of the studied gradient, located in the tropical zone of Mexico, we found a moderate diversity of herbaceous angiosperms (Chapter 2), as the 264 reported species represent $5.7 \%$ of species of Veracruz' herbaceous angiosperm flora and about $1.8 \%$ of Mexico (Villaseñor 2003, 2004, 2016, Espejo-Serna et al. 2004, Villaseñor et al. 2007, Villaseñor \& Ortíz 2014). This species richness is considered as moderate because the sampled area represents only $0.0001 \%$ of the total area of the state of Veracruz. The observed species richness, including endemic elements, highlights the importance of the area for plant conservation and shows the need to continue with floristic studies in order to actualize and complete the inventories of the existing biodiversity in specific regions (Magaña \& Villaseñor 2002).

The elevational sites with highest species richness of herbaceous angiosperms were $2,500 \mathrm{~m} \mathrm{(76)}$ and $1,500 \mathrm{~m}$ (52), which is a diversity pattern similar to other elevational gradients realized in other latitudes of the Neotropics, where the highest diversity was found at mid-elevations (Vázquez \& Givnish 1998, Nogués-Bravo et al. 2008). 
The climate gradient along the elevational gradient also shows the registered pattern of these studies, with a linear decrease in the temperature as the elevation increases. In the case of light intensity, this increases with elevation due to is more intense solar radiation in the higher areas (Carvajal-Hernández 2016). However, in this gradient, the mean annual temperature values are different compared with other zones of the Neotropics (Lippok et al. 2014), with lower values at the high areas of the gradient due to snow in winter and higher values in the lowlands due to prolonged drought periods. The harsh climatic conditions at the extremes of the studied gradient are considered as limiting factors for many species, which entails to a lower diversity.

The highest species richness was concentrated at higher elevations (2500-3000 m), which corresponds to the distribution area of the pine-oak forest and pine forest, while the number of species decreases at the extremes in more than $80 \%$ (Chapter 2 ). A humpshaped pattern has been found in different groups of vascular plants along tropical elevational gradients, such as ferns (Salazar et al. 2015), terrestrial herbs (Willinghöfer et al. 2011) and shrubs (Chawla et al. 2008). In our study, the highest species richness was found at 2,500 m, which has been also reported from Ecuador for all endemic vascular plant species, endemic species of Acanthaceae, Asteraceae, Lamiaceae, Piperaceae and Scrophulariaceae (Kessler 2002), and for liverworts in the Northern Andes (Wolf 1993). However, our results show differences in previous findings as the peak in species richness shifted towards higher, instead of mid-elevations (Kluge \& Kessler 2006). The concentration of species richness in this area corresponds to the record of moderate temperatures and high environmental humidity, which have been shown to favor the establishment of herbaceous angiosperms (Hawkins et al. 2011). Notably, the species richness recorded in azonal vegetation (ravines or riparian vegetation), was higher than in old-growth forest in two elevational belts, which indicates that these specific areas are important reservoirs of herbaceous angiosperms diversity.

Due to the large elevational range of the study gradient, it was not possible to compare it completely with similar works realized with herbs in Mexico. However, when comparing it by sections, it was observed that the richness we found was lower (Vazquez et al. 1995, Vázquez \& Givnish 1998, Castillo-Campos et al. 2007, García-Franco et al. 2008), 
coincident (Encina-Domínguez et al. 2007) or even higher (Krömer et al. 2013, PalaciosWassenaar et al. 2014). When comparing the richness of our study with other regions near to the Equator, our study area has lower values than in those areas. Thus, it is corroborated that the diversity of herbs decreases slightly along a latitudinal gradient from the Equator to the poles (Hawkins et al. 2011), as for example the tropical area in Mexico.

\subsection{Objective 2: Evaluation of forest use intensity effect on the patterns of richness and composition of herb species}

The forest use intensity does not affect the species richness of herbaceous angiosperms in a direct way since there was no loss of herb diversity caused by land use change. However, it affects the floristic composition (Chapter 3 ). Though, the degree of community affectation does not occur equally along the altitudinal gradient and also depends on the intensity of the forest use. For example, at low and high elevations there is a slight increase in alpha diversity of herbs due to the effect of forest use intensity, whereas the opposite happens at mid elevations. It is interesting to note that at both extremes of the gradient (50 and $3500 \mathrm{~m}$ ), there is no shift on alpha diversity between habitats.

The lack of a detectable net-change in alpha diversity might indicate that the level of forest use intensity is still moderate and that herbs are better adapted to changes in the environment with a profit from better light conditions in degraded or secondary habitats. The Asteraceae and Poaceae were the families with the greatest increase in species richness in relation to land use intensity, consequently, it has been demonstrated that they are adapted to high light incidence and drought (De Moraes et al. 2016).

In terms of beta diversity, the middle part of the elevational gradient presented the highest species turnover (with replacement rates ranging from $60 \%$ to $78 \%$ according to the Sørensen index) (Fig. 3.4); thus, this area requires special attention for its conservation. The values of beta diversity are higher when a forest habitat is transformed into another one than within the same forest. The species composition is highly modified when the oldgrowth forests are transformed into secondary forests, especially at mid-elevations. This is because forest degradation causes a higher heterogeneity of environmental conditions 
(Warren et al. 2007), which leads to higher competition between species adapted to disturbance and old-growth forest species (Schultz \& Dibble 2012).

The values of alfa and beta diversity present along the land use intensity gradient are related with conditions in the microclimate. Carvajal-Hernández (2016) corroborated in the same plots that when there is an anthropogenic disturbance, the clearings in the canopy and the radiation towards the interior of the undergrowth increase. This situation influences directly the microclimatic conditions, observing an increase in the incidence of light and temperature, as well as a decrease in relative humidity (Scatena et al. 2005). In general terms, there is an increase of $0.6^{\circ} \mathrm{C}$ in mean daily temperature (CarvajalHernández 2016), which might be related to a high turnover of species (Chapter 3 ). These changes are more notable in the vegetation types located at mid-elevations of the gradient (humid montane forest and pine-oak forest). Such situation is alarming due to the fact that those areas along the elevational gradient are under high anthropogenic pressure (CONABIO 2010). Also, there we found two endemic species to Veracruz, which corroborates the marked specificity of conditions that require most of the sensitive species of herbaceous angiosperms (Chapter 3 ).

\subsection{Objective 3: Analysis of the current conservation status of forest fragments in the study area}

The analysis of deforestation in Central Veracruz, Mexico revealed that almost $57 \%$ of the original natural cover disappeared since 1993 at an annual deforestation rate of $-0.44 \%$ for the period of $1993-2000$ followed by a reforestation rate of $0.11 \%$ for the period of 2000-2014, showing a marked or slight decrease of deforestation during the last fourteen years. However, when it was considered the annual gross forest loss rate the perspective changes because in the first period the rate was $-1.17 \%$ and in the second period, the rate was reduced to $-0.14 \%$ (Chapter 4 ). Even with this decrease in the deforestation and gross forest loss rates, Central Veracruz has actually one of the highest deforestation rates in Mexico together with the seasonal tropical forests of Southern Yucatán (Ramírez-Delgado et al. 2014), Selva Maya region (Simbangala \& Cámara 2016) and Sierra Madre de Chiapas (Cortina-Villar et al. 2012). In the study area, the deforestation is mainly 
concentrated at low elevations where tropical semi-deciduous forest and tropical oak forest are the two vegetation types that exhibit the highest rates of conversion. Most of the human settlements and productive activities on the Eastern slopes of Cofre de Perote are located in the tropical semi-deciduous forest and humid montane forest close to main rivers and roads, indicating that accessibility is one of the main drivers of deforestation in this zone. In the case of a tropical oak forest, which is mainly located in the humid and warm valleys, the patterns of deforestation are more diffuse because major agricultural activities date back to the colonial era. Although, the rates of deforestation of the humid montane forest and pine-oak forest are less important compared with the other vegetation types, about $1 \%$ of their area disappeared every year since 1993. This is important to emphasize because the largest well-preserved remnants of humid montane forest and pine-oak forest in the state are located in Central Veracruz (Gillespie et al. 2012). Here, the forests are being degraded and converted to pastures which are common all over the country but particularly in this region most soils are of low fertility. These pastures are not very productive with the consequence that the remaining forest is being cleared progressively (Poore 2013).

Like deforestation, the fragmentation process has also reduced in the region where the number of forest fragments has decreased by $18 \%$ compared with the number of fragments registered in 1993, although it is still a high number of small fragments $(63,273)$. Actually, the regional landscape is characterized by few large fragments most of which are without protection and many patches of less than $1 \mathrm{~km}^{2}$. Additionally to the decrease of forest patch size, it was also observed that separation grows between patches by $15 \%$ and a decrease in the regularity of patch shapes (Chapter 4$)$. The current composition and configuration of Central Veracruz' landscape could have a direct influence on its ecological functionality jeopardizing the availability of viable populations, species richness and the high biodiversity that characterizes this area (Fahrig 2003).

Both processes, deforestation, and fragmentation are the results of human pressure on natural habitats. In Central Veracruz, the levels of human pressure have increased since 1993, but the increase is more noticeable in the mid- and low elevations. This is because at mid-elevations are located some localities that were least accessible and populated 
areas until the late 1960s when the government constructed several connecting roads and highways. Since then, human density and human activities have increased in this area. Despite this, it still has some of the largest forest fragments without modification since 1993, especially on the Southwestern slopes of Cofre de Perote at the border with the state of Puebla (Chapter 4).

An important finding of this investigation is how human impact differentially influences the natural vegetation types. For example, forest cover was mainly transformed into arable and grassland in all vegetation types with the exception of fir forest, where the forest was mainly transformed into no vegetation. As mentioned by Ellis \& Ramankutty (2008) it is essential to propose more effective conservation plans to recognize the different patterns and drivers that promote transformation.

\subsection{Overall conclusions}

The current study demonstrates that alpha diversity of herbaceous angiosperms does not necessarily decrease with increasing forest use intensity (Chapter 3 ). However, values of beta diversity show that there is a high species turnover due to forest use intensity.

In terms of diversity along the elevational gradient, we found high values of beta diversity (which indicates a high environmental heterogeneity) when different elevations were compared, even if these are contiguous or even if they share the same vegetation type (Chapter 3). This situation highlights the vulnerability of herbaceous angiosperms adapted to old-growth forests and requires to reconsider the conservation efforts in the study area. It is preferable to focus the efforts in preserve heterogeneous systems that include a mosaic of different vegetation types (Chapter 4). The high number of species adapted to azonal areas (ravines and riparian forests) highlights also the importance of this vegetation type as a reservoir of native herbaceous angiosperms. Therefore, the conservation of fragments of those environments in Central Veracruz should be considered in future conservation plans (Chapter 2).

As in the mid-elevation ecosystems is concentrated the highest diversity of species and in those environments, the climatic contrast caused by the anthropogenic disturbance is 
more accentuated, which is an indication that these are the most vulnerable ecosystems for the conservation of native herbaceous angiosperms. Similarly, most of the natural forests present along the studied elevational gradient are at risk of disappearing due to the existing anthropogenic pressures (Chapter 4).

The results and findings described in the different chapters of this dissertation add new information related to the poor knowledge on herbaceous angiosperms along gradients of elevation and land use intensity so far available for Mexico, especially for Veracruz. However, additional studies are needed to understand better how the environmental conditions or territorial dynamics influence the persistence of herbaceous angiosperms in the long term. For example, we need to understand which abiotic factors (e.g. microclimate or soil) are influencing the observed diversity patterns, also how the highly fragmented landscape in Central Veracruz is influencing the population dynamics of native herb species. Here we describe the patterns of alpha, beta, and gamma diversity, but it is necessary to generate more information about the factors that are affecting each of these patterns.

There is information about factors (e.g. paedogenesis, latitude, nutrient availability) that promote alpha diversity in many other taxa (e.g. trees, herbivores, soil microbes) but information about factors promoting alpha or beta diversity of herbs is still insufficient. Besides, more research about the concordance of alpha and beta diversity patterns in different taxa would be helpful to understand the potential of using biodiversity surrogates (e.g. endemic plant species).

It is important to remark that a lot of data on soil properties, microclimatic and spatial information has been generated, which is going to be used in further analyses:

- To understand how soil and microclimate influence the patterns of alpha and beta diversity of herbaceous angiosperms along the elevational gradient.

- To create species distribution models in order to understand how climate change is going to influence the patterns of alpha and beta diversity.

- To describe the immediate and underlying causes of deforestation. 


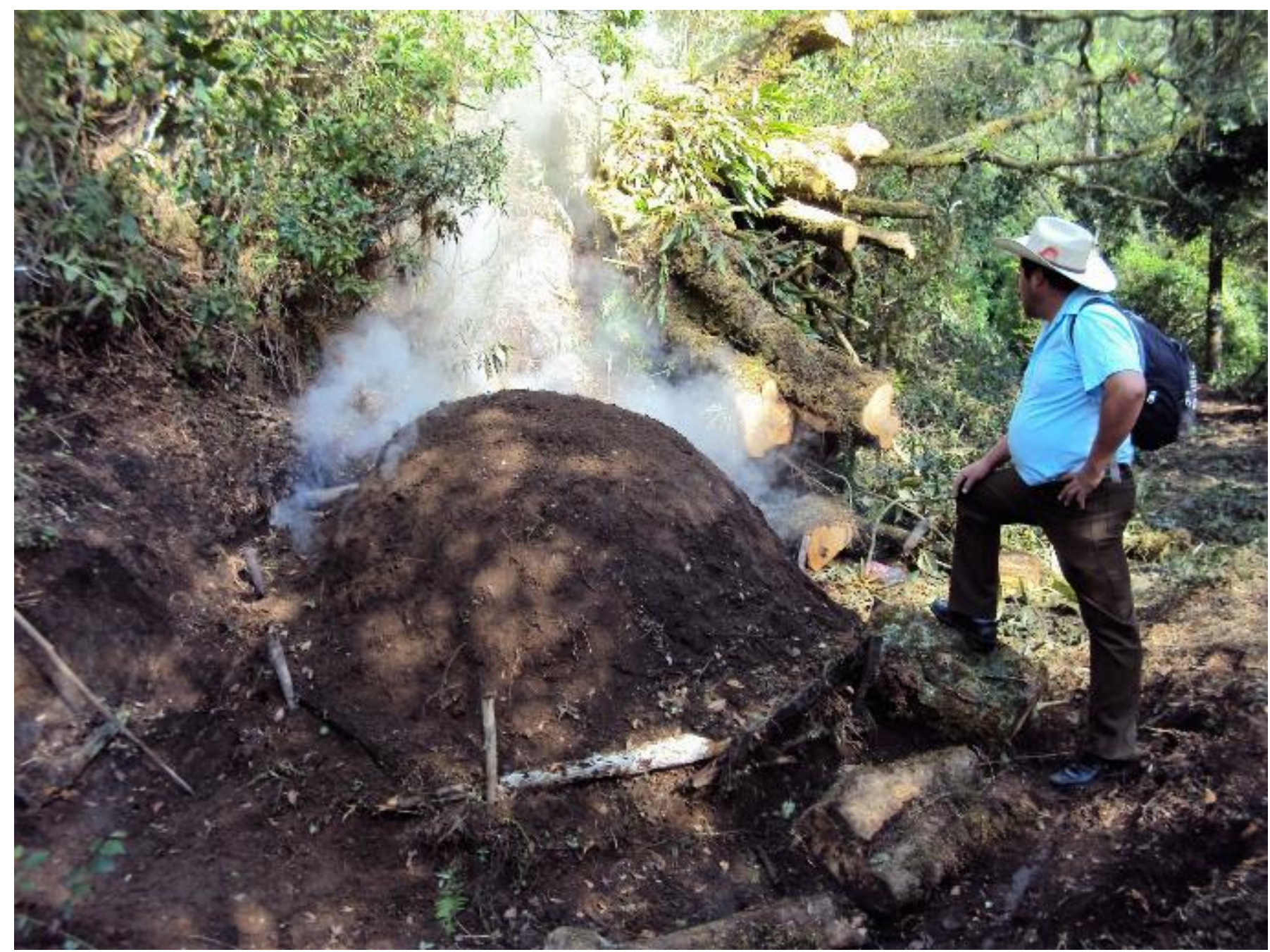

Deforestation for charcoal production at the humid montane forest in Los Capulines, Tlalnelhuayocan, Mexico at $1500 \mathrm{~m}$. 


\section{Bibliography}

Abou Rajab YJM. 2016. Shade trees in cacao agroforestry systems: influence on roots and net primary production. PhD. Thesis, Georg-August-Universität Göttingen.

Achard F, Eva HD, Stibig H-J, Mayaux P, Gallego J, Richards T, Malingreau J-P. 2002. Determination of deforestation rates of the world's humid tropical forests. Science. 297: 999-1002. DOI: 10.1126/science.1070656

Aide TM, Clark ML, Grau HR, López-Carr D, Levy MA, Redo D, Bonilla-Moheno M, Riner G, Andrade-Núñez MJ, Muñiz M. 2013. Deforestation and reforestation of Latin America and the Caribbean (2001-2010). Biotropica. 45: 262-271. DOI: 10.1111/j.1744-7429.2012.00908.x

Akhtar N, Bergmeier E. 2015. Species richness, alpha and beta diversity of trees, shrubs and herbaceous plants in the woodlands of swat, Pakistan. Pakistan Journal of Botany. 47: 2017-2113.

Ali M. 2013. Genetic architecture of species level differences in Begonia Section Gireoudia. Ph.D. Thesis, University of Edinburgh.

Anderson MJ, Ellingsen KE, McArdle BH. 2006. Multivariate dispersion as a measure of beta diversity. Ecology letters. 9: 683-93. DOI: 10.1111/j.1461-0248.2006.00926.x

Andrén H. 1994. Effects of habitat fragmentation on birds and mammals in landscapes with different proportions of suitable habitat: a review. Oikos. 71: 355-366. DOI: $10.2307 / 3545823$

Armenta-Montero S, Carvajal-Hernández CI, Ellis EA, Krömer T. 2015. Distribution and conservation status of Phlegmariurus (Lycopodiaceae ) in the state of Veracruz, Mexico. Tropical Conservation Science. 8: 114-137.

Baccini A, Goetz SJ, Walker WS, Laporte NT, Sun M, Sulla-Menashe D, Hackler J, Beck PSA, Dubayah R, Friedl MA, Samanta S, Houghton RA. 2012. Estimated carbon dioxide emissions from tropical deforestation improved by carbon-density maps. Nature Climate Change. 2: 182-185. DOI: 10.1038/nclimate1354 
Barlow J, Gardner T. 2007. Quantifying the biodiversity value of tropical primary, secondary, and plantation forests. Proceedings of the National Academy of Sciences of the United States of America. 104: 18555-18560.

Barsimantov J, Kendall J. 2012. Community forestry, common property, and deforestation in eight Mexican states. The Journal of Environment \& Development. 21: 414-437. DOI: $10.1177 / 1070496512447249$

Becker A, Körner C, Brun J, Guisan A, Tappeiner U. 2007. Ecological and land use studies along elevational gradients. Mountain Research and Development. 27: 58-65. DOI: 10.1659/0276-4741(2007)27[58:EALUSA]2.0.CO;2

Benton T, Vickery J, Wilson J. 2003. Farmland biodiversity: is habitat heterogeneity the key? Trends in Ecology and Evolution. 18: 182-188. DOI: http://dx.doi.org.ep.fjernadgang.kb.dk/10.1016/S0169-5347(03)00011-9

Bonilla-Moheno M, Redo DJ, Aide TM, Clark ML, Grau HR. 2013. Vegetation change and land tenure in Mexico: A country-wide analysis. Land Use Policy. 30: 355-364. DOI: 10.1016/j.landusepol.2012.04.002

Borcard D, Gillet F, Legendre P. 2011. Numerical Ecology with R. DOI: 10.1007/978-0387-78171-6

Boyette C, Hoagland R, Stetina K. 2015. Biological control of spreading dayflower (Commelina diffusa) with the fungal pathogen Phoma commelinicola. Agronomy. 5: 519-536. DOI: 10.3390/agronomy5040519

Bremer B, Bremer K, Chase M. 2009. An update of the Angiosperm Phylogeny Group classification for the orders and families of flowering plants: APG III. Botanical Journal of the Linnean Society. 161: 105-121.

Brown S, Lugo AE. 1990. Tropical secondary forests. Journal of Tropical Ecology. 6: 132. DOI: $10.1017 / \mathrm{S} 0266467400003989$

Bumiller J. 2015. Bodenkundliche Untersuchungen an der Ostabdachung des Cofre de Perote, Mexico. Bachelor. Thesis, Georg-August-Universität Göttingen. Göttingen. 
Buscardo E, Smith G, Kelly D. 2008. The early effects of afforestation on biodiversity of grasslands in Ireland. Biodiversity and Conservation. 17: 1057-1072.

Cadotte MW, Borer ET, Seabloom EW, Cavender-Bares J, Harpole WS, Cleland E, Davies KF. 2010. Phylogenetic patterns differ for native and exotic plant communities across a richness gradient in Northern California. Diversity and Distributions. 16: 892-901. DOI: 10.1111/j.1472-4642.2010.00700.x

Camenzind T, Hempel S, Homeier J, Horn S, Velescu A, Wilcke W, Rillig MC. 2014. Nitrogen and phosphorus additions impact arbuscular mycorrhizal abundance and molecular diversity in a tropical montane forest. Global Change Biology. 20: 36463659. DOI: Doi 10.1111/Gcb.12618

Cameron AC, Trivedi PK. 1990. Regression-based tests for overdispersion in the Poisson model. Journal of Econometrics. 46: 347-364. DOI: 10.1016/0304-4076(90)90014-K

Carabias J, Arriaga V, Cervantes G. 2007. Las políticas públicas de la restauración ambiental en México: limitantes, avances, rezagos y retos. Boletín de la Sociedad Botánica de México. 80: 85-100.

Carvajal-Hernández Cl. 2016. Diversidad, distribución y adaptaciones ecológicas de helechos y licófitos a lo largo de gradientes de altitud e influencia antrópica en las faldas del Cofre de Perote, Veracruz. Ph.D. Thesis, Universidad Veracruzana.

Carvajal-Hernández CI, Krömer T. 2015. Riqueza y distribución de helechos y licófitos en el gradiente altitudinal del Cofre de Perote, Centro de Veracruz, Mexico. Botanical Sciences. 93: 601-614. DOI: 10.17129/botsci.165

Carvajal-Hernández Cl, Krömer T, Vázquez-Torres M. 2014. Riqueza y composición florística de pteridobiontes en bosque mesófilo de montaña y ambientes asociados en el centro de Veracruz, México. Revista Mexicana de Biodiversidad. 85: 491-501. DOI: $10.7550 / \mathrm{rmb} .41292$

Castañeda-Zárate M, Viccon-Esquivel J, Ramos-Castro SE, Solano-Gómez R. 2012. Registros nuevos de Orchidaceae para Veracruz, México. Revista Mexicana de Biodiversidad. 83: 281-284. 
Castellón RD, Núñez GC, Álvarez-Manilla Aceves A. 2008. Mechanical instability quantification of slopes at Cofre de Perote volcano, eastern Mexico. Boletin de la Sociedad Geologica Mexicana. 60: 187-201.

Castillo-Campos G. 2011. Diversidad de Ambientes. In: Cruz-Angón A, ed. La biodiversidad en Veracruz estudio de estado. México: Gobierno del Estado de Veracruz, Universidad Veracruzana, Instituto de Ecología, A.C., 159-283.

Castillo-Campos G, Dávila-Aranda P, Zavala-Hurtado J. 2007. La selva baja caducifolia en una corriente de lava volcánica en el centro de Veracruz: lista florística de la flora vascular. Boletín de la Sociedad Botánica de México. 80: 77-104.

Castillo-Campos G, Halffter G, Moreno CE. 2008. Primary and secondary vegetation patches as contributors to floristic diversity in a tropical deciduous forest landscape. Biodiversity and Conservation. 17: 1701-1714. DOI: 10.1007/s10531-008-9375-7

Castillo-Campos G, Travieso-Bello AC. 2006. La flora. In: Moreno-Casasola P, ed. Entornos veracruzanos: la costa de La mancha. Xalapa: Instituto de Ecología, A.C., 171-204.

Chandy S, Gibson DJ, Robertson PA. 2006. Additive partitioning of diversity across hierarchical spatial scales in a forested landscape. Journal of Applied Ecology. 43: 792-801. DOI: 10.1111/j.1365-2664.2006.01178.x

Chao A, Chazdon RL, Colwell RK, Shen T-J. 2005. A new statistical approach for assessing similarity of species composition with incidence and abundance data. Ecology Letters. 8: 148-159. DOI: 10.1111/j.1461-0248.2004.00707.x

Chao A, Chiu $\mathrm{CH}$, Hsieh TC, Inouye BD. 2012. Proposing a resolution to debates on diversity partitioning. Ecology. 93: 2037-2051. DOI: 10.1890/11-1817.1

Chawla A, Rajkumar S, Singh KN, Lal B, Singh RD, Thukral AK. 2008. Plant species diversity along an altitudinal gradient of Bhabha Valley in western Himalaya. Journal of Mountain Science. 5: 157-177. DOI: 10.1007/s11629-008-0079-y

Cházaro-Basáñez M de J. 1992. Exploraciones botánicas en Veracruz y estados circunvecinos I. Pisos altitudinales de vegetación en el centro de Veracruz y zonas 
limítrofes con Puebla. La Ciencia y el Hombre. 10: 67-115.

Chazdon RL. 2008. Beyond deforestation: Restoring forests and ecosystem services on degraded lands. Science. 320: 1458-1460. DOI: 10.1126/science.1155365

Chiarucci A. 1994. Successional pathway of Mediterranean ultramafic vegetation in central Italy. Acta Botanica Croatica. 53: 83-94.

Cicuzza D, Clough Y, Tjitrosoedirdjo SS, Kessler M. 2011. Responses of terrestrial herb assemblages to weeding and fertilization in cacao agroforests in Indonesia. Agroforestry Systems. 85: 75-83. DOI: 10.1007/s10457-011-9456-6

Cicuzza D, Krömer T, Poulsen AD, Abrahamczyk S, Delhotal T, Piedra HM, Kessler M. 2013. A transcontinental comparison of the diversity and composition of tropical forest understory herb assemblages. Biodiversity and Conservation. 22: 755-772. DOI: 10.1007/s10531-013-0447-y

Clough Y, Holzschuh A, Gabriel D, Purtauf T, Kleijn D, Kruess A, Steffan-Dewenter I, Tscharntke T. 2007. Alpha and beta diversity of arthropods and plants in organically and conventionally managed wheat fields. Journal of Applied Ecology. 44: 804-812. DOI: $10.1111 / \mathrm{j} .1365-2664.2007 .01294 . x$

Collinge SK. 1996. Ecological consequences of habitat fragmentation: implications for landscape architecture and planning. Landscape and Urban Planning. 36: 59-77. DOI: 10.1016/s0169-2046(96)00341-6

Colwell R. 2013. EstimateS: Statistical estimation of species richness and shared species from samples.

Colwell R, Brehm G, Cardelús C. 2008. Global warming, elevational range shifts, and lowland biotic attrition in the wet tropics. Science. 322: 258-261.

CONABIO. 2010. El bosque mesófilo de montaña en México: amenazas y oportunidades para su conservacion y manejo sostenible. Aceves T T, ed. Mexico City, Mexico: Comisión Nacional para el Conocimiento y Uso de la Biodiversidad.

CONABIO. 2011. La biodiversidad en Veracruz: Estudio de estado. Cruz-Angón A, ed. 
México: Comisión Nacional para el Conocimiento y Uso de la Biodiversidad (CONABIO) Gobierno del Estado de Veracruz Universidad Veracruzana Instituto de Ecología, A.C. DOI: 10.5154/r.rchscfa.2010.11.124

CONABIO. 2016. Sistema de información sobre especies invasoras en México. <http://www.biodiversidad.gob.mx/invasoras> (accessed October 13, 2016).

Condit R, Ashton PS, Baker P, Bunyavejchewin S, Gunatilleke S, Gunatilleke N, Hubbell SP, Foster RB, Itoh A, LaFrankie J V., Lee HS, Losos E, Manokaran N, Sukumar R, Yamakura T. 2000. Spatial patterns in the distribution of tropical tree species. Science. 288: 1414-1418. DOI: 10.1126/science.288.5470.1414

Congalton RG. 2004. Putting the map back in map accuracy assessment. In: Lunetta R, Lyon J, eds. Remote sensing and GIS accuracy assessment. London: CRC PressTaylor \& Francis Group, 1-11.

Connell JH. 1978. Diversity in tropical rain forests and coral reefs. Science. 199: 13021310. DOI: $10.1126 /$ science.199.4335.1302

Cook R. 2005. Kappa. In: Armitage P, Colton T, eds. Encyclopedia of biostatistics. Chichester, UK: John Wiley \& Sons, Ltd. DOI: 10.1002/0470011815

Cortés D, Díaz S, Cabal A, del Ángel O. 2013. Análisis del sector agroindustrial piloncillero en la Región Huatusco-Fortin, Veracruz. In: Espinoza Zamora J, López Ramírez ME, eds. Ciencias Agropecuarias Handbook. Spain: ECORFAN, 13-20.

Cortina-Villar S, Plascencia-Vargas H, Vaca R, Schroth G, Zepeda Y, Soto-Pinto L, Nahed-Toral J. 2012. Resolving the conflict between ecosystem protection and land use in protected areas of the Sierra Madre de Chiapas, Mexico. Environmental management. 49: 649-62. DOI: 10.1007/s00267-011-9799-9

Costa FRC. 2004. Structure and composition of the ground-herb community in a terrafirme Central Amazonian forest. Acta Amazonica. 34: 53-59. DOI: 10.1590/S004459672004000100007

Crist T, Veech J, Gering J, Summerville K. 2003. Partitioning species diversity across landscapes and regions: a hierarchical analysis of $\alpha, \beta$, and $y$ diversity. The American 
Naturalist. 162: 734-743.

Crutzen PJ. 2006. The "Anthropocene." In: Ehlers E, Krafft T, eds. Earth System Science in the Anthropocene. Berlin/Heidelberg: Springer-Verlag, 13-18. DOI: 10.1007/3540-26590-2_3

Currie DJ, Mittelbach GG, Cornell H V., Field R, Guegan J-F, Hawkins BA, Kaufman DM, Kerr JT, Oberdorff T, O'Brien E, Turner JRG. 2004. Predictions and tests of climatebased hypotheses of broad-scale variation in taxonomic richness. Ecology Letters. 7: 1121-1134. DOI: 10.1111/j.1461-0248.2004.00671.x

Dale V, Joyce L, McNulty S, Neilson R. 2001. Climate change and forest disturbances. BioScience. 51: 723-734.

de Albuquerque FS, Benito B, Beier P, Assunção-Albuquerque MJ, Cayuela L. 2015. Supporting underrepresented forests in Mesoamerica. Natureza \& Conservação. 13: 152-158. DOI: 10.1016/j.ncon.2015.02.001

de Castro WAC, Almeida R V., Leite MB, Marrs RH, Silva Matos DM. 2016. Invasion strategies of the white ginger lily Hedychium coronarium J. König (Zingiberaceae) under different competitive and environmental conditions. Environmental and Experimental Botany. 127: 55-62. DOI: 10.1016/j.envexpbot.2016.03.010

de Lange N. 2013. Geoinformatik. Berlin, Heidelberg: Springer Berlin Heidelberg. DOI: $10.1007 / 978-3-642-34807-5$

De Moraes MG, De Carvalho MAM, Franco AC, Pollock CJ, Figueiredo-Ribeiro RDCL. 2016. Fire and drought: soluble carbohydrate storage and survival mechanisms in herbaceous plants from the Cerrado. BioScience. 66: 107-117. DOI: 10.1093/biosci/biv178

DeClerck FAJ, Chazdon R, Holl KD, Milder JC, Finegan B, Martinez-Salinas A, Imbach P, Canet L, Ramos Z. 2010. Biodiversity conservation in human-modified landscapes of Mesoamerica: Past, present and future. Biological Conservation. 143: 2301-2313. DOI: 10.1016/j.biocon.2010.03.026

Decocq G, Beina D, Jamoneau A, Gourlet-Fleury S, Closset-Kopp D. 2014. Don't miss 
the forest for the trees! Evidence for vertical differences in the response of plant diversity to disturbance in a tropical rain forest. Perspectives in Plant Ecology, Evolution and Systematics. 16: 279-287. DOI: 10.1016/j.ppees.2014.09.001

Delgado De Cantú GM. 2003. México, estructuras política, económica y social. Mexico: Pearson Educación.

Desalegn W, Beierkuhnlein C. 2010. Plant species and growth form richness along altitudinal gradients in the southwest Ethiopian highlands. Journal of Vegetation Science. 21: 617-626. DOI: 10.1111/j.1654-1103.2010.01177.x

Dice LR. 1945. Measures of the Amount of Ecologic Association Between Species. Ecology. 26: 297-302. DOI: 10.2307/1932409

Edwards EJ, Osborne CP, Strömberg CAE, Smith SA, C4 Grasses Consortium CG, Bond WJ, Christin P-A, Cousins AB, Duvall MR, Fox DL, Freckleton RP, Ghannoum O, Hartwell J, Huang Y, Janis CM, Keeley JE, Kellogg EA, Knapp AK, Leakey ADB, Nelson DM, Saarela JM, Sage RF, Sala OE, Salamin N, Still CJ, Tipple B. 2010. The origins of C4 grasslands: integrating evolutionary and ecosystem science. Science. 328: 587-91. DOI: 10.1126/science.1177216

Eiserhardt W, Svenning J, Kissling WD, Balslev H. 2011. Geographical ecology of the palms (Arecaceae): determinants of diversity and distributions across spatial scales. Annals of Botany. 108: 1391-1416.

Ellis EA, Martínez M. 2010. Vegetación y uso de suelo. In: Florescano E, Ortíz J, eds. Atlas del patrimonio natural, histórico y cultural de Veracruz. Xalapa, Veracruz: Comisión del Estado de Veracruz para la Conmemoración de la Independencia Nacional y la Revolución Mexicana, Mexico, 203-226.

Ellis E, Antill E, Kreft H. 2012. All is not loss: plant biodiversity in the Anthropocene. PloS one. 7: e30535. DOI: 10.1371/journal.pone.0030535

Ellis EC, Ramankutty N. 2008. Putting people in the map: anthropogenic biomes of the world. Front Ecol Environ. 6: 439-447. DOI: 10.1890/070062

Encina-Domínguez JA, Zárate-Lupercio A, Valdes-Reyna J, Villarreal-Quintanilla J. 2007. 
Caracterización ecológica y diversidad de los bosques de encino de la sierra de Zapalinamé, Coahuila, México. Boletín de la Sociedad Botánica de México. 81: 5163.

Espejo-Serna A. 2012. El endemismo en las liliopsida mexicanas. Acta Botanica Mexicana. 100: 195-258.

Espejo-Serna A, López-Ferrari A, Ugarte I. 2004. A current estimate of angiosperm diversity in Mexico. Taxon. 53: 127-130.

Fahrig L. 2003. Effects of habitat fragmentation on biodiversity. Annual Review of Ecology, Evolution \& Systematics. 34: 487-515. DOI: 10.1146/annurev.ecolsys.34.011802.132419

FAO. 2014a. Country report Mexico. Global Forest Resources Assessment 2015. Rome: FAO.

FAO. 2014b. State of the World's Forests 2014. Rome: Food and Agriculture Organization of the United Nations.

Firn J, Moore J, MacDougall A. 2011. Abundance of introduced species at home predicts abundance away in herbaceous communities. Ecology Letters. 3: 1-8.

Flynn DFB, Gogol-Prokurat M, Nogeire T, Molinari N, Richers BT, Lin BB, Simpson N, Mayfield MM, DeClerck F. 2009. Loss of functional diversity under land use intensification across multiple taxa. Ecology Letters. 12: 22-33. DOI: 10.1111/j.14610248.2008.01255.x

Foley JA, DeFries R, Asner GP, Barford C, Bonan G, Carpenter SR, Chapin FS, Coe MT, Daily GC, Gibbs HK, Helkowski JH, Holloway T, Howard EA, Kucharik CJ, Monfreda C, Patz JA, Prentice IC, Ramankutty N, Snyder PK. 2005. Global consequences of land use. Science. 309: 570-574. DOI: 10.1126/science.1111772

Franzese J, Ghermandi L. 2014. Early competition between the exotic herb Rumex acetosella and two native tussock grasses with different palatability and water stress tolerance. Journal of Arid Environments. 106: 58-62. DOI: 10.1016/j.jaridenv.2014.03.004 
Galicia L, Gómez-Mendoza L, Magaña V. 2013. Climate change impacts and adaptation strategies in temperate forests in Central Mexico: a participatory approach. Mitigation and Adaptation Strategies for Global Change. 20: 21-42. DOI: 10.1007/s11027-0139477-8

García-Franco JG, Castillo-Campos G, Mehltreter K, Martínez ML, Vázquez G. 2008. Composición florística de un bosque mesófilo del centro de Veracruz, México. Boletín de la Sociedad Botánica de México. 83: 37-52.

García-Romero A, Montoya Y, Ibarra M, Garza G. 2010. Economía y política en la evolución contemporánea de los usos del suelo y la deforestación en México: El caso del volcán Cofre de Perote. Interciencia. 35: 321-328.

Gerez-Fernández P, Pineda-López M del R. 2011. Los bosques de Veracruz en el contexto de una estrategia estatal REDD+. Madera y Bosques. 17: 7-27.

Gibson L, Lee TM, Koh LP, Brook BW, Gardner TA, Barlow J, Peres CA, Bradshaw CJA, Laurance WF, Lovejoy TE, Sodhi NS. 2011. Primary forests are irreplaceable for sustaining tropical biodiversity. Nature. 478: 378-381. DOI: 10.1038/nature10425

Gillespie TW, Lipkin B, Sullivan L, Benowitz DR, Pau S, Keppel G. 2012. The rarest and least protected forests in biodiversity hotspots. Biodiversity and Conservation. 21: 3597-3611. DOI: 10.1007/s10531-012-0384-1

Gilroy JJ, Edwards FA, Medina Uribe CA, Haugaasen T, Edwards DP. 2014. EDITOR'S CHOICE: Surrounding habitats mediate the trade-off between land-sharing and landsparing agriculture in the tropics. Journal of Applied Ecology. 51: 1337-1346. DOI: $10.1111 / 1365-2664.12284$

Givnish TJ. 1995. Plant stems: biomechanical adaptation for energy capture and influence on species distributions. In: Gartner BL, ed. Plant stems: Physiology and functional morphology. Elsevier, 3-49.

Gobierno del Estado de Veracruz. 2015. Decreto por el que se declara Área Natural Protegida en la categoría de Corredor biólogico multifuncional y se denomina Archipiélago de bosques y selvas de la región capital del estado de Veracruz, un total 
de 7 polígonos ubicados en la zona establecida c, CXCI Gaceta Oficial del Estado De Veracruz 52. Mexico:

Godfray HCJ, Beddington JR, Crute IR, Haddad L, Lawrence D, Muir JF, Pretty J, Robinson S, Thomas SM, Toulmin C. 2010. Food security: the challenge of feeding 9 billion people. Science. 327: 812-818.

Gómez-Díaz JA, Krömer T, Carvajal-Hernández CI, Gerold G, Heitkamp F. (n.d.). Richness and distribution of herbaceous angiosperms along gradients of elevation and forest disturbance in central Veracruz, Mexico. Botanical Sciences.

Gómez-Mendoza L, Arriaga L. 2007. Modeling the effect of climate change on the distribution of oak and pine species of Mexico. Conservation Biology. 21: 1545-1555.

Gómez-Pompa A, Castillo-Campos G. 2010. La vegetación de Veracruz. In: GómezPompa A, Krömer T, Castro-Cortés R, eds. Atlas de la flora de Veracruz: un patrimonio natural en peligro. Mexico D.F.: Comisión del Estado de Veracruz para la Conmemoración de la Independencia Nacional y la Revolución Mexicana, 57-76.

Gómez-Pompa A, Krömer T, Castro-Cortés R. 2010. Atlas de la flora de Veracruz: un patrimonio natural en peligro. México D.F.: Comisión del Estado de Veracruz para la Conmemoración de la Independencia Nacional y la Revolución Mexicana.

Gonzalez-Montagut R. 1999. Factors that contributed to the expansion of cattle ranching in Veracruz, Mexico. Mexican Studies-Estudios Mexicanos. 15: 101-104. DOI: 10.1525/msem.1999.15.1.03a00040

Grime JP. 1977. Evidence for the existence of three primary strategies in plants and its relevance to ecological and evolutionary theory. The American Naturalist. 111: 11691194.

Grubb PJ. 1977. Control of forest growth and distribution on wet tropical mountains: with special reference to mineral nutrition. Annual Review of Ecology and Systematics. 8: 83-107. DOI: 10.1146/annurev.es.08.110177.000503

Guevara S, Laborde J. 2007. Composición florística en potreros de Los Tuxtlas, Veracruz, México. Acta Botanica Mexicana. 87: 59-87. 
Gustafson EJ, Parker GR. 1994. Using an index of habitat patch proximity for landscape design. Landscape and Urban Planning. 29: 117-130.

Halffter G. 2005. Towards a culture of biodiversity conservation. Acta Zoológica Mexicana. 21: 133-153.

Hansen, M. C., P. V. Potapov, R. Moore, M. Hancher, S. A. Turubanova, A. Tyukavina, D. Thau, S. V. Stehman, S. J. Goetz, T. R. Loveland, A. Kommareddy, A. Egorov LC, Justice CO, Townshend JRG. 2013. High-resolution global maps of 21st-century forest cover change. Science. 342: 850-853.

Hansen MC, Potapov P V., Moore R, Hancher M, Turubanova SA, Tyukavina A. 2016. Global Forest Change. <http://earthenginepartners.appspot.com/science-2013global-forest> (accessed November 8, 2016).

Harris NL, Brown S, Hagen SC, Saatchi SS, Petrova S, Salas W, Hansen MC, Potapov P V, Lotsch A. 2012. Baseline map of carbon emissions from deforestation in tropical regions. Science. 1573: 1573-1576. DOI: 10.1126/science.1217962

Harvey CA, Komar O, Chazdon R, Ferguson BG, Finegan B, Griffith DM, Martínez-Ramos M, Morales H, Nigh R, Soto-Pinto L, Van Breugel M, Wishnie M. 2008. Integrating agricultural landscapes with biodiversity conservation in the Mesoamerican hotspot. Conservation Biology. 22: 8-15. DOI: 10.1111/j.1523-1739.2007.00863.x

Hausermann H, Eakin HC. 2008. Producing "viable" landscapes and livelihoods in Central Veracruz, Mexico: institutional and producer responses to the coffee commodity crisis. Journal of Latin American Geography. 7: 109-131. DOI: 10.1353/lag.2008.0001

Hawkins B, Albuquerque FaS, Araújo MB, Beck J, Bini LM, Cabrero-Sañudo FJ, CastroParga I, Diniz-Filho JA, Ferrer-Castan D, Field R, Gómez JF, Hortal J, Kerr JT, Kitching IJ, León-Cortés JL, Lobo JM, Montoya D, Moreno JC, Olalla-Tárraga MA, Pausas JG, Qi H, Williams P. 2007. A global evaluation of metabolic theory as an explanation for terrestrial species richness gradients. Ecology. 88: 1877-1888. DOI: 10.1016/j.cognition.2008.05.007 
Hawkins BA, Rodríguez MÁ, Weller SG. 2011. Global angiosperm family richness revisited: linking ecology and evolution to climate. Journal of Biogeography. 38: 1253-1266. DOI: 10.1111/j.1365-2699.2011.02490.x

Hemp A. 2005. Continuum or zonation? Altitudinal gradients in the forest vegetation of Mt. Kilimanjaro. Plant Ecology. 184: 27-42. DOI: 10.1007/s11258-005-9049-4

Hernández T, Valles B, Castillo E. 1990. Evaluación de gramíneas y leguminosas forrajeras en Veracruz, México. Pasturas Tropicales. 12: 29-33.

Hietz P, Hietz-Seifert U. 1995. Composition and ecology of vascular epiphyte communities along an altitudinal gradient in central Veracruz, Mexico. Journal of Vegetation Science. 6: 487-498. DOI: 10.2307/3236347

Holeksa J, Saniga M, Szwagrzyk J, Dziedzic T, Ferenc S, Wodka M. 2007. Altitudinal variability of stand structure and regeneration in the subalpine spruce forests of the Pol'ana biosphere reserve, Central Slovakia. European Journal of Forest Research. 126: 303-313. DOI: 10.1007/s10342-006-0149-z

Holwerda F, Bruijnzeel LA, Muñoz-Villers LE, Equihua M, Asbjornsen H. 2010. Rainfall and cloud water interception in mature and secondary lower montane cloud forests of central Veracruz, Mexico. Journal of Hydrology. 384: 84-96. DOI: 10.1016/j.jhydrol.2010.01.012

Homeier J, Werner FA, Gawlik J, Peters T, Diertl K-HJ, Richter M. 2013. Plant diversity and its relevance for the provision of ecosystem services. In: Bendix J, Beck E, Bräuning A, Makeschin F, Mosandl R, Scheu S, Wilcke W, eds. Ecosystem services, biodiversity and environmental change in a tropical mountain ecosystem of South Ecuador. Berlin, Heidelberg: Springer Berlin Heidelberg, 93-106. DOI: 10.1007/9783-642-38137-9

Houghton RA, Skole DL, Nobre CA, Hackler JL, Lawrence KT, Chomentowski WH. 2000. Annual fluxes of carbon from deforestation and regrowth in the Brazilian Amazon. Nature. 403: 301-304. DOI: 10.1038/35002062

Ibarra-Manríquez G, Sinaca C. S. 1987. Estación de biología tropical los Tuxtlas, 
Veracruz. In: Listados Florísticos de México VII. Mexico City, Mexico: Instituto de Biología, U.N.A.M., 51.

INEGI. 2000. Vegetación y uso de suelo. In: Informe de la situación del medioambiente en México. Mexico City, Mexico: , 31-83.

INEGI. 2007. Censo agricola ganadero y forestal. $<$ http://www3.inegi.org.mx/sistemas/tabuladosbasicos/default.aspx?c=17177\&s=est $>$ (accessed November 10, 2016).

Jácome Reyes JH. 2005. Factors controlling the lower elevational limits in tropical montane plants in the Andes and their implications under the current climatic change. Ph.D. Thesis, Georg-August-Universität Göttingen.

Kessler M. 2001. Maximum plant-community endemism at intermediate intensities of anthropogenic disturbance in Bolivian montane forests. Conservation Biology. 15: 634-641. DOI: 10.1046/j.1523-1739.2001.015003634.x

Kessler M. 2002. The elevational gradient of Andean plant endemism: varying influences of taxon-specific traits and topography at different taxonomic levels. Journal of Biogeography. 29: 1159-1165. DOI: 10.1046/j.1365-2699.2002.00773.x

Kessler M, Bach K. 1999. Using indicator families for vegetation classification in speciesrich Neotropical forests. Phytocoenologia. 29: 485-502.

Kessler M, Herzog SK, Fjeldsa J, Bach K. 2001. Species richness and endemism of plant and bird communities along two gradients of elevation, humidity and land use in the Bolivian Andes. Diversity and Distributions. 7: 61-77.

Kessler M, Krömer T, Jimenez I. 2000. Inventory of selected plant groups in the Masicuri Valley (Cochabamba - Bolivia). Revista Boliviana de Ecología y Conservación Ambiental. 8: 3-15.

Klepeis P, Vance C. 2003. Neoliberal policy and deforestation in southeastern Mexico: an assessment of the PROCAMPO program. Economic Geography. 79: 221-240. DOI: 10.1111/j.1944-8287.2003.tb00210.x 
Kluge J, Kessler M. 2006. Fern endemism and its correlates: Contribution from an elevational transect in Costa Rica. Diversity and Distributions. 12: 535-545. DOI: 10.1111/j.1366-9516.2006.00231.x

Köster N, Friedrich K, Nieder J, Barthlott W. 2009. Conservation of epiphyte diversity in an Andean landscape transformed by human land use. Conservation Biology. 23: 911-919. DOI: 10.1111/j.1523-1739.2008.01164.x

Krömer T, Acebey AR, Kluge J, Kessler M. 2013. Effects of altitude and climate in determining elevational plant species richness patterns: A case study from Los Tuxtlas, Mexico. Flora. 208: 197-210. DOI: 10.1016/j.flora.2013.03.003

Krömer T, Gradstein SR. 2003. Species richness of vascular epiphytes in two primary forests and fallows in the Bolivian Andes. Selbyana. 24: 190-195. DOI: $10.2307 / 41760132$

Kwak MM, Velterop O, van Andel J. 1998. Pollen and gene flow in fragmented habitats. Applied Vegetation Science. 1: 37-54. DOI: 10.2307/1479084

Landis JR, Koch GG. 1977. The measurement of observer agreement for categorical data. Biometrics. 33: 159-174. DOI: 10.2307/2529310

Lauer W. 1973. Zusammenhänge zwischen Klima und Vegetation am Ostabfall der mexikanischen Meseta. Erdkunde. 5: 192-213.

Laurance WF, Vasconcelos HL, Stouffer PC, Laurance SG. 2002. Ecosystem decay of Amazonian forest fragments: a 22-Year investigation. Conservation Biology. 16: 605618.

Lavorel S, Grigulis K. 2011. Using plant functional traits to understand the landscape distribution of multiple ecosystem services. Journal of Ecology. 99: 135-147.

Leopold A. 1950. Vegetation zones of Mexico. Ecology. 31: 507-518.

Linares-Palomino R, Kessler M, Linares-Palomino R, Kessler M. 2009. The role of dispersal ability, climate and spatial separation in shaping biogeographical patterns of phylogenetically distant plant groups in seasonally dry Andean forests of Bolivia. 
Journal of Biogeography. 36: 280-290. DOI: 10.1111/j.1365-2699.2008.02028.x

Lindenmayer DB, Franklin JF, Fischer J. 2006. General management principles and a checklist of strategies to guide forest biodiversity conservation. Biological Conservation. 131: 433-445. DOI: 10.1016/j.biocon.2006.02.019

Lippok D, Beck SG, Renison D, Hensen I, Apaza AE, Schleuning M. 2014. Topography and edge effects are more important than elevation as drivers of vegetation patterns in a neotropical montane forest. Journal of Vegetation Science. 25: 724-733. DOI: $10.1111 /$ jvs. 12132

Logan M. 2010. Biostatistical Design and Analysis Using R: A Practical Guide. Singapore: Wiley-Blackwell. DOI: 10.1002/9781444319620

López-Barrera F, Manson RH, Landgrave R. 2014. Identifying deforestation attractors and patterns of fragmentation for seasonally dry tropical forest in central Veracruz, Mexico. Land Use Policy. 41: 274-283. DOI: 10.1016/j.landusepol.2014.06.004

Lot A, Chiang-Cabrera F. 1986. Manual de Herbario: Administración y manejo de colecciones, técnicas de recolección y preparación de ejemplares botánicos. Consejo Nacional de la Flora de México.

Lovett JC, Marshall AR, Carr J. 2006. Changes in tropical forest vegetation along an altitudinal gradient in the Udzungwa Mountains National Park, Tanzania. African Journal of Ecology. 44: 478-490. DOI: 10.1111/j.1365-2028.2006.00660.x

Löwenberg-Neto P. 2014. Neotropical region: a shapefile of Morrone's (2014) biogeographical regionalisation. Zootaxa. 3802: $300 . \quad$ DOI: 10.11646/zootaxa.3802.2.12

Lozada T, de Koning GHJ, Kessler M, Klein A-M, Tscharntke T. 2008. Geographical range size of tropical plants influences their response to anthropogenic activities. Diversity and Distributions. 14: 59-68. DOI: 10.1111/j.1472-4642.2007.00413.x

Luna-Vega I, Espinosa D. 2013. Geographical patterns and determinants of species richness in Mexico across selected families of vascular plants: implications for conservation. Systematics and Biodiversity. 11: 237-256. 
MacArthur RH, Wilson EO. 1976. The theory of island biogeography. Princeton, New Jersey: Princeton University Press.

Magaña P, Villaseñor JL. 2002. La flora de México. ¿Se podrá conocer completamente? Ciencias. 66: 24-26.

Magrach A, Rodríguez-Pérez J, Campbell M, Laurance WF. 2014. Edge effects shape the spatial distribution of lianas and epiphytic ferns in Australian tropical rain forest fragments. Applied Vegetation Science. 17: 754-764. DOI: 10.1111/avsc.12104

Magurran AE. 2004. Measuring Biological Diversity. Oxford, UK: Blackwell Publishing Ltd. DOI: $10.2989 / 16085910409503825$

Malhi Y, Roberts JT, Betts RA, Killeen TJ, Li W, Nobre CA. 2008. Climate change, deforestation, and the fate of the Amazon. Science. 319: 169-172. DOI: 10.1126/science. 1146961

Marchal J, Grayeb R, Arriaga Cabrera R. 1985. Análisis gráfico de un espacio regional: Veracruz. Veracruz: Instituto Nacional de Investigaciones sobre Recursos Bióticos.

Marin-Spiotta E, Silver W, Ostertag R. 2007. Long-term patterns in tropical reforestation: plant community composition and aboveground biomass accumulation. Ecological Applications. 17: 828-839.

Marion ZH, Fordyce JA, Fitzpatrick BM. 2015. Extending the Concept of Diversity Partitioning to Characterize Phenotypic Complexity. The American Naturalist. 186: 348-361. DOI: 10.1086/682369

Márquez E, Fariñas M, Briceño B, Rada F. 2004. Distribution of grasses along an altitudinal gradient in a Venezuelan paramo. Revista Chilena de Historia natural. $\mathbf{7 7 :}$ 649-660.

Márquez EJ, Rada F, Fariñas MR. 2006. Freezing tolerance in grasses along an altitudinal gradient in the Venezuelan Andes. Oecologia. 150: 393-397. DOI: 10.1007/s00442006-0556-3

Martin PA, Newton AC, Bullock JM. 2013. Carbon pools recover more quickly than plant 
biodiversity in tropical secondary forests. Proceedings of the Royal Society B: Biological Sciences. 280: 20132236-20132236. DOI: 10.1098/rspb.2013.2236

Martinez-Camilo R, Pérez-Farrera MÁ, Martínez-Meléndez N. 2012. Listado de plantas endemicas y en riesgo de la reserva de la biosfera el Triunfo, Chiapas, México. Botanical Sciences. 90: 263-285.

Masera OR, Ordóñez MJ, Dirzo R. 1997. Carbon emissions from Mexican forests: Current situation and long-term scenarios. Climatic Change. 35: 265-295. DOI: 10.1023/A:1005309908420

Mathieu G, Vergara-Rodríguez D, Krömer T, Karger DN. 2015. Peperomia (Piperaceae) novelties from Veracruz state, Mexico. Phytotaxa. 205: 268-276. DOI: 10.11646/phytotaxa.205.4.6

Mayfield MM, Daily GC. 2005. Countryside biogeography of neotropical herbaceous and shrubby plants. Ecological Applications. 15: 423-439. DOI: 10.1890/03-5369

McCain C, Grytnes J. 2010. Elevational gradients in species richness. In: Encyclopedia of Life Sciences (ELS). Chichester: John Wiley \& Sons, Ltd, 10. DOI: 10.1002/9780470015902.a0022548

McGarigal K, Cushman S, Ene E. 2012. FRAGSTATS v4: Spatial pattern analysis program for categorical and continuous maps. Computer software program produced by the authors at the University of Massachusetts, Amherst.

Meekins JF, McCarthy B. 2001. Effect of environmental variation on the invasive success of a nonindigenous forest herb. Ecological Applications. 11: 1336-1348.

Mejía-Saulés T, Castillo-Campos G, Reyes S. 2002. New reports of Poaceae in the rocky substratum of municipality of Perote, Veracruz, Mexico. Rhodora. 104: 304-308.

Melo FPL, Arroyo-Rodríguez V, Fahrig L, Martínez-Ramos M, Tabarelli M. 2013. On the hope for biodiversity-friendly tropical landscapes. Trends in Ecology and Evolution. 28: 461-468. DOI: 10.1016/j.tree.2013.01.001

Meyer C, Struebigm M, Willig M. 2016. Responses of tropical bats to habitat 
fragmentation, logging, and deforestation. In: Bats in the Anthropocene: Conservation of Bats in a Changing World. Cham: Springer International Publishing, 63-103. DOI: 10.1007/978-3-319-25220-9

Miranda F, Hernández-Xolocotzi E. 1963. Los tipos de vegetación de México y su clasificación. Boletín de la Sociedad Botánica de México. 28: 29-162.

Mittermeier R, Gil R, Hoffman M, Pilgrim J, Brooks TM, Mittermeier CG, Lamoreux JF, Da Fonseca GAB. 2005. Hotspots revisited: Earth's biologically richest and most endangered terrestrial ecoregions. Boston: University of Chicago Press.

Moreno-Molina I, Beutelspacher CR, Baigts C, Moreno-Molina I, Beutelspacher CR. 2014. Situación actual en Chiapas de Oeceoclades maculata (Lindl.) Lindl. (1833), Orquídea terrestre invasora. Lacandonia. 8: 39-46.

Moreno NP. 1984. Glosario botánico ilustrado. Xalapa, Veracruz: Instituto Nacional de Investigaciones sobre Recursos Bióticos.

Morrone JJ. 2005. Hacia una síntesis biogeográfica de México. Revista Mexicana de Biodiversidad. 76: 207-252.

Muñiz-Castro MA, Williams-Linera G, Benítez-Malvido J. 2015. Restoring montane cloud forest: establishment of three Fagaceae species in the old fields of central Veracruz, Mexico. Restoration Ecology. 23: 26-33. DOI: 10.1111/rec.12155

Muñoz-Villers LE, Holwerda F, Gómez-Cárdenas M, Equihua Zamora M, Asbjornsen H, Bruijnzeel LA, Marín-Castro BE, Tobón C. 2012. Water balances of old-growth and regenerating montane cloud forests in central Veracruz, Mexico. Journal of Hydrology. 462-463: 53-66. DOI: 10.1016/j.jhydrol.2011.01.062

Muñoz-Villers LE, López-Blanco J. 2008. Land use/cover changes using Landsat TM/ETM images in a tropical and biodiverse mountainous area of central-eastern Mexico. International Journal of Remote Sensing. 29: 71-93. DOI: $10.1080 / 01431160701280967$

Murphy GEP, Romanuk TN. 2014. A meta-analysis of declines in local species richness from human disturbances. Ecology and Evolution. 4: 91-103. DOI: 10.1002/ece3.909 
Myers N, Mittermeier RA, Mittermeier CG, Da Fonseca GAB, Kent J. 2000. Biodiversity hotspots for conservation priorities. Nature. 403: 853-858. DOI: 10.1038/35002501

Naeem S, Raffaelli D, Schmid B, Bengtsson J, Grime JP, Hector A, Loreau M, Hooper DU, Tilman D, Inchausti P, Wardle DA, Huston MA. 2001. Biodiversity and ecosystem functioning: current knowledge and future challenges. Science. 294: 804-808. DOI: 10.1126/science. 1064088

Narave-Flores H. 1985. La vegetación del cofre de Perote, Veracruz, Mexico. Biotica. 10: 35-64.

Negrete-Yankelevich S, Porter-Bolland L, Blanco-Rosas JL, Barois I. 2013. Historical roots of the spatial, temporal, and diversity scales of agricultural decision-making in sierra de Santa Marta, Los Tuxtlas. Environmental Management. 52: 45-60. DOI: 10.1007/s00267-013-0095-8

Newbold T, Hudson LN, Hill SLL, Contu S, Lysenko I, Senior RA, Börger L, Bennett DJ, Choimes A, Collen B, Day J, De Palma A, Díaz S, Echeverria-Londoño S, Edgar MJ, Feldman A, Garon M, Harrison MLK, Alhusseini T, Ingram DJ, Itescu Y, Kattge J, Kemp V, Kirkpatrick L, Kleyer M, Correia DLP, Martin CD, Meiri S, Novosolov M, Pan Y, Phillips HRP, Purves DW, Robinson A, Simpson J, Tuck SL, Weiher E, White HJ, Ewers RM, Mace GM, Scharlemann JPW, Purvis A. 2015. Global effects of land use on local terrestrial biodiversity. Nature. 520: 45-50. DOI: 10.1038/nature14324

Nogués-Bravo D, Araújo MB, Romdal T, Rahbek C. 2008. Scale effects and human impact on the elevational species richness gradients. Nature. 453: 216-219. DOI: $10.1038 /$ nature 06812

Novelo-Retana A. 1978. La vegetación de la estación biológica El Morro de la Mancha, Veracruz. Biótica. 3: 9-23.

Oksanen J, Blanchet FG, Kindt R, Legendre P, Minchin PR, O'Hara RB, Simpson GL, Solymos $\mathrm{P}$, Stevens $\mathrm{MHH}$, Wagner H. 2016. vegan: Community ecology package. $<$ https://cran.r-project.org/package=vegan> (accessed May 3, 2016).

Olguín EJ. 2011. La biodiversidad del estado y algunas de sus amenazas. In: Cruz-Angón 
A, ed. La biodiversidad en Veracruz estudio de estado. Mexico: Comisión Nacional para el Conocimiento y Uso de la Biodiversidad (CONABIO) Gobierno del Estado de Veracruz Universidad Veracruzana Instituto de Ecología, A.C., 349-397.

Olson DM, Dinerstein E, Wikramanayake ED, Burgess ND, Powell GVN, Underwood EC, D'amico JA, Itoua I, Strand HE, Morrison JC, Loucks CJ, Allnutt TF, Ricketts TH, Kura Y, Lamoreux JF, Wettengel WW, Hedao P, Kassem KR. 2001. Terrestrial ecoregions of the world: a new map of life on earth. BioScience. 51: 933. DOI: 10.1641/00063568(2001)051[0933:TEOTWA]2.0.CO;2

Palacios-Wassenaar O, Castillo-Campos G, Vázquez-Torres SM, Del Amo-Rodríguez S. 2014. Flora vascular de la selva mediana subcaducifolia del centro de Veracruz, México. Revista Mexicana de Biodiversidad. 85: 125-142. DOI: 10.7550/rmb.34663

Parry M, Canziani O, Palutikof J, van der Linden P, Hanson C. 2007. Climate change 2007: impacts, adaptation and vulnerability. Contribution of working group II to the fourth assesment report of the Intergovernmental Panel on Climate Change. Cambridge.

Pascual U, Barbier EB. 2007. On price liberalization, poverty, and shifting cultivation: an example from Mexico. Land Economics. 83: 192-216.

Pfaff A, Santiago-Avila F, Carnovale M, Joppa L. 2014. Protected areas' impacts upon land cover within Mexico: the need to add politics and dynamics to static landuse economics. In: Agricultural and Applied Economics Association Annual Meeting. Minneapolis: , 27-29.

Pons TL, Poorter H. 2014. The effect of irradiance on the carbon balance and tissue characteristics of five herbaceous species differing in shade-tolerance. Frontiers in Plant Science. 5: 12. DOI: 10.3389/fpls.2014.00012

Poore D. 2013. No timber without trees: sustainability in the tropical forest. London: Routledge.

Poulsen AD. 1996. Species richness and density of ground herbs within a plot of lowland rainforest in north-west Borneo. Journal of Tropical Ecology. 12: 177-190. 
Poulsen AD, Balslev H. 1991. Abundance and cover of ground herbs in an Amazonian rain forest. Journal of Vegetation Science. 2: 315-322. DOI: 10.2307/3235922

Poulsen AD, Tuomisto H, Balslev H. 2006. Edaphic and Floristic Variation within a 1-ha Plot of Lowland Amazonian Rain Forest. Biotropica. 38: 468-478.

Power PJ, Stanley T, Cowan C, Roberts JR. 2014. Native plant recovery in study plots after fennel (Foeniculum vulgare) control on Santa Cruz Island. Monographs of the Western North American Naturalist. 7: 465-476. DOI: 10.3398/042.007.0136

Puyravaud JP. 2003. Standardizing the calculation of the annual rate of deforestation. Forest Ecology and Management. 177: 593-596. DOI: 10.1016/S03781127(02)00335-3

R Core Team. 2014. R: A language and environment for statistical computing. $R$ Foundation for Statistical Computing, Vienna, Austria. <https://www.r-project.org/> (accessed January 20, 2016).

Rahbek C. 1995. The elevational gradient of species richness: a uniform pattern? Ecography. 18: 200-205.

Ramírez-Delgado JP, Christman Z, Schmook B. 2014. Deforestation and fragmentation of seasonal tropical forests in the southern Yucatán, Mexico (1990-2006). Geocarto International. 6049: 1-38. DOI: 10.1080/10106049.2013.868039

Ramos L, Anaya AL, de Pascual JN. 1983. Evaluation of allelopathic potential of dominant herbaceous species in a coffee plantation. Journal of Chemical Ecology. 9: 10791097. DOI: 10.1007/BF00982213

Rao M, Rao C. 2014. Handbook of Statistics: Computational Statistics with R. Amsterdam: Elsevier.

Richards P. 1996. The tropical rain forest: an ecological study. Cambridge: Cambridge University Press, 2nd ed.

Robinson D. 1994. The responses of plants to nonuniform supplies of nutrients. New Phytologist. 127: 635-674. DOI: 10.1111/j.1469-8137.1994.tb02969.x 
Rueda-Hernández R, MacGregor-Fors I, Renton K. 2015. Shifts in resident bird communities associated with cloud forest patch size in Central Veracruz, Mexico. Avian Conservation and Ecology. 10: 2. DOI: 10.5751/ACE-00751-100202

Rzedowski J. 1991. Diversidad y orígenes de la flora fanerogámica de México. Acta Botanica Mexicana. 14: 3-21.

Rzedowski J. 1993. Diversity and origins of the phanerogamic flora of Mexico. In: Ramamoorthy TP, Bye R, Lot A, Fa J, eds. Biological diversity of Mexico: origins and distribution. New York, USA: Oxford University Press, 129-144.

Rzedowski J. 2006. Vegetación de México. 1ra Edición digital. México: Comisión Nacional para el Conocimiento y Uso de la Biodiversidad.

Saatchi SS, Harris NL, Brown S, Lefsky M, Mitchard ETA, Salas W, Zutta BR, Buermann W, Lewis SL, Hagen S, Petrova S, White L, Silman M, Morel A. 2011. Benchmark map of forest carbon stocks in tropical regions across three continents. Proceedings of the National Academy of Sciences. 108: 9899-9904. DOI: 10.1073/pnas.1019576108

Salas-Morales SH, Meave JA. 2012. Elevational patterns in the vascular flora of a highly diverse region in southern Mexico. Plant Ecology. 213: 1209-1220. DOI: 10.1007/s11258-012-0077-6

Salazar G. 1999. Novelties in Mexican Orchidaceae, mainly from the UxpanapaChimalapa region, Veracruz and Oaxaca. Anales del Instituto de Biología, Universidad Nacional Autónoma de México. Serie Botánica. 70: 1-12.

Salazar L, Homeier J, Kessler M, Abrahamczyk S, Lehnert M, Krömer T, Kluge J. 2015. Diversity patterns of ferns along elevational gradients in Andean tropical forests. Plant Ecology \& Diversity. 8: 13-24. DOI: 10.1080/17550874.2013.843036

Sánchez-González A, López-Mata L. 2003. Clasificación y ordenación de la vegetación del norte de la Sierra Nevada, a lo largo de un gradiente altitudinal. Anales del Instituto de Biología. Serie Botánica. 74: 47-71.

Sánchez Mateo MA. 2007. Caracterización del hábitat de la cotorra serrana occidental 
Rhynchopsitta pachyrhyncha en el Municipio de Madera, Chihuahua, México. MSc. Thesis, Universidad Autónoma de Chihuahua.

Sarukhan J, Urquiza-Haas T, Koleff P, Carabias J, Dirzo R, Ezcurra E, Cerdeira-Estrada S, Soberon J. 2014. Strategic actions to value, conserve, and restore the natural capital of megadiversity countries: the case of Mexico. BioScience. 65: 164-173. DOI: 10.1093/biosci/biu195

Scatena F, Planos-Gutierrez E, Schellekens. J. 2005. Natural disturbances and the hydrology of humid tropical forests. In: Bonell M, Bruijnzeel LA, eds. Forest, water and people in the humid tropics. Cambridge: Cambridge University Press, 489-512.

Schultz R, Dibble E. 2012. Effects of invasive macrophytes on freshwater fish and macroinvertebrate communities: the role of invasive plant traits. Hydrobiologia. 684: 1-14. DOI: 10.1007/s10750-011-0978-8

SEMARNAT. 2010. Norma Oficial Mexicana. Protección ambiental-Especies nativas de México de flora y fauna silvestres. Categorias de riesgo y especificaciones para su inclusión, exclusión o cambio. Mexico: Diario Oficial. DOI: 10.1007/s13398-0140173-7.2

Simbangala M, Cámara B. 2016. Transiciones sistemáticas de cobertura de suelo en la Región Costa Maya, Quintana Roo, México, 1993-2010. Perspectiva Geográfica. 20: 103-132.

Skutsch M, Mas JF, Bocco G, Bee B, Cuevas G, Gao Y. 2014. Deforestation and land tenure in Mexico: A response to Bonilla-Moheno et al. Land Use Policy. 39: 390-396. DOI: 10.1016/j.landusepol.2013.11.013

Sluyter A, Siemens AH. 1992. Vestiges of prehispanic, sloping-field terraces on the piedmont of Central Veracruz, Mexico. Latin American Antiquity. 3: 148-160. DOI: $10.2307 / 971941$

Smith SA, Beaulieu JM. 2009. Life history influences rates of climatic niche evolution in flowering plants. Proceedings of the Royal Society B: Biological Sciences. 276: 43454352. DOI: $10.1098 / \mathrm{rspb} .2009 .1176$ 
SMN. 2016. Servicio Meteorológico Nacional. Normales climatológicas. <http://smn.cna.gob.mx/index.php?option=com_content\&view=article\&id=164\&tmpl $=$ component $>$ (accessed March 8, 2016).

Sosa V, Platas T. 1998. Extinction and persistence of rare orchids in Veracruz, Mexico. Conservation Biology. 12: 451-455. DOI: 10.1046/j.1523-1739.1998.96306.x

Sosa V, Vovides APA, Castillo-Campos G. 1998. Monitoring endemic plant extinction in Veracruz, Mexico. Biodiversity and Conservation. 7: 1521-1527. DOI: 10.1023/A:1008809332490

Soto-Esparza M, Giddings BL. 2011. Clima. In: CONABIO, ed. La biodiversidad en Veracruz: Estudio de Estado. Mexico: Comisión Nacional para el Conocimiento y Uso de la Biodiversidad, Gobierno del Estado de Veracruz, Universidad Veracruzana, Instituto de Ecología, A. C., 35-52.

Stroud JT, Bush MR, Ladd MC, Nowicki RJ, Shantz AA, Sweatman J. 2015. Is a community still a community? Reviewing definitions of key terms in community ecology. Ecology and Evolution. 5: 4757-4765. DOI: 10.1002/ece3.1651

Tapia-Armijos MF, Homeier J, Espinosa Cl, Leuschner C, de la Cruz M. 2015. Deforestation and forest fragmentation in South Ecuador since the 1970s - losing a hotspot of biodiversity. PloS one. 10: e0133701. DOI: 10.1371/journal.pone.0133701

Tewksbury JJ, Levey DJ, Haddad NM, Sargent S, Orrock JL, Weldon A, Danielson BJ, Brinkerhoff J, Damschen El, Townsend P. 2002. Corridors affect plants, animals, and their interactions in fragmented landscapes. Proceedings of the National Academy of Sciences of the United States of America. 99: 12923-6. DOI: 10.1073/pnas.202242699

The World Bank. 2016. CO2 emissions (kt) | Data. <http://data.worldbank.org/indicator/EN.ATM.CO2E.KT?year_high_desc=true> (accessed November 8, 2011).

Torres-Cantú G. 2013. Lista florística de la Barranca de Monte Obscuro, municipio de Emiliano Zapata, Veracruz, México. MSc. Thesis, Colegio de Postgraduados. 
Tscharntke T, Tylianakis JM, Rand TA, Didham RK, Fahrig L, Batáry P, Bengtsson J, Clough Y, Crist TO, Dormann CF, Ewers RM, Fründ J, Holt RD, Holzschuh A, Klein AM, Kleijn D, Kremen C, Landis DA, Laurance W, Lindenmayer D, Scherber C, Sodhi N, Steffan-Dewenter I, Thies C, van der Putten WH, Westphal C. 2012. Landscape moderation of biodiversity patterns and processes - eight hypotheses. Biological Reviews. 87: 661-685. DOI: 10.1111/j.1469-185X.2011.00216.x

Tuirán R. 2002. Migración, remesas y desarrollo. In: Consejo Nacional de Población, ed. La situación demográfica de México 2002. Mexico: Consejo Nacional de Población.

Tuomisto H. 2010. A consistent terminology for quantifying species diversity? Yes, it does exist. Oecologia. 164: 853-60. DOI: 10.1007/s00442-010-1812-0

Tuomisto H. 2011. Commentary: Do we have a consistent terminology for species diversity? Yes, if we choose to use it. Oecologia. 167: 903-911. DOI: $10.1007 / \mathrm{s} 00442-011-2128-4$

Valencia V, Naeem S, García-Barrios L, West P, Sterling EJ. 2016. Conservation of tree species of late succession and conservation concern in coffee agroforestry systems. Agriculture, Ecosystems and Environment. 219: 32-41. DOI: 10.1016/j.agee.2015.12.004

van der Werf GR, Morton DC, DeFries R, Olivier JG, Kasibhatla P, Jackson RB, Collatz G, Randerson JT. 2009. CO2 emissions from forest loss. Nature Geoscience. 2: 737738. DOI: $10.1038 / \mathrm{ngeo6} 71$

van Wesenbeeck BK, van Mourik T, Duivenvoorden JF, Cleef AM. 2003. Strong efects of a plantation with Pinus patula on Andean paramo vegetation: a case study from Colombia. Biological Conservation. 114: 207-218. DOI: 10.1016/S00063207(03)00025-9

Vargas G J de J, Whitacre D, Mosquera R, Albuquerque J, Piana R, Thiollay J-M, Márquez C, Sánchez JE, Lezama López M, Midence S, Matola S, Aguilar S, Rettig N, Sanalotti T, Sanaiotti13. 2006. Estado y distribucion actual del aguila arpia (Harpia harpyja) en Centro y Sur America. Ornitología Neotropical. 17: 39-55. 
Vázquez JA, Givnish TJ. 1998. Altitudinal gradients in tropical forest composition, structure, and diversity in the Sierra de Manantlan. Journal of Ecology. 86: 999-1020. DOI: $10.1046 / \mathrm{j} .1365-2745.1998 .00325 . x$

Vazquez J, Cuevas R, Cochrane T, Iltis H, Santana M, Guzmán H. L. 1995. Flora de Manantlán. Botanical Miscellany No. 13, ed. Texas: Botanical Research Institute of Texas, Inc. Fort Worth.

Vellend M, Verheyen K, Flinn KM, Jacquemyn H, Kolb A, Van Calster H, Peterken G, Graae BJ, Bellemare J, Honnay O, Brunet J, Wulf M, Gerhardt F, Hermy M. 2007. Homogenization of forest plant communities and weakening of species-environment relationships via agricultural land use. Journal of Ecology. 95: 565-573. DOI: 10.1111/j.1365-2745.2007.01233.x

Venables WN, Ripley BD. 2002. Modern Applied Statistics with S. New York, New York, USA: Springer, Fourth.

Villaseñor JL. 2003. Diversidad y distribución de las Magnoliophyta de México. Interciencia. 28: 160-167.

Villaseñor JL. 2004. Los géneros de plantas vasculares de la flora de México. Boletín de la Sociedad Botánica de México. 105-135.

Villaseñor JL. 2010. El bosque húmedo de montaña en México y sus plantas vasculares: catálogo florístico-taxonómico. D.F., Mexico: Comisión Nacional para el Conocimiento y Uso de la Biodiversidad-Universidad Nacional Autónoma de México.

Villaseñor JL. 2016. Checklist of the native vascular plants of Mexico. Revista Mexicana de Biodiversidad. 87: 559-902. DOI: 10.1016/j.rmb.2016.06.017

Villaseñor JL, Delgadillo C, Ortíz E. 2006. Biodiversity hotspots from a multigroup perspective: Mosses and Senecios in the Transmexican Volcanic Belt. Biodiversity and Conservation. 15: 4045-4058. DOI: 10.1007/s10531-005-3056-6

Villaseñor JL, Maeda P, Colín L, Ortíz E. 2005. Estimación de la riqueza de especies de asteraceae mediante extrapolación a partir de datos de presencia-ausencia. Boletín de la Sociedad Botánica de México. 76: 5-18. 
Villaseñor JL, Maeda P, Rosell J a., Ortíz E. 2007. Plant families as predictors of plant biodiversity in Mexico. Diversity and Distributions. 13: 871-876. DOI: 10.1111/j.14724642.2007.00385.x

Villaseñor JL, Ortíz E. 2012. La familia asteraceae en la flora del bajío y de regiones adyacentes. Acta Botanica Mexicana. 100: 259-292.

Villaseñor JL, Ortíz E. 2014. Biodiversidad de las plantas con flores (División Magnoliophyta) en México. Revista Mexicana de Biodiversidad. 85: 134-142. DOI: $10.7550 / \mathrm{rmb} .31987$

Wang G, Zhou G, Yang L, Li Z. 2003. Distribution, species diversity and life-form spectra of plant communities along an altitudinal gradient in the northern slopes of Qilianshan Mountains, Gansu, China. Plant Ecology. 165: 169-181. DOI: 10.1023/A:1022236115186

Wang S-X, Guo H, Wang X-A, Fan W-Y, Duan R-Y. 2014. Multiple-scale assessment of understory herb species diversity in pine plantations after long-term restoration. Nordic Journal of Botany. 32: 680-688. DOI: 10.1111/j.1756-1051.2013.00268.x

Wang X, Fang J, Sanders NJ, White PS, Tang Z. 2009. Relative importance of climate vs local factors in shaping the regional patterns of forest plant richness across northeast China. Ecography. 32: 133-142. DOI: 10.1111/j.1600-0587.2008.05507.x

Warren SD, Holbrook SW, Dale DA, Whelan NL, Elyn M, Grimm W, Jentsch A. 2007. Biodiversity and the heterogeneous disturbance regime on military training lands. Restoration Ecology. 15: 606-612. DOI: 10.1111/j.1526-100X.2007.00272.x

Wesche K, Cierjacks A, Assefa Y, Wagner S, Fetene M, Hensen I. 2008. Recruitment of trees at tropical alpine treelines: Erica in Africa versus Polylepis in South America. Plant Ecology \& Diversity. 1: 35-46. DOI: 10.1080/17550870802262166

Whitmore TC, Sayer JA. 1992. Tropical deforestation and species extinction. Boca Raton: Chapman \& Hall.

Whittaker RH. 1975. Communities and ecosystems. New York, NY: MacMillan, 2nd ed. 
Williams-Linera G. 2002. Tree species richness complementarity, disturbance and fragmentation in a Mexican tropical montane cloud forest. Biodiversity and Conservation. 11: 1825-1843.

Williams-Linera G. 2013. The cloud forest communities in the mountains of central Veracruz, México: heterogeneity along an elevation gradient? In: New Frontiers in Tropical Biology: The Next 50 years. San Jose, Costa Rica: .

Williams-Linera G, Álvarez-Aquino C, Muñiz-Castro MÁ, Pedraza RA. 2016. Evaluación del éxito de la restauración del bosque nublado en la región de Xalapa, Veracruz. In: Ceccon E, Martínez-Garza C, eds. Experiencias mexicanas en la restauración de los ecosistemas. Mexico City, Mexico: UNAM, CRIM, Universidad Autónoma del estado de Morelos, CONABIO, 81-101.

Williams-Linera G, Guillén Servent A, Gómez García O, Lorea Hernández F. 2007. Conservación en el centro de Veracruz, México. El bosque de niebla: ¿reserva archipiélago o corredor biológico? In: Halffter G, Guevara S, Melic A, eds. Hacia una cultura de conservación de la diversidad biológica. Spain: Sociedad Entomológica Aragonesa Comisión Nacional para el Conocimiento y Uso de la Biodiversidad Comisión Nacional de Áreas Naturales Protegidas Consejo Nacional de Ciencia y Tecnología Instituto de Ecología, A. C. Organización de las Naciones Unidas para, 303-310.

Willinghöfer S, Cicuzza D, Kessler M. 2011. Elevational diversity of terrestrial rainforest herbs: when the whole is less than the sum of its parts. Plant Ecology. 213: 407-418. DOI: $10.1007 / \mathrm{s} 11258-011-9986-z$

Wolf J. 1993. Diversity patterns and biomass of epiphytic bryophytes and lichens along an altitudinal gradient in the northern Andes. Annals of the Missouri Botanical Garden. 80: 928-960. DOI: 10.2307/2399938

Wright SJ. 2005. Tropical forests in a changing environment. Trends in Ecology and Evolution. 20: 553-560. DOI: 10.1016/j.tree.2005.07.009

Wright SJ, Muller-Landau HC. 2006. The future of tropical forest species. Biotropica. 38: 287-301. DOI: 10.1111/j.1744-7429.2006.00154.x 
Yang Y, Shen Z, Han J, Zhongyong C. 2016. Plant Diversity along the Eastern and Western Slopes of Baima Snow Mountain, China. Forests. 7: 89. DOI: $10.3390 / f 7040089$

Zambrano J, Coates R, Howe HF. 2014. Effects of forest fragmentation on the recruitment success of the tropical tree Poulsenia armata at Los Tuxtlas, Veracruz, Mexico. Journal of Tropical Ecology. 30: 209-218. DOI: 10.1017/S0266467414000108

Zamora-Crescencio P, Castillo-Campos G. 1997. Vegetación y flora del municipio de Tlalnelhuayocan, Veracruz. Textos Universitarios. Xalapa, Veracruz: Universidad Veracruzana.

Zivanai T, Griffiths ME, Gunton RM, Franks PJ, Lawes J. 2010. Ecological filtering by a dominant herb selects for shade tolerance in the tree seedling of coastal dune forest community. Oecologia. 164: 861-870. DOI: 10.1007/s00442-010-1711-4 


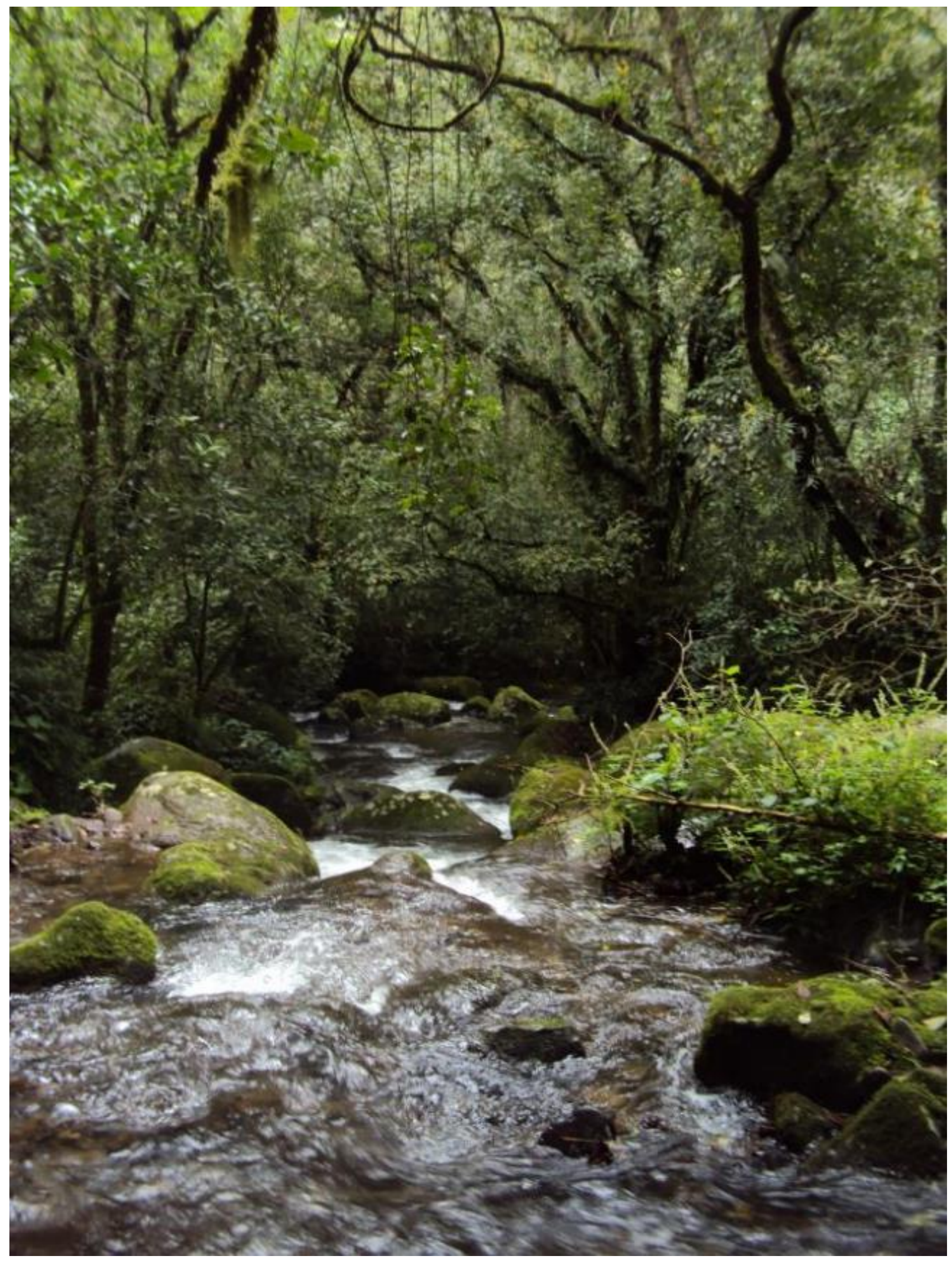




\section{Jorge Antonio Gómez Díaz}

Born on December $28^{\text {th }}$, 1988 in Xalapa, Veracruz, Mexico

\section{EDUCATION}

2012 - Jan. 2017 University of Göttingen. Department of Physical Geography

Research. Dr. candidate

Jun. $2012 \quad$ Especialist in Statistical Methods graduation.

2011 - $2012 \quad$ Universidad Veracruzana (UV), Xalapa, Veracruz, Mexico.

Faculty of Statistics and Informatics, School of Statistical Sciences.

Oct. $2010 \quad$ Licenciatura in Biological Sciences graduation (equivalent to Diplom).

$2006-2010 \quad$ Universidad Veracruzana (UV), Xalapa, Veracruz, Mexico.

Faculty of Biology.

$2003-2006 \quad$ "Colegio preparatio de Xalapa" High school. Xalapa, Mexico.

\section{LANGUAGES}

Spanish Native competence.

English Full professional competence.

German Basic professional competence.

\section{EXPERIENCE}

2012 - present Dr. rer. nat. Studies. Research student in BIOVERA project sponsor by CONACYT, DAAD, DFG in Mexico. 
$2011-2012$ Research assistant. Centro de Investigaciones Tropicales (CITRO), Universidad Veracruzana (UV). Fieldwork and herbarium assitent in several projects in Mexico.

$2011-2012 \quad$ Ecotourism guide. "Huella" Club, Xalapa, Mexico.

\section{OTHER RELEVANT EXPERIENCE}

2012

Research Scholar. School of Statistical Sciences, Universidad de Costa Rica (UCR), San José, Costa Rica.

2010

Research Scholar. El Colegio de la Frontera Sur, Campeche, Mexico.

2009

Research Scholar. Center of Biological Sciences, Universidad de Guadalajara (UDG), Guadalajara, Mexico.

\section{PRESENTATIONS}

Feb. 2016

Species richness and distribution of herbaceous angiosperms along gradients of elevation and human disturbance in Central Veracruz, Mexico. Annual Conference of the Society for Tropical Ecology (GTÖ), Göttingen, Germany. Oral presentation.

Sep. 2015 Species richness and complementarity of herbaceous angiosperms along an elevational gradient in Central Veracruz, Mexico. The annual meeting of the German Society of Ecology, Göttingen, Germany. Poster.

Apr. 2015

Species richness and complementarity of herbaceous angiosperms along an elevational gradient in central Veracruz, Mexico. Annual Conference of the Society for Tropical Ecology, Zurich, Switzerland. Poster. 
Oct. 2014

Feb. 2014

Nov. 2013

Jul. 2013

Dec. 2012

Nov. 2012
Influence of altitude and human impacts on diversity of ferns and herbs and soil parameters at the "Cofre de Perote" (Veracruz, Mexico). 11th Latin-American Botanical Congress. Salvador da Bahia, Brazil. Poster.

Herbaceous angiosperms along elevational and disturbance gradients in central Veracruz, Mexico. Annual Conference of the Society for Tropical Ecology. "Tropical Ecosystems - Between Protection and Production", at the Ludwig Maximilian University of Munich, Freising in February. Oral presentation.

Influence of altitude and human impacts on diversity of ferns and herbs and soil parameters at the "Cofre de Perote" (Veracruz, Mexico). Symposium on Interdisciplinary project Cofre de Perote, at the Centro de Investigaciones Tropicales (CITRO), Xalapa, Mexico in November.

Herbaceous ferns and angiosperms as indicators of soil parameters along an altitudinal gradient at the "Cofre de Perote" (Veracruz, Mexico). XI Symposium of Mexican students and studies in the UK. Sheffield, United Kingdom. 11-13 July. Oral presentation.

Herbaceous ferns and angiosperms as indicators of soil quality and microclimate along an altitudinal gradient in the central gulf of Mexico. Latin America Symposium, Neotropic-Challenges for Integrative Ecology. Bonn, Germany. 17-18 December. Oral presentation.

Efectos altitudinales, antropológicos y ambientales sobre patrones ecológicos de helechos y angiospermas herbáceas. $2^{\circ}$ Grantees and former grantees Symposium CONACyT in Europe. Strasburg, France. 29-30 November. Oral presentation.

\section{AWARDS}

CONACYT - DAAD Scolarship 2012-2016. Consejonacional de ciencia y tecnología (Mexico) and Deutscher Akademischer Austausch Dienst. 